\title{
A FUNÇÃO WEIBULL COMO MODELO PARA A DISTRIBUIÇÃO DE DIÂMETROS DE ESPÉCIES ARBÓREAS TROPICAIS
}

\author{
JOÃO LUÍS FERREIRA BATISTA
}

Engenheiro Florestal

Orientador: Prof. Dr. HILTON THADEU Z. DO COUTO

Dissertação apresentada d̀ Escola Superior de Agricultura "Luiz de Queiroz", da Universidade de São Paulo, para obten ção do titulo de Mestre em Ciências Florestais.

PIRACICABA

Estado de São Paulo - Brasil

Março - 1989 


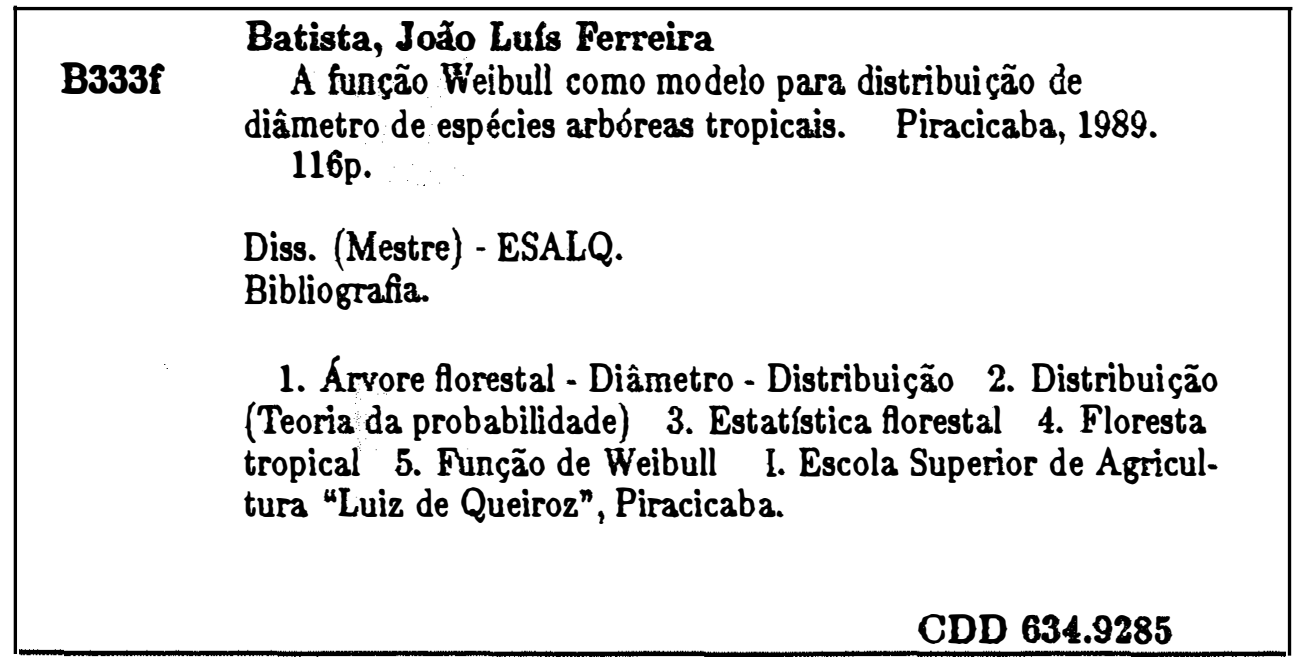




\title{
A FUNCCEOO WLIBULI COMO MODELO PARA AISTRIBUICÃO DE DIAMTTROS DE ESPTCIRS ARBOREAS TROPICAIS
}

\author{
JOÃO LUIS FERRERA BATISTA
}

Aprovado em $03 / 04 / 1989$

Banca Examinadora:

Hilton Thadeu Tarate do Couto

Paulo Sodero Martins

Cássio Roberto de Melo Godoi
ESALQ - USP

ESALQ - USP

PSALQ - USP

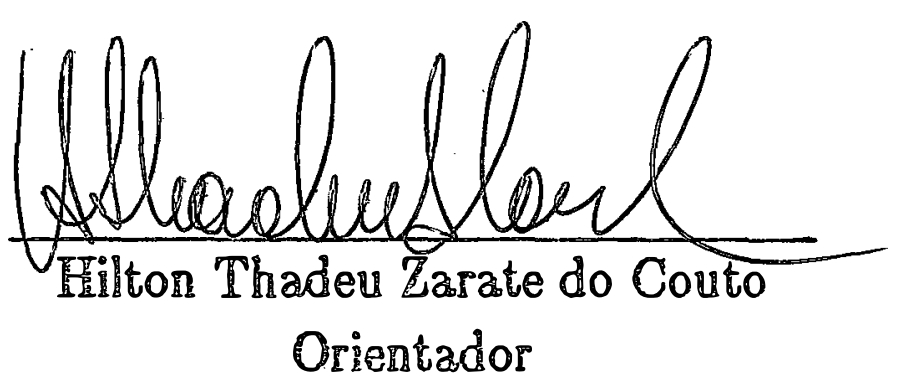


para Amanda, José e

Débora 


\section{AGRADECIMENTOS}

Agradeço inicialmente a todos os que contribuiram para realização desse trabalho sem o saber: o mateiro que identificou as árvores no campo, a equipe de medição e o engenheiro responsável pelo inventário florestal que produziu as informações utilizadas nesse trabalho.

O prof. Dr. Hilton Thadeu Zarate do Couto, além de me fornecer os dados para a realização do trabalho, me orientou sempre com a disponibilidade de discutir em profundidade as idéias e os métodos de análise, sendo durante todo o desenvolvimento do trabalho um ponto de referência crítico e abalizador. A ele fico devendo minha gratidão.

Agradeço também a Noemi M. V. Leão e sua equipe de campo da EMBRAPA/CPATU, pelo auxfio na identificação das caracteristicas vegetativas e reprodutivas das espécies estudadas.

Tive oportunidade de discutir esse trabalho com várias pessoas. A todas elas fico grato, mas em especial aos professores Paulo Y. Kageyama, Ricardo R. Rodrigues e Paulo Sodero Martins, que muito contribuiram com suas críticas e sugestões.

Finalmente, agradeço profundamente a disponibilidade e paciência de Débora, minha esposa, Luiz Antônio, meu sogro, e Elaine, minha irmã, na análise minuciosa da correção gramatical e ortográfica desse trabalho. 


\section{INDICE}

LISTA DE FIGURAS $\quad \ldots \ldots \ldots \ldots \ldots \ldots \ldots \ldots \ldots \ldots \ldots \ldots \ldots, \ldots \ldots \ldots$

LISTA DE QUADROS $\quad \ldots \ldots \ldots \ldots \ldots \ldots \ldots \ldots \ldots \ldots \ldots \ldots \ldots \ldots$ ii

LISTA DE FÓRMULAS $\quad \ldots \ldots \ldots \ldots \ldots \ldots \ldots \ldots \ldots \ldots \ldots \ldots \ldots \ldots$ iv

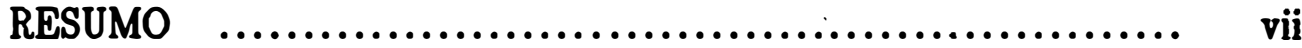

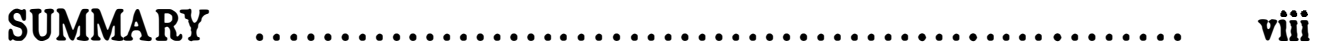

1. INTRODUÇÃO $\quad \ldots \ldots \ldots \ldots \ldots \ldots \ldots \ldots \ldots \ldots \ldots \ldots \ldots \ldots \ldots \ldots \ldots$

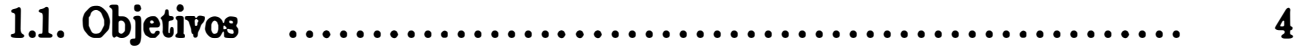

1.2. A Estrutura das Florestas Tropicais $\quad . . \ldots \ldots \ldots \ldots \ldots \ldots \ldots \ldots . . \ldots$

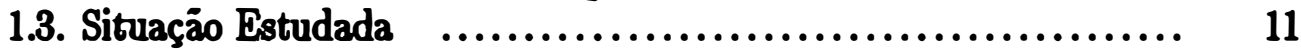

2. MODELAGEM DA DISTRIBUIÇÃO DE DIÂMETROS

ATRAVES DA DISTRIBUIÇẢO WEIBULL $\quad$..................... 14

2.1. Apresentação da Distribuição Weibull ..................... 14

2.2. Métodos de Ajuste da Distribuição Weibull $\ldots . . \ldots \ldots \ldots \ldots . . . .21$

2.2.1. Métodos de máxima verossimilhança $\ldots . . \ldots \ldots \ldots . . \ldots \ldots .21$

2.2.2. Métodos baseados nos momentos da distribuiçäo $\ldots . . \ldots \ldots .23$

2.2.3. Métodos baseados nos percentis da distribuição $\ldots . \ldots \ldots \ldots .25$

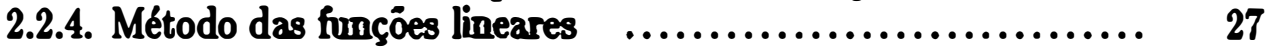

2.2.5. Métodos de regressāo linear e não linear $\ldots . \ldots \ldots \ldots \ldots \ldots . . .28$

2.2.6. Comparaçảo entre os métodos $\ldots \ldots \ldots \ldots \ldots \ldots \ldots \ldots \ldots \ldots . . \ldots 29$

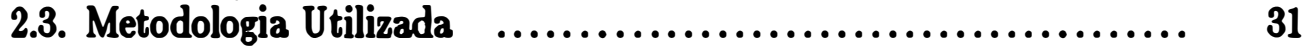

2.3.1. Classes diamétricas testadas $\ldots . \ldots \ldots \ldots \ldots \ldots \ldots \ldots \ldots \ldots . . . \ldots 31$

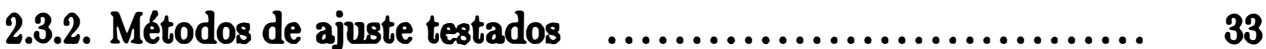

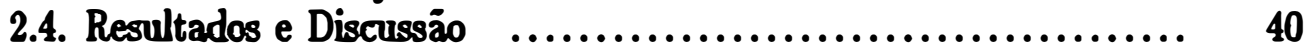

2.4.1. Ajustamento em relação d̀ distribuições originais $\ldots . . . \ldots .40$

2.4.2. Influência do tamanho da amostra ................... 44

2.4.3. Intervalo de confiança das estimativas dos parâmetros $\ldots . .4 .46$

2.4.4. Comparação entre $0 s$ métodos de ajuste

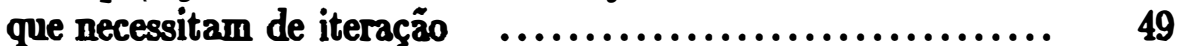

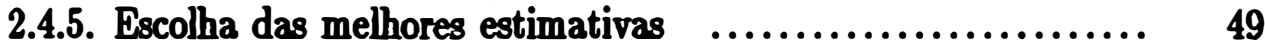

3. INTERPRETAÇĀO BIOLÓGICA DOS PARÂMETROS

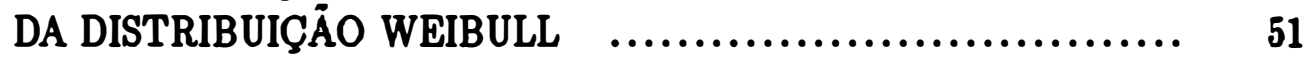

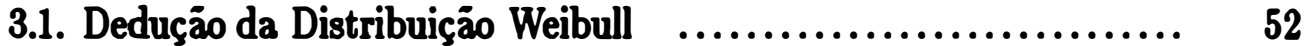

3.2. Caracterização das Espécies Arbóreas Tropicais $\ldots . . . . . . . . . . .57$

3.3. Sucessão Secundária e Padrōes de Distribuição de Diâmetros ... 60

3.3.1. Estágios da sucessão secundária $\ldots . \ldots \ldots \ldots \ldots \ldots \ldots \ldots \ldots .60$

3.3.2. Padrōes de distribuição de diâmetros $\ldots \ldots \ldots \ldots \ldots \ldots \ldots \ldots .66$

3.4.Identificação do Padrão de Distribuição de Diâmetros $\ldots . . . . . . . .72$

3.5. Distribuição de Diâmetros e Características Fitossociológicas ... 76

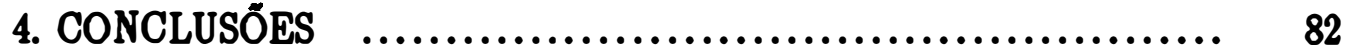


5. BIBLIOGRAFIA CITADA $\ldots \ldots \ldots \ldots \ldots \ldots \ldots \ldots \ldots \ldots \ldots \ldots . \ldots \ldots, 87$

ANEXO 1 - Nomes Populares e Nomes Cientificos das Espécies

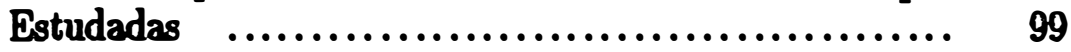

ANEXO 2 - Tabela da Distribuição Weibull Estandartizada $\quad . . . . . \quad 102$

ANEXO 3 - Dedução dos Estimadores de Máxima Verossimilhança para

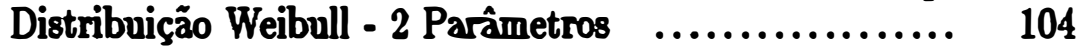

ANEXO 4 - Número de Passos de Iteração Necessários para a Convergência para cada um dos Métodos Testados ...... 110

ANEXO 5 - Estimativas e Intervalo de Confiança dos Parâmetros da Weibull Ajustada pelo Método dos Percentis ........ 112

ANEXO 6 - Dendrograma Resultante da Análise de Agrupamento Utilizando os Parâmetros da Distribuição Weibull como Variáveis de Análise $\quad$............................. 117

ANEXO 7 - Grupos de Padrões de Distribuição de Diâmetros $\quad \ldots . . \quad 111$ ANEXO 8 - Índices Fitossociológicos das Espécies Estudadas por Grupos Representativos dos Padröes de Distribuição de

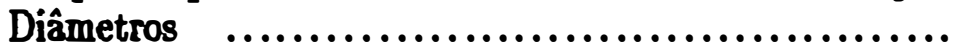




\section{LISTA DE FIGURAS}

\section{Pág.}

(2.1.) Influência do valor do parâmetro da localização (a) sobre a Distribuição Weibull.

(2.2.) Influência do valor do parâmetro de escala (b) sobre a Distribuição Weibull.

(2.3.) Influência do valor do parâmetro da forma (c) sobre a Distribuição Weibull.

(2.4.) Gráfico esquemático da distribuição dos desvios para cada método testado.

(3.1.) Tipos básicos de curva de sobrevivência segundo PINDER et alii (1978).

(3.2.) Curvas de distribuição de diâmetros para espécies características dos estágios da sucessão.

(3.3.) Curvas de sobrevivência para espécies características dos estágios da sucessão.

(3.4.) Posição dos grupos de padrão de distribuição de diâmetros em relação 208 parâmetros $c$ e $b$ da Distribuiçäo Weibull.

(3.5.) Curvas de distribuição de diâmetros para os grupos representativos do padröes de distribuição de diâmetros.

(3.6.) Curvas de sobrevivência para os grupos representativos dos padrōes de distribuição de diâmetros.

(3.7.) Curvas de taxa instantânea relativa de mortalidade para os grupos representativos do padrōes de distribuição de diâmetros. 


\section{LISTA DE QUADROS}

(1.1.) Nág.

(1.1.) Número de árvores, número de parcelas e área amostrada. ..... 13

(2.1.) Teste de Tukey para comparação dos valores médios das estimativas dos parâmetros da Weibull, obtidas em dados agrupados por diferentes amplitudes de classe.

(2.2.) Número e amplitude de classes utilizadas para as 60 espécies estudadas.

(2.3.) Resumo dos métodos testados para o ajuste da Distribuição Weibull.

(2.4.) Valores médios (MED), mínimos (MIN) e máximos (MAX) dos critérios de ajustamento encontrados entre as 60 espécies estudadas.

(2.5.) Teste $\mathbf{t}$ (mínima diferença significativa) para comparaçào dos métodos de ajuste da Weibull, através dos valores médios das estimativas dos parâmetros nas 60 espécies estudadas.

(2.6.) Comparação dos métodos de ajuste da Weibull para grupos de espécies com diferentes números de árvores amostradas. Analisou- se o desvio absoluto de cada classe de diâmetro através da soma das ordens (Wilcoxon) e qui-quadrado aproximado do teste de Kruskall - Wallis.

(2.7.) Valores de $\mathrm{T}$ do teste das Ordens assinaladas (Wilcoxon) na comparação do método dos percentis (PTL) com os demais, em termos de desvios absolutos nas classes diamétricas.

(2.8.) Teste t pareado comparando o intervalo de confiança (em porcentagem) das estimativas dos parâmetros Weibull obtidas pelos métodos dos percentis (PTL), momentos (MCV) e máxima verosssimilhança (MVN) (n= 60 espécies).

(3.1.a) Características reprodutivas de algumas das 60 espécies estudadas.

(3.1.b) Características vegetativas de algumas das 60 espécies estudadas.

(3.2.) Classificação das espécies nos quatro estágios da sucessão propostos por BUDOWSKI (1963).

(3.3.) Fórmulas utilizadas no cálculos dos f́ndices fitossociológicos. ....

(3.4.) Coeficiente de correlação de Kendall e níveis de probabilidade para a correlação entre os parâmetros da distribuição Weibull e os índices fitossociológicos e os diâmetros médio aritmético (DAP) e médio quadrático (DAPQ). 
(3.5.) Coeficiente de correlação de Kendall e níveis de probabilidade para correlação entre os parâmetros da distribuição Weibull e os índices fitossociológicos para cada um dos grupos de espécie. 


\section{LISTA DE FÓRMULAS}

(2.1) f.d.p. da Distribuição Weibull* . ........................ 15

(2.2) f.d.a. da Distribuição Weibull*. ....................... 15

(2.3) f.d.p. da Distribuição Weibull. $\ldots \ldots \ldots \ldots \ldots \ldots \ldots \ldots \ldots \ldots \ldots \ldots . . \ldots$

(2.4) f.d.a. da Distribuição Weibull. $\ldots \ldots \ldots \ldots \ldots \ldots \ldots \ldots \ldots \ldots \ldots . \ldots \ldots$

(2.5) Função geradora de momentos da Distribuição Weibull. ........ 18

(2.6) Fórmula para se obter a média na Distribuição Weibull. ........ 18

(2.7) Fórmula para se obter a variância na Distribuição Weibull. ..... 19

(2.8) Fórmula para se obter 0 percentis na Distribuição Weibull. ..... 19

(2.9) Fórmula para se obter a moda na Distribuição Weibull. ........ 19

(2.10) Estimador de máxima verossimilhança para o parâmetro c, segundo

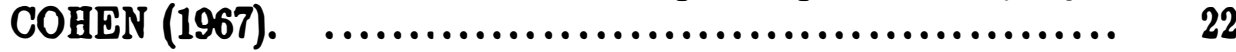

(2.11) Estimador de máxima verossimilhança para o parâmetro b, segundo COHEN (1967).

(2.12) Função de iteração para obtenção da estimativa de máxima verossi-

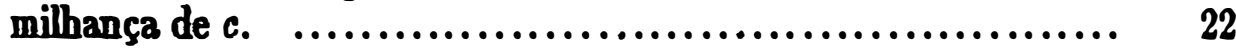

(2.13) f.d.p. da Distribuição Weibull truncada à esquerda. .......... 22

(2.14) f.d.a. da Distribuição Weibull truncada à esquerda. ......... 22

(2.15), (2.16), (2.17) Três primeiros momentos centrais da Weibull*. .. 23

(2.18), (2.19), (2.20) Estimadores baseados nos momentos para os parâmetros a, b e c, respectivamente, segundo BURK e NEWBERRY (1984).

(2.21), (2.22), (2.23) Estimadores baseados nos momentos para os parâmetros $a, b$ e $c$, respectivamente, segundo BURK e BURKHART (1984).

(2.24) Estimador do parâmetro b segundo NEWBY (1980). .......... 25

(2.25), (2.26) Estimadores baseados nos percentis dos parâmetros c e b, respectivamente, segundo DUBEY (1967).

(2.27), (2.28), (2.29) Estimadores dos parâmetros a, b e c, respectivamente, baseados nos percentis segundo Zanakis citado por ZARNOCH e DELL (1985). 
(2.30), (2.31) Estimadores lineares para os parâmetros c e b, respectivamente,

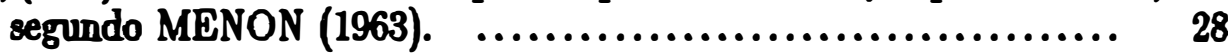

(2.32) Forma linearizada da f.d.a. da Weibull, segundo WEIBULL (1951).

(2.33) Algoritmo de Ramsdell para cálculo do número de classes para o agrupamento de dados (COUTO, comunicação pessoal). ........

(2.34) Fórmula para cálculo dos percentis a partir de dados agrupados, se-

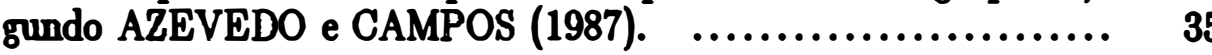

(2.35), (2.36) Adaptação dos estimadores de MENON (1963) para dados agrupados.

(2.37), (2.38) Adaptação dos estimadores de COHEN (1967) para dados agrupados.

(2.39), (2.40) Adaptação dos estimadores dos parâmetros da Weibull truncada à esquerda para dados agrupados.

(2.41) Algoritmo adaptado do método iterativo de Newton-Raphson.

(2.42) Fórmula do Índice de Ajustamento utilizado por KNOEBEL et alii (1986).

(2.43), (2.44) Variância das estimativas baseadas nos percentis segundo DUBEY (1967).

(2.45), (2.46) Variância das estimativas baseadas nos momentos segundo NEWBY (1980).

(2.47), (2.48) Variância das estimativas de máxima verossimilhança segundo DUBEY (1967).

(3.1) Curva de mortalidade com base em probabilidade. ........... 52

(3.2) Curva de sobrevivência com base em probabilidade. ........... 52

(3.3) Taxa instantânea absoluta de mortalidade. .................. 53

(3.4) Taxa instantânea relativa de mortalidade. .................. 53

(3.5) Função para representação da taxa instantânea relativa de mortalidade.

(3.6) Função da Curva de sobrevivência. $\quad$...................... 53

(3.7) Função da Curva de mortalidade, compatível com a f.d.a. da Dis-

(3.8) Função da taxa instantânea absoluta de mortalidade compatível com a f.d.p. da Distribuição Weibull.

(3.9), (3.10) Formas simplificadas da função representativa da taxa instantânea relativa de mortalidade.

(3.11) Forma genérica da função discriminante. 
(3.12) Probabilidade de uma espécie com o vetor de parâmetros $X$ pertencer

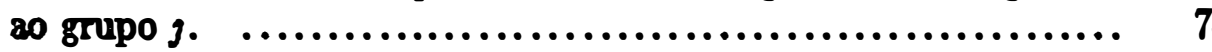

(3.13) Forma genérica da função generalizada do quadrado da distância da análise discriminante. 


\section{A FUNCEOO WERULE CORO MODRLO PARA A DISTTRBUIGAOO DI DIAMRTROS DE RSPTCIRS ARBÓREAS TROPICAIS}

Autor: JOÄO LUIS FERREIRA BATISTA Orientador: prof. Dr. RILTON THADEU Z. DO COUTO

\section{RESTMO}

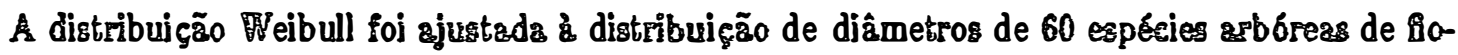
reste tropical pluvial situads no Estado do R\&anhão. Foram testadios estimadores de máxima verossimilhanģa momentos, percentis e funções lineares. Com exceção dos estimadores de funções lineares, todos 08 demajs produxiram, pare todas as espécies, distribuições que não diferipm estatisticamente das distribuiçōes observadas. Os estimadores de maxima verossimilhaşa produziram estimativas com a menor variância, emborz os estimacoores de percentis tenhan produrido as distribuições más próximas das observadas. Observourse que as estima. tivas obtidas pelo método dos percentis são inf̂uenciadas pelo número e amplitude das clases diamétricas utilisadis, quando os percentis são calculados com dados aroupados. Apesar da distribuiçẽo Weibull ter sido proposta inicialmente como umo distribuição empfrica, observou-

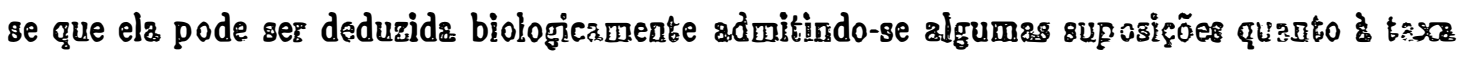

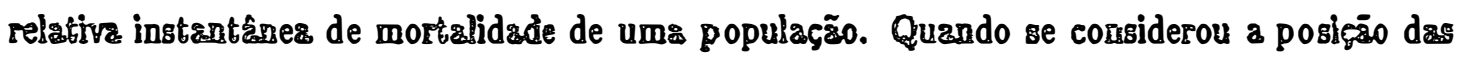

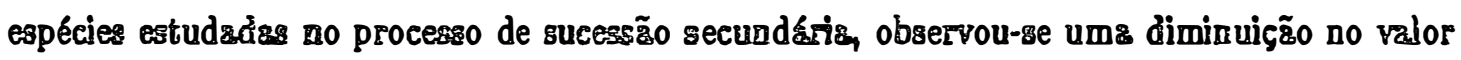
do parsmetro da forma (c) e um aumento no pafámetro da escala (b), do infeio para o final da sucessão. Foi possfvel identin̂car quatro padrōes de distribuição de diâmetros entre

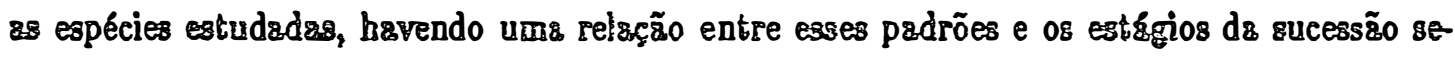

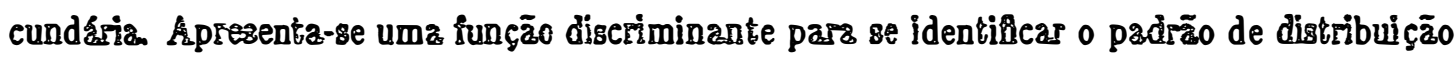
de đismetro de espécies abb6ress usando as estimstivas dos parf́metros de Weibull. N\&̊o se ob-

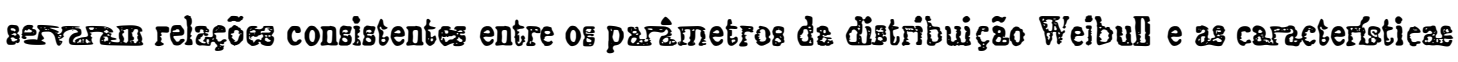
îtossociologieas das espécies estudadas. 


\section{TPEP W FOR DIA

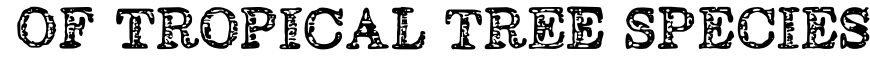

Author: BOÄO LUŚS FERREIRA BATISTA Adviser. prof. Dr. HILTON THADEU Z. DO COUTO

\section{SURrerer}

The Belbull distribuition fras ftted bo diameter data of 60 tropical rain forest species from State of Maranbão, Brazil. It were tested the following methods of parameter estimation: maximum likelihood method, percentile method, moments method and linear function method. All methods produced distributions not statistically difierent from observed ones, except the lineas function method. The meximum likelihood estimates had the lowest variances, but observed distributions were better represented by percentile method. The number and width of dismeter classes infinenced the percentile estimates, when percentile were obtained trom grouped data. Although the Weibull distribution had been originally proposed as an empirical distribution, it was observed that it can be derived making some assumptions about the population instantaneous desth relative rate (hadsad function). It was found from early to late secondisy succession gpecies that the scaled parameter (b) increases and the shape parameter (c) de-

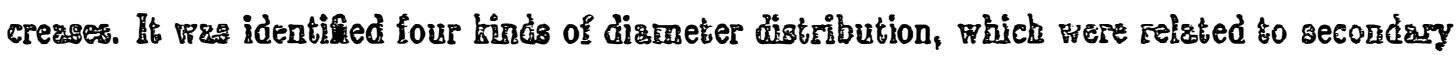
succession stages. A diseriminant funetion was developed to identify the diameter distribution standisd of each species. No consistent relstionship between Wreibull prameters and species fitossociological characterişics mere found. 


\section{INTRODUÇÃO}

"O que os objetos são, em si mesmos, fora da maneira como a nossa sensibilidade os recebe, permanece totalmente desconhecido para nós."

Kant 


\section{INTRODUÇÃO}

As florestas pluviais tropicais representam um importante recurso natural que precisa ser utilizado para promover o desenvolvimento das nações subdesenvolvidas (BUDOWSKI, 1984). Entretanto, o seu ecossistema é o mais complexo do mundo (RANKIN, 1979), tornando o seu uso auto-sustentado muito difícil. As dificuldades aumentam por influência dos aspectos éticos e econômicos que orientam o sistema de produção no ocidente e particularmente no terceiro mundo (BUDOWSKI, 1984).

Nas florestas pluviais tropicais a reprodução e sobrevivência das espécies vegetais e animais estão intimamente ligadas (GILBERT,1980) formando ụma trama tão complexa e delicada que, sob o impacto da nossa atual tecnologia, a floresta poderia ser considerada um recurso natural não renovável (GÓMEZ-POMPA et alii, 1972).

Atualmente, a expansão da fronteira agropecuária representa o principal fator de destruição das florestas pluviais tropicais na America Latina, sendo que 
setenta e sete por cento (77\%) da sua expansão ocorre em área de florestas pluviais tropicais (DOUROJEANNI, 1983). No Brasil, o ritmo do desmatamento na região Norte e Centro-Oeste tende a assumir taxas exponenciais (FEARNSIDE, 1984).

A exploração madeireira, embora menos nociva, tem também a sua importância na destruição da floresta pluvial tropical, pois transforma profundamente as florestas tropicais primárias, comprometendo a sua regeneração e produtividade. A retirada de toras de grandes dimensões para produção de madeira serrada altera o piso florestal, prejudicando a regeneração natural e modifica a estrutura da floresta num nível ainda não muito bem definido. 0 resultado são florestas secundárias de baixo valor econômico e pouca importância para a conservação da natureza.

Para se manejar a floresta tropical de forma auto-sustentada, devese conhecer o impacto das intervenções de manejo sobre a regeneração e estrutura da floresta. O conceito de "capacidade-suporte" é a chave para o uso auto-sustentado (BUDOWSKI, 1984) e consiste na quantificação do impacto que a floresta pode suportar, sem ter a sua estrutura e regeneração comprometidas.

A estrutura das florestas tropicais tem sido estudada sob o ponto de vista espacial. Para estudo da estrutura horizontal, vários f́ndices de dispersão vêm sendo utilizados. A estrutura vertical tem sido representada principalmente através do perfil diagrama (RICHARDS, 1983), existindo o modelo de TERBORGH (1985) para explicar como a interação entre a luz e a copa das árvores influencia a formação dos diferentes estratos numa floresta.

A abordagem demográfica utilizada por SARUKHÁN $(1976,1980)$ e HARTSHORN (1975) no estudo de populações de espécies arbóreas tropicais, pode auxiliar no manejo das florestas tropicais respondendo questóes como: qual o impacto da 
retirada das árvores de maior diâmetro sobre a estrutura e sobrevivência das populaçōes arbóreas? quais as fases de crescimento mais críticas à sobrevivência dessas populaçōes ? seria possível estabelecer diâmetros mínimos e máximos para a exploração florestal de modo a reduzir o impacto sobre a estrutura e regeneração das populações arbóreas? Infelizmente, as informações disponíveis até o momento não são suficientes para dar suporte a essa abordagem.

A estrutura diamétrica das florestas e espécies tropicais está intimamente ligada à quantificação da produção e exploração das florestas tropicais, principalmente quando se pretende diversificar o uso da madeira. Embora a estrutura diamétrica não possa ser assumida como sendo a estrutura etária (WHITE, 1980), o seu estudo possibilitaria o início de uma abordagem mais demográfica dos problemas florestais, particularmente se a estrutura diamétrica for relacionada com fatores ambientais (solo e clima) e biológicos (regeneração natural, sucessão secundária, competição), fornecendo alguns subsídios para o desenvolvimento de técnicas de manejo auto-sustentado. 


\subsection{Objetivos}

O presente trabalho procurará modelar a estrutura diamétrica de uma floresta pluvial tropical e das populaçōes de espécies arbóreas que a compõem. Para isso a distribuição de Weibull será utilizada, tendo em vista a sua grande flexibilidade, tanto em termos das formas que pode assumir, quanto em termos dos métodos de ajustamento.

Deseja-se obter uma técnica de aplicação relativamente fácil, que possa ser utilizada nos planos de manejos de florestas tropicais. Portanto, nesse trabalho serão utilizados dados provenientes de um inventário florestal que visava estimar o volume de madeira existente na floresta, para que a técnica desenvolvida não exija dos métodos de amostragem e medição um rigor superior ao utilizado em operações florestais corriqueiras.

As estimativas dos parâmetros da distribuição também serão relacionadas com os índices fitossociológicos comumente utilizados em estudos de florestas tropicais e com as características sucessionais das espécies, analisando se a estrutura diamétrica reflete o estágio da sucessão que as espécies ocupam.

Resumindo, os objetivos são:

1. Verificar a capacidade da distribuição de Weibull representar a estrutura diamétrica das espécies arbóreas presentes na florestal tropical.

2. Estudar a relação entre os parâmetros da distribuição Weibull e os f́ndices fitossociológicos. 
3. Relacionar as características sucessionais das espécies arbóreas com os parâmetros da distribuição, analisando se a estrutura das populações reflete o estágio sucessional das espécies arbóreas. 


\subsection{A Estrutura das Florestas Tropicais}

O termo estrutura da floresta tropical é utilizado de maneira muito variada, dependendo do autor que o utiliza. BRUNIG (1983) apresenta três abordagens diferentes para o estudo da estrutura: 1. "estrutura vertical" : forma de copas nos diferentes estratos e sobreposição das arquiteturas das árvores; 2. "estrutura horizontal” : variação do volume, área basal, altura, DAP e fitomassa no espaço; 3. ”estrutura do dossel ${ }^{\rrbracket}$ : arquitetura, forma e aerodinâmica do dossel.

Segundo BOURGERON (1983) o conceito de estrutura se relaciona com o de diversidade, principalmente quando se busca uma explicação para o grande nưmero de espécies existentes nas florestas tropicais. A maioria dos estudos da estrutura das florestas tropicais se enquadra no estudo da estrutura horizontal, entendida como a distribuição dos indivíduos no espaço principalmente em função de variaçōes edáficas, e da estrutura vertical, a qual resulta da interação das diferentes arquiteturas arbóreas. Dentro de ambas as linhas de estudo pode-se adotar um enfoque qualitativo ou quantitativo. O primeiro, mais tradicional nos estudos em florestas tropicais, concentra-se na descrição e estratificação da floresta, tendo grande peso os aspectos florísticos. Já o segundo, inicialmente desenvolvido em florestas temperadas, busca desenvolver modelos matemáticos que representem a estrutura das florestas.

Vários autores vêm utilizando o perfil-diagrama para a representação da estrutura vertical de florestas (HALL€́ et alii, 1978; GUILLAUMET e KAHN, 1982; WHITMORE, 1975). Esta metodologia, entretanto, é útil para ilustrar diferenças entre tipos florestais muito diferentes (RICHARDS, 1983), mas é muito pouco quantitativa para indicar diferenças pouco marcantes entre florestas de um mesmo tipo. 
Os estudos da estrutura vertical procoram relacioná-la com variaçōes ambientais, principalmente do solo. BRUNIG e HEUVELDOP (1976) estudando a estrutura vertical de florestas pluviais tropicais em Sarawak (Bornéo) e São Carlos do Rio Negro (Venezuela), observaram que a variaçảo destas, segundo a topossequência, estava relacionada com a profundidade e drenagem do solo. O trabalho comparou tipos florestais distintos e atribuiu a existência de uma variação em pequena escala da estrutura, isto é, dentro de um mesmo tipo florestal, à dinâmica de morte e regeneração que ocorre nas clareiras. Além do perfil- diagrama os autores utilizaram outros parâmetros para representar a estrutura como a razão altura/DAP, a força de flexão relativa (função do cubo do DAP) e a firmeza relativa ao vento (função da força de flexão relativa e da área de projeção da copa da árvore).

GUILLAUMET e KAHN (1982) analisaram a variação da estrutura vertical em duas topossequências na Amazônia central (regiảo de Manaus). Concluíram que a floresta se mostrou muito homogênea e que a principal fonte de variação é o ciclo Silvigenético (na concepção de HALLÉ et alii, 1978).

Em floresta pluvial tropical na Sumatra, VAN SCHAIK e MIRMANTO (1985) representaram a estrutura através de cinco estratos: superior, médio, inferior, sub-bosque e clareiras. Esses autores chegaram à conclusão de que quanto menor a fertilidade do solo (mais velho o solo) mais complexa se torma a estrutura da floresta. Uma das explicações possíveis seria a adaptação a solos pobres que produz um ritmo de crescimento mais lento e, portanto, um ciclo de vida mais longo. Consequientemente, os estratos superior e médio se tornam mais desenvolvidos e com pequena mortalidade de árvores, isso resulta numa floresta mais desenvolvida com poucas e pequenas clareiras. Tal hipótese parece concordar com as considerações de BRUNIG 
e HEUVELDOP (1976) de que, do ponto de vista termodinâmico, os solos exauridos, isto é, altamente intemperizados (com baixa entropia) devem suportar florestas de alta diversidade (com alta entropia) para manterem um sistema estável eficientemente.

TEOBORGH (1985) propôs um modelo para explicar a formação de estrutura vertical em florestas temperadas e tropicais. No seu modelo a altura dos estratos inferiores ao dossel é função de: a) altura do dossel, b) ângulo limite de penetração dos rajos solares na floresta $\left(\theta_{L}\right)$, c) espaço entre as copas do dossel, sendo que o ângulo limite é a variável mais importante, dependendo da forma e altura das copas que formam o dossel. Segundo esse modelo, a variação da complexidade da estrutura das florestas com a latitude é função da variação do ângulo de incidência dos raios solares, da altura e da forma das copas do dossel. Estes três fatores controlam o ângulo de penetração dos raios solares nas florestas. 0 menor ângulo de incidência dos rajos solares nos trópicos, juntamente com as formas hemisféricas das copas com pequena altura, permitem a penetração da luz de modo a formar uma estrutura pluri-estratificada.

Alguns autores procuram estudar a estrutura horizontal das florestas através do estudo da forma de distribuição dos indivíduos de uma mesma espécie no espaço. Admitem-se três padrōes básicos de distribuição dos indivíduos: casual, uniforme e agrupado. SILVA e LOPES (1982), estudando a dispersão dos indivíduos das espécies da floresta amazônica na Floresta Nacional do Tapajós, observaram que a maioria das espécies possuía uma baixa frequeência e dispersão agrupada. OLIVEIRA e ROTTA (1982), estudando a Mata de Araucária no Paraná, observaram que as espécies de maior frequência possuiam uma distribuição contínua, enquanto a alta correlação da composição florística entre as parcelas de amostragem indica que a maioria das espécies tende a uma distribuição uniforme. 
ARMESTO et alii (1986) estudando o padrão de dispersão de espécies em florestas de diferentes latitudes concluíram que existe uma tendência maior nas florestas tropicais para o agrupamento dos indivíduos da mesma espécie. Esses autores levantam a hipótese de que os distúrbios que ocorrem nos diferentes tipos de florestas seriam o fator determinante no padrão de dispersão dos indivíduos. As florestas sujeitas a distúrbios freqüentes e de grande escala possuem dispersão casual ou uniforme, enquanto que as florestas sujeitas a distúrbios de pequena escala tendem para a dispersão agrupada em função da regeneração em clareiras.

WHITMORE $(1978,1982)$ relaciona a estrutura com a dinâmica de regeneração das florestas tropicais, reconhecendo três fases estruturais que formam um “continuum” de regeneração: a fase de clareira ( ${ }^{\alpha}$ gap-fase $\left.{ }^{\text {}}\right)$, a fase de reconstrução da estrutura ("building fase") e a fase de maturidade ("mature fase"). Segundo esse autor as três fases formam um mosaico estrutural que representa um equilíbrio dinâmico no ciclo de crescimento e regeneração da floresta, no qual as clareiras tem papel fundamental. A estratificação vertical é criticada por ser um conceito extremamente tipológico e estático que ignora a dinâmica do dossel da floresta, como as mudanças na arquitetura e fisiologia que as árvores sofrem à medida que crescem na floresta.

HALLÉ et alii (1978), partindo do estudo da arquitetura das espécies individuais, formularam uma teoria que procura explicar, não só os processos de regeneração em pequena escala e em períodos curtos do tempo, como também busca uma explicação para a formação e evolução das florestas em grandes regiōes em longos períodos de tempo. Tal teoria, denominada Silvigênese, propöe que a regeneração e formação das florestas é um processo cíclico de distúrbio, destruição e reconstrução, de modo a formar uma vegetação progressivamente complexa até atingir o máximo 
de complexidade que as condiçōes abióticas do meio permitem. WHITMORE (1982) afirma que a teoria da Silvigênese embora muito ilustrativa não pode ser corroborada pelas observações até hoje realizadas nas florestas tropicais.

Outra conceituação do termo estrutura de floresta envolve o estudo da distribuição dos diâmetros. Tais estudos têm sido desenvolvidos visando aumentar a precisão das estimativas da produção de madeira de florestas temperadas (ALEXANDER e EDMINSTER,1977; ALEXANDER,1985; NELSON, 1964; LEAK, 1964; LENHART e CLUTTER, 1971; dentre muitos outros). Alguns trabalhos desenvolvidos em florestas tropicais e subtropicais utilizaram essa metodologia para representar não só a estrutura da floresta como um todo, mas também a estrutura das populações arbóreas individualmente( KNIGHT, 1975; PIRES, 1976; OLIVEIRA e ROTTA, 1982; CARVALHO, 1981).

ZEIDE (1984) procurou interpretar biologicamente a distribuição de diâmetros de florestas temperadas dissetâneas, representada pela distribuição “de Liocourt" (distribuição exponencial negativa). Ele concluiu que a relação entre os parâmetros da distribuição “de Liocourt” representa, na verdade, a relação entre o diâmetro médio e densidade (número de indivíduos por hectare), refletindo diferentes níveis de tolerância ao sombreamento. 


\subsection{Situação Estudada}

Estudou-se uma área de 50.000 ha de floresta tropical localizada no Municícipio de Bom Jardim, Estado do Maranhão, entre os meredianos $46^{\circ} 30^{\prime} \mathrm{W}$ e $46^{\circ} 40^{\prime} \mathrm{W}$ e os paralelos $3^{\circ} 50^{\prime} \mathrm{S}$ e $4^{\circ} 20^{\prime} \mathrm{S}$. A geomorfologia da região caracteriza-se por uma sequiência de platôs com altitude média de 400 a $600 \mathrm{~m}$ e baixadas que sofrem inundaçōes periódicas (BRASIL, 1973a e 1973b).

Localizada no Planalto Setentrional Pará - Maranhäo, a área é considerada de transição entre o Pediplano Central do Maranhão e a superície litorânea de Bacabal. Os solos predominantes são do tipo Latossolo Amarelo com textura argilosa a muito argilosa. A fertilidade natural e a saturação de bases são baixas, sendo solos ácidos, profundos, permeáveis e com boa drenagem. Os solos argilosos situam-se tanto nos platôs quanto nos terraços de cotas menores, sendo que os solos de textura muito argilosa ocorrem em locais de relevo plano enquanto que os de textura argilosa ocorrem onde o relevo é suavemente ondulado (BRASIL, 1973a e 1973b).

O clima da região é tropical com estação seca pronunciada. A temperatura média anual oscila entre 25 e $26^{\circ} C$, sendo estável durante todo o ano. A precipitaçào anual média é de $1.420 \mathrm{~mm}$ com estação seca no período de junho a novembro e estação chuvosa de dezembro a maio. A estação chuvosa concentra $91 \%$ da precipitação anual, com uma média mensal de $216 \mathrm{~mm}$, enquanto que durante a estação seca o déficit hídrico atinge $300 \mathrm{~mm}$, segundo balanço de Thornthwaite (BRASIL, 1973a).

Segundo a classificação do Projeto RADAM (BRASIL, 1973a e 1973b), a área de estudo situa-se na Região de Floresta Densa, Sub-regiäo dos Al- 
tos Platôs do Pará - Maranhão, com o predomínio de três tipos básicos de formação vegetal: floresta ombrófila densa de altos platôs, floresta ombrófila densa de terraços e floresta ombrófila densa aluvial.

Segundo VELOSO e GÓES-FILHO (1982), as florestas ombrófilas densas são florestas pluviais constituídas por árvores perenifólias que ocorrem "nas regiōes tropicais mais úmidas, sem período biologicamente seco (de 0 a 60 dias secos no ano) durante o ano". A floresta ombrófila densa é subdividida em cinco formaçōes, conforme uma hierarquia topográfica e fisionômica: floresta aluvial, floresta das terras baixas (correspondente à floresta de terraços), floresta submontana (correspondente á floresta de altos platôs), floresta montana e floresta alta montana.

A área estudada foi dividida, através de imagem de satélites, em cinco estratos. O estrato 1 e 4 foram compostos por pequenos platôs, os estratos 2 e 3 representaram dois grandes platôs e o estrato 5 foi composto por áreas de encosta (flancos) entre os platôs e as baixadas. Dentro de cada estrato foi realizada uma amostragem simples ào acaso (COUTO, comunicação pessoal).

No levantamento foram utilizadas parcelas retângulares de $10 \times 500 \mathrm{~m}$ $\left(5.000 \mathrm{~m}^{2}\right)$, parcelas menores $(10 \times 250 \mathrm{~m}$ e $10 \times 115 \mathrm{~m})$ foram usadas nas situaçōes em que 0 efeito de bordadura e 0 acidentes do terreno limitavam a instalação das parcelas normais. Em cada parcela foram medidas todas as árvores com CAP (circunferência à altura do peito) superior a $40 \mathrm{~cm}$ (aproximadamente $13 \mathrm{~cm}$ de DAP), tomando-se ainda a altura comercial (altura do solo à primeira bifurcação do tronco). O QUADRO 1.1. apresenta o número de árvores e parcelas amostradas por estrato. 
QUADRO 1.1: Número de árvores, número de parcelas e área amostrada.

\begin{tabular}{|c|c|ccc|cc|}
\hline \multirow{2}{*}{ ESTRATOS } & $\begin{array}{c}\text { Número de } \\
\text { Árvores } \\
\end{array}$ & \multicolumn{2}{|c|}{$\begin{array}{c}\text { Número de Parcelas } \\
(\text { Medidas }\end{array}$} & 5.000 & 2.500 & \multicolumn{2}{|c|}{ Amostragem por Estrato } \\
& Med & 1.150 & Parcelas & Area (ha) \\
\hline 1 & 1.862 & 13 & - & 1 & 14 & 6,615 \\
2 & 2.205 & 15 & 1 & - & 16 & 7,750 \\
3 & 2.525 & 16 & 3 & - & 19 & 8,000 \\
4 & 2.028 & 9 & 8 & - & 17 & 6,500 \\
5 & 3.366 & 18 & 4 & - & 22 & 10,000 \\
\hline TOTAL & 11.986 & 72 & 16 & 1 & 89 & 38,865 \\
\hline
\end{tabular}

Durante o levantamento as árvores foram identificadas por um único mateiro por seus nomes populares. Posteriormente, TOMAZELLO et alii (1983) fizeram a identificação dendrológica das espécies com base em material coletado durante o levantamento.

Foram identificadas 206 espécies pelo mateiro. Nem todas foram identificadas no estudo dendrológico e várias foram identificadas apenas a nível de gênero. Somente uma espécie (Piptadenia phyllostachia) recebeu mais de um nome popular (macapá - branco, alho - bravo, barracão, fava - amarela e baba - de - boi).

Nesse trabalho apenas 60 espécies foram estudadas, devido a um número mínimo de 30 árvores ser necessário para o estudo da distribuição diamétrica. Nem todas as espécies estudadas foram identificadas dendrologicamente e, portanto, foram adotados os nomes populares durante todo o trabalho. No ANEXO 1 podem ser vistos os nomes populares e científicos das espécies estudadas. 


\section{MODELAGEM DA DISTRIBUIÇÃO DE DIÂMETROS ATRAVÉS DA DISTRIBUIÇÃO WEIBULL}

${ }^{\alpha} A$ questão realmente importante é: em que circunstâncias essa fórmula é verdadeira, e em que circunstâncias ela é falsa?"

A.N. Whitehead 


\section{MODELAGEM DA DISTRIBUIÇÃO DE DIÂMETROS ATRAVŔS DA DISTRIBUIÇÃO WEIBULL}

Nesse capítulo a distribuição Weibull é apresentada juntamente com algumas de suas aplicaçōes. Uma breve revisão sobre os diferentes métodos de ajuste também é apresentada, detalhando-se os métodos testados nesse trabalho para ajustar a distribuição de diâmetros de algưmas espécies arbóreas tropicais. Procura-se ao final definir a precisão dos diferentes métodos para o caso em estudo.

\subsection{Apresentação da Distribuição Weibull}

A distribuição de probabilidades Weibull foi proposta primeiramente por Fisher e Tippet em 1928, tendo sido desenvolvida independentemente por Waloddi Weibull, físico sueco, em 1939 no estudo de resistência de materiais. Provavelmente, após a Segunda Guerra Mundial, com a ênfase no estudo da resitência dos materiais, o 
trabalho de Weibull se destacou e a distribuição passou a ser chamada pelo seu nome (BAILEY, 1973). Na literatura russa é reconhecida ainda a importância de um outro autor, sendo a distribuição normalmente chamada de ${ }^{\circledR}$ WEIBULL - GNEDENKO" (JOHNSON e KOTZ, 1970).

Sua função de densidade probabilística (f.d.p.) é apresentada de diversas formas, sendo comum nos trabalhos de distribuição de diâmetros apresentá-la como:

$$
\begin{aligned}
f(x) & =(c / b)\left(\frac{x-a}{b}\right)^{c-1} \exp \left(-\left(\frac{x-a}{b}\right)^{c}\right) \quad \text { para } x \geq a \\
e f(x) & =0 \text { para } x<a
\end{aligned}
$$

onde: $x$ é a variável aleatória, $\mathrm{e}$

$$
a \geq 0, b>0 \text { e c }>0 \text { os parâmetros da distribuição. }
$$

Nessa forma a distribuição é normalmente chamada de ${ }^{\circledR}$ Weibull - 3 parâmetros”. A sua função de densidade acumulada (f.d.a.) é:

$$
F(x)=\int_{0}^{+\infty} f(x) d x=1-\exp \left(-\left(\frac{x-a}{b}\right)^{c}\right)
$$

Uma das razōes que fazem a distribuição Weibull ser aplicada em muitas situaçōes é a íntima relação entre os parâmetros e o comportamento da distribuição. 0 parâmetro a é chamado de parâmetro de posição pois controla a posição da curva sobre o eixo das abcissas (FIGURA 2.1). Quando $a=0$ a distribuição inicia-se na origem surgindo um caso especial, sendo então chamada de ${ }^{\text {}}$ Weibull - 2 parâmetros” . Nesse caso as f.d.p. e f.d.a. passam a ser, respectivamente:

$$
\begin{aligned}
& f(x)=(c / b)\left(\frac{x}{b}\right)^{c-1} \exp \left(-\left(\frac{x}{b}\right)^{c}\right) \\
& F(x)=1-\exp \left(-\left(\frac{x}{b}\right)^{c}\right)
\end{aligned}
$$




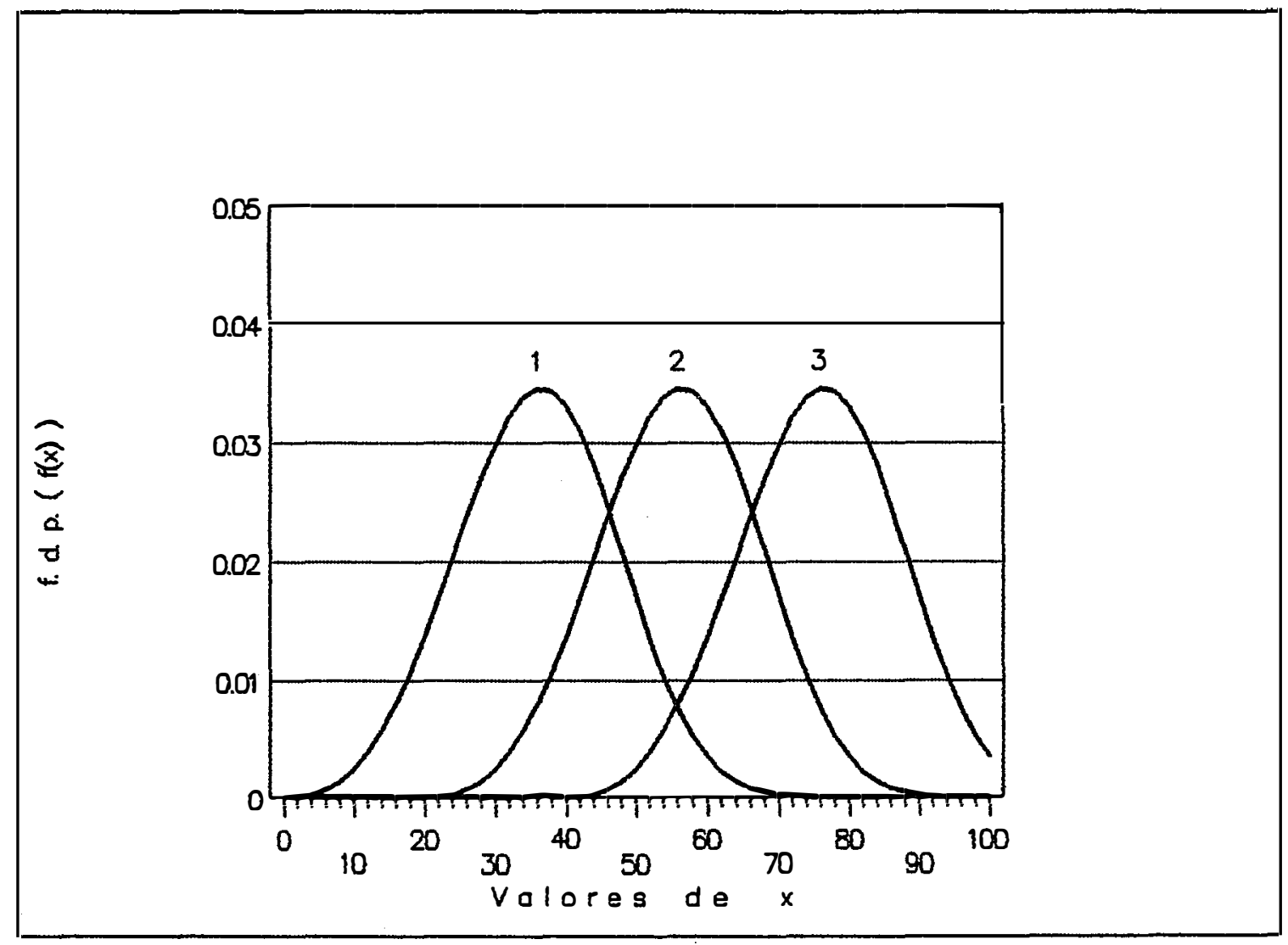

FIGURA 2.1: Influência do valor do parâmetro da localização (a) sobre a distribuição Weibull. Valores dos parâmetros: $c=3,6, b=$ 40, $a=0$ na curva (1), $a=20 \mathrm{na}$ (2) e $a=40 \mathrm{na}$ (3).

O parâmetro da escala (b) controla as dimensões que a curva assume, dada uma forma constante. $A$ medida que o valor de $b$ aumenta a curva se torna mais dispersa, isso pode ser facilmente notada quando a Weibull assume a forma de sino como pode ser visto na FIGURA 2.2 .

A grande variedade de formas que a Weibull pode assumir é controlada pelo parâmetro $c$, chamado parâmetro da forma. Quando $c \leq 1$ a distribuição assume a forma de "J invertido", típica da distribuição diamétrica de florestas temperadas dissetâneas e de florestas tropicais naturais. A distribuição exponencial, ou de 


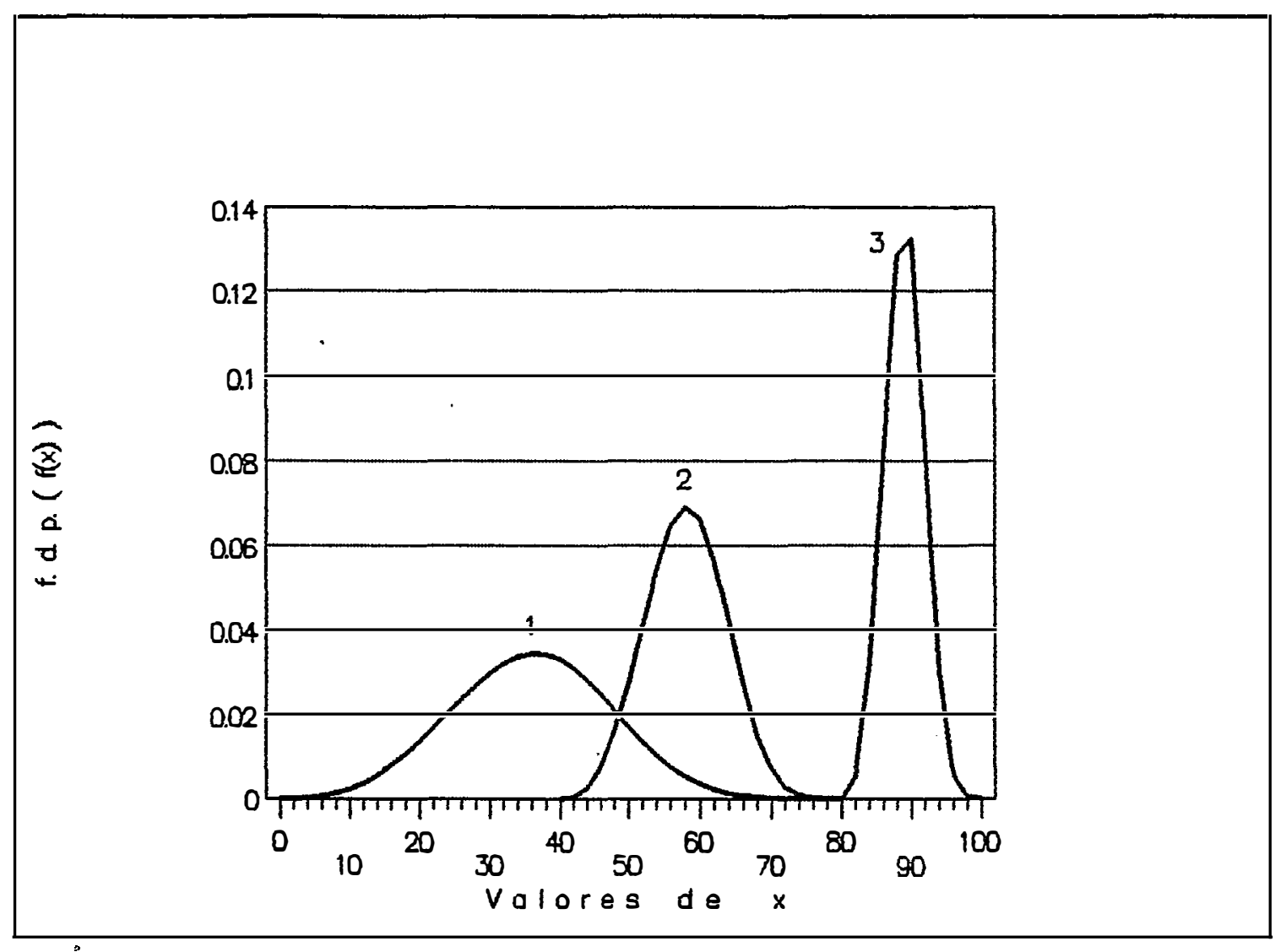

FIGURA 2.2: Influência do valor do parâmetro de escala $(b)$ sobre a distribuição Weibull. Valores dos parâmetros: (1) $b=40(a=0 ; c=$ $3,6),(2) b=20(a=40 ; c=3,6)$, e (3) $b=10(a=80 ; c=3,6)$.

De Liocourt como é conhecida na Biometria Florestal, pode ser considerada um caso particular da Weibull no qual $c=1$. Para valores de $c$ entre 1 e 3,6 a distribuição torna-se positivamente assimétrica, tomando a forma de sino praticamente simétrica semelhante a distribuição normal quando $c=3,6$. $\AA$ medida que o valor de $c$ passa de 3,6 e tende ao infinito, a distribuição torna-se negativamente assimétrica tendendo a uma forma extremamente leptocúrtica (FIGURA 2.3).

Algumas propriedades da Weibull - 2 parâmetros (equação 3) são apresentadas por JOHNSON e KOTZ (1970) e SHAPIRO e GROSS (1981): 


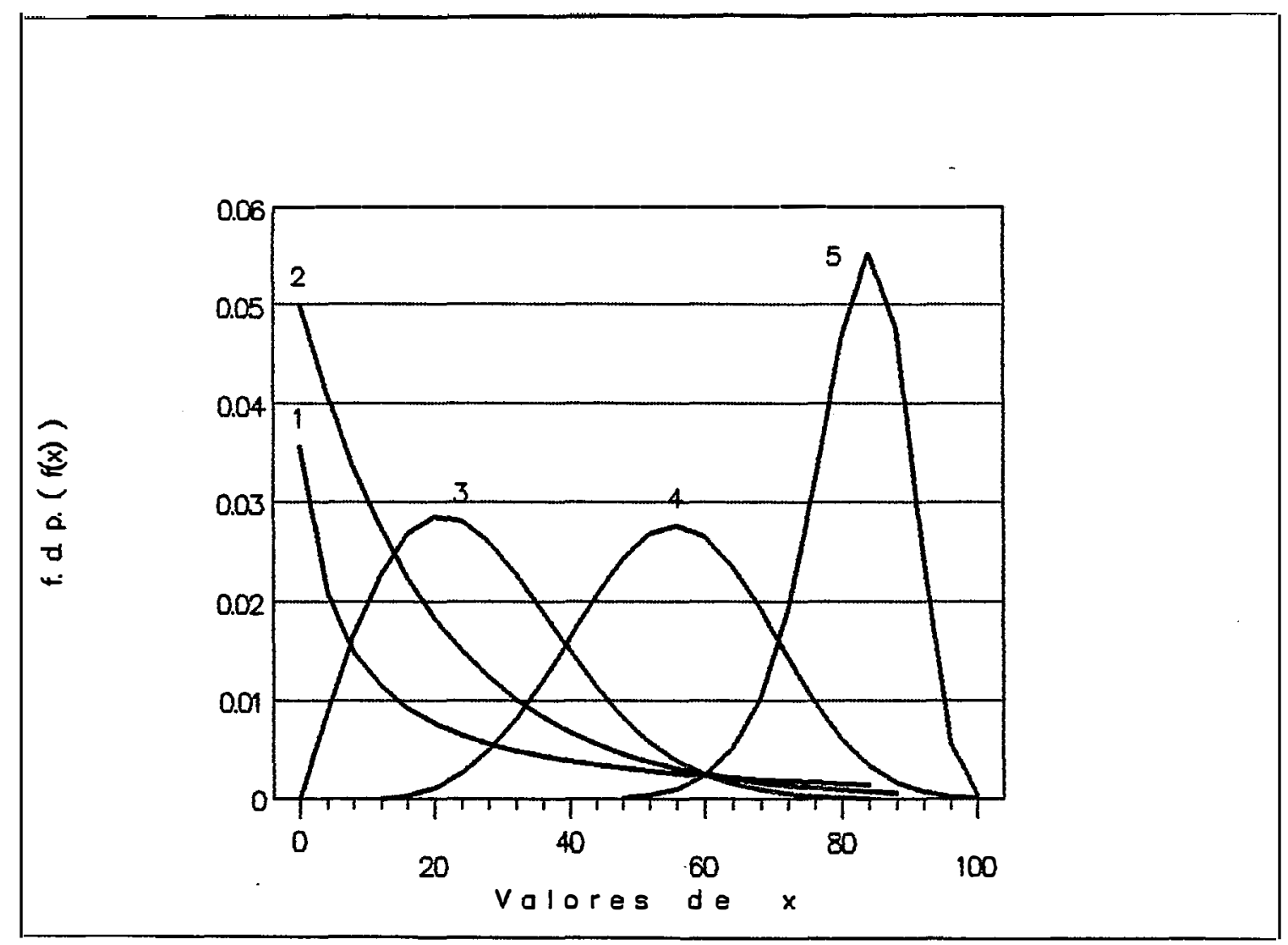

FIGURA 2.3: Influência do valor do parâmetro da forma $(c)$ sobre a distribuição Weibull. Valores dos parâmetros: (1) $c=0,5(a=$ $0 ; b=20),(2) c=1,0(a=0 ; b=20)$, e (3) $c=2.0(a=0 ; b=30)$, (4) $c=3,6(a=10 ; b=50)(5) c=12,0(a=5 ; b=80)$.

a) Momentos em relação à origem:

$$
\mu_{r}^{\prime}=E\left(x^{r}\right)=\int_{0}^{+\infty} x^{r} f(x) d x=b^{r} \Gamma(1+r / c)
$$

onde: $\Gamma(1+r / c)$ é a função gama.

Conseqüentemente a média é obtida por:

$$
\mu=6 \Gamma(1+1 / c)
$$


e a variância por:

$$
\sigma^{2}=\mu_{2}^{\prime}-\left(\mu_{1}^{\prime}\right)^{2}-b^{2}\left(\Gamma(1+2 / c)-(\Gamma(1+1 / c))^{2}\right)
$$

b) Os percentis $(p)$ são facilmente obtidos através da logaritmização da f.d.a. :

$$
x_{p}=b(-\ln (1-p))^{1 / 0}
$$

c) A moda é dada por:

$$
x_{M}=b\left(\frac{c-1}{c}\right)^{1 / c} \text { para } c>1
$$

Apesar da distribuição Weibull ter surgido originalmente no estudo de resistência de materiais, já em 1951 WEIBULL (1951) defendia a sua ampla aplicabilidade, mostrando que esta podia ser igualmente bem adaptada a dados de: fadiga de um aço ST-37, força das fibras do algodão indiano, superfície de grãos de Phaseolus velgoris, estaturo de homens adultos nascidos nas ilhas britânicas, entre outros.

A partir dal seu uso se ampliou, tendo sido aplicada no controle de qualidade de materiais (Kao, 1958 e 1959, citado por JOHNSON e KOTZ, 1970), em dados de sobrevivência tanto na área médica (ELANDT-JOHNSON e JOHNSON, 1980; GROSS e CLARK, 1975), quanto em estudo de populaçōes animais (PINDER et alii, 1978), ou ainda na sobrevivência de árvores em florestas plantadas (SOMERS et alii, 1980),no estudo do vigor de sementes (BONNER e DELL , 1976), no estudo do incremento de anéis de crescimento de árvores (KRUG et alii, 1984), e na representação 
da distribuição de diâmetros, da área basal, da área de superfície foliar e da biomassa (SCHREUDER E SWANK, 1974).

O uso da distribuição Weibull na representação da distribuição de diâmetros de florestas foi sugerido por BAILEY e DELL (1973), tendo sido aplicada principalmente em trabalhos que visavam construir modelos de crescimento e produção de madeira, como por exemplo em BURK e BURKHART (1984), BURKHART et alii (1981), KNOEBEL et alii (1986), LENHART (1986), LITTLE (1983), WHYTE (1986), HOSOKAWA e GLADE (1986), entre outros.

Seu uso em florestas tropicais foi testado por BARROS et alii (1979), enquanto COUTO (1980) testou-a em plantaçōes de Pinus caribaea var caribaea no Estado de São Paulo. SILVA (1986) utilizou-a para estudar o efeito de adubação em florestas de Pinus taeda e HOSOKAWA e GLADE (1986) se basearam na Weibull para construir um modelo de prognose de produção por classes diamétricas para Araucario angustifolia. 


\subsection{Métodos de Ajuste da Distribuição Weibull}

Muitas formas de estimar os parâmetros da distribuição Weibull foram desenvolvidas, contribuindo, junto com a sua grande flexibilidade de forma, para sua utilização em diversas áreas. A maior parte dos estimadores se referem à Weibull 2 parâmetros, pois seu ajuste é mais simples e sua utilização mais freqüênte na área de resistência de materiais, onde surgiram os principais trabalhos sobre o ajuste da Weibull.

Os principais métodos de ajuste da distribuição Weibull são:
a) métodos de máxima verossimilhança;
b) métodos baseados nos momentos da distribuição;
c) métodos baseados nos percentis da distribuição;
d) métodos de funçōes lineares; $e$
e) métodos de regressão linear e não linear.

\subsubsection{Métodos de máxima verossimilhança.}

HATER e MOORE (1965) deduziram os estimadores de máxima verossimilhança para Weibull - 3 parâmetros. Como os parâmetros são correlacionados, a estimativa de um dos parâmetros necessita do valor dos outros dois. Para resolver isso, aqueles autores desenvolveram um algoritmo baseado no método iterativo da falsa posição.

Para a Weibull - 2 parâmetros, COHEN (1965) desenvolveu estimadores de máxima verossimilhança tanto para amostras completas, quanto para amostras censuradas e amostras progressivamente censuradas. COUTO (1980) deduziu 
os estimadores de máxima verossimilhança da Weibull - 2 parâmetros tendo chegado a 0 mesmos estimadores de COHEN (1965). A dedução encontra-se no ANEXO 3 e os estimadores resultantes são:

$$
\begin{aligned}
& \hat{c}=n /\left[(1 / \hat{b} \hat{c}) \sum_{i=1}^{n}\left(x_{i}^{\hat{c}} \ln \left(x_{i}\right)\right)-\sum_{i=1}^{n} \ln \left(x_{i}\right)\right] \\
& \hat{b}=\left(\frac{\sum_{i=1}^{n} \frac{x_{i}^{\hat{c}}}{n}}{n}\right)^{1 / \hat{c}}
\end{aligned}
$$

Nota-se que $\hat{b}$ é função de $\hat{c}$, enquanto este é função de $\hat{b}$ e de si próprio. Normalmente a solução desse sịstema é obtida substituindo (2.11) em (2.10) e transformando para:

$$
\frac{\sum_{i=1}^{n} x_{i}^{\hat{c}} \ln \left(x_{i}\right)}{\sum_{i=1}^{n} x_{i}^{\hat{c}}}-\frac{\sum_{i=1}^{n} \ln \left(x_{i}\right)}{n}-\frac{1}{\hat{c}}=0
$$

Encontra-se, então $\hat{c}$ resolvendo (2.12) por um processo iterativo, em geral o método de Newton-Raphson (vide DIXON, 1974, e BERCKETT e HURT, 1967), e encontra-se $\hat{b}$ por meio de (2.11) a partir de $\hat{c}$.

ZUTTER et alii (1982) apresentaram um programa de computador em FORTRAN para estimar os parâmetros da Weibull - 3 parâmetros (completa e truncada à direita) e Weibull - 2 parâmetros (completa, truncada à direita, truncada à esquerda e bitruncada). 0 programa utiliza métodos iterativos sendo os valores iniciais obtidos por regressão linear. No caso da Weibull - 2 parâmetros truncada à esquerda a f.d.p. e f.d.a. utilizadas foram respectivamente:

$$
\begin{aligned}
& f(x)=\frac{c}{b}\left(\frac{x}{b}\right)^{c-1} \exp \left[\left(\frac{t}{b}\right)^{c}-\left(\frac{x}{b}\right)^{c}\right] \\
& F(x)=1-\exp \left[\left(\frac{t}{b}\right)^{c}-\left(\frac{x}{b}\right)^{c}\right]
\end{aligned}
$$


onde: $t \leq x$ é o ponto de truncagem.

Dada a dificuldade em utilizar os métodos iterativos complexos necessários para solucionar os estimadores de máxima verossimilhança da Weibull 3 parâmetros, JOHNSON e KOTZ (1970) sugeriram três formas de considerar o parâmetro de localização (a) para facilitar o ajuste.

1) Para $a=0$ temos a Weibull - 2 parâmetros podendo-se utilizar os estimadores apresentados por COHEN (1965).

2) Para a conhecido e diferente de zero pode-se utilizar os mesmos estimadores, substituindo-se $x_{i}$ por $y_{i}=\left(x_{i}-a\right)$.

3) Para a desconhecido pode-se utilizar os mesmos estimadores, substituindo-se $x_{i}$ por $y_{i}=\left(x_{i}-x_{m i n}\right)$, onde $x_{m i n}$ é o valor mínimo de $x_{i}$.

\subsubsection{Métodos baseados nos Momentos da Distribuição}

BURK e NEWBERRY (1984) apresentaram estimadores para Weibull - 3 parâmetros baseados nos três primeiros momentos centrais da distribuição, que são:

$$
\begin{aligned}
& \mu_{1}^{\prime}=a+b \Gamma_{1} \\
& \mu_{2}^{\prime}=a^{2}+2 a b \Gamma_{1}+b^{2} \Gamma_{2} \\
& \mu_{3}^{\prime}=a^{3}+3 a^{2} b \Gamma_{1}+3 a b^{2} \Gamma_{2}+b^{3} \Gamma_{3}
\end{aligned}
$$

onde: $\Gamma_{k}=\Gamma(1+k / c)$ é a função gama. 
A partir dos momentos esses autores deduziram os seguintes esti-

madores:

$$
\begin{aligned}
\hat{a} & =\mu_{1}^{\prime}-b \Gamma_{1} \\
\hat{b} & =\sqrt{\frac{\mu_{2}^{\prime}-\left(\mu_{1}^{\prime}\right)^{2}}{\Gamma_{2}-\Gamma_{1}^{2}}} \\
\mu_{3}^{\prime} & =\hat{b}^{3}\left[\Gamma_{3}-3 \Gamma_{1} \Gamma_{2}+2 \Gamma_{1}^{3}\right]+3 \mu_{1}^{\prime} \mu_{2}^{\prime}-2\left(\mu_{1}^{\prime}\right)^{3}
\end{aligned}
$$

A equação (2.20) é resolvida por um método iterativo adequado encontrando-se o valor de $\hat{c}$. Utilizam-se então as equaçōes (2.18) e (2.19) para obter $\hat{a}$ e $\hat{b}$ em função de $\hat{c}$.

BURK e BURKHART (1984) simplificaram o método de BURK e NEWBERRY (1984) aplicando-o à distribuição de diâmetros, inicialmente eles assumiram o valor de â como o diâmetro mínimo:

$$
\hat{a}=\min \left(D A P_{i}\right)
$$

onde: $D A P_{i}(i=1,2, \ldots, n)$ é o diâmetro d̀ altura do peito.

Tomando então os primeiros dois momentos centrais ( equaçōes (2.15) e (2.16) ) e assumindo que $\hat{\mu}_{1}^{\prime}=\overline{D A P}$ (diâmetro médio aritmético) e $\hat{\mu}_{2}^{\prime}=\overline{D A P Q}{ }^{2}$ (diâmetro médio quadrático), eles deduziram os estimadores:

$$
\begin{gathered}
\hat{b}=\frac{D A P-a}{\Gamma_{1}} \\
D A P Q^{2}-a^{2}-2 a(D A P-a)-\frac{(D A P-a)^{2} \Gamma_{2}}{\Gamma_{1}{ }^{2}}=0
\end{gathered}
$$

Para obter as estimativas encontra-se $\hat{a}$ por (2.21) e resolve-se (2.23) para $\hat{c}$ através de um método iterativo. Os autores utilizaram uma combinação do 
método da bissecção e o método da secante. Obtidos $\hat{a}$ e $\hat{c}$ encontra-se $\hat{b}$ através de (2.22).

NEWBY (1980) desenvolveu estimadores para Weibull - 2 parâmetros baseados no coeficiente de variação da amostra (CV). Este autor demonstrou que na Weibull - 2 parâmetros o coeficiente de variação é função única do parâmetro da forma (c). Assim, dada uma tabela da "Weibull Estandardizada" (distribuição Weibull onde $b=1$ ), obtem-se a estimativa de $c$ entrando com o CV da amostra. A estimativa de $b$ é obtida utilizando-se o primeiro momento central da Weibull 2 parâmetros:

$$
\hat{b}=\frac{\mu_{1}^{\prime}}{\Gamma_{1}}
$$

\subsubsection{Métodos baseados nos Percentis da Distribuição.}

DUBEY (1967) foi quem introduziu estimadores da Weibull - 2 parâmetros baseados nos percentis supondo três situações:

1) c e b são desconhecidos,

2) $c$ é conhecido, $\mathrm{e}$

3) $b$ é conhecido.

Os estimadores de DUBEY (1967) apresentados para o primeiro caso foram utilizados por BAILEY (1973) no estudo da distribuição de diâmetros. Os estimadores de $c$ e $b$ baseado em dois percentis utilizados foram:

$$
\begin{aligned}
\hat{c} & =\frac{k}{\left(\ln \left(x_{1}\right)-\ln \left(x_{2}\right)\right)} \\
\hat{b} & =\frac{x_{3}}{\left[-\ln \left(1-p_{3}\right)\right]^{1 / \bar{c}}}
\end{aligned}
$$


onde: $k=\ln \left(-\ln \left(1-p_{1}\right)\right)-\ln \left(-\ln \left(1-p_{2}\right)\right)$,

$p_{1}, p_{2}$ e $p_{3}$ são probabilidades,

$x_{1}, x_{2}$ e $x_{3}$ são os percentis, e

In indica logatimo neperiano.

DUBEY (1967) deduzindo uma expressão da variância do estimador de $c$ em função das probabilidades $p_{1}$ e $p_{2}$, concluindo que os valores de $p_{1}=0.16730679$ e $p_{2}=0.97366352$ minimizam a variância de $\hat{c}$ e, conseqüentemente, são as melhores probabilidades a serem utilizados nesse caso. Para o estimador de $b, 0$ melhor percentil é o relativo a $p_{3}=0.797$, que atinge $63 \%$ de eficiência em relação aos estimadores de máxima verossimilhança.

Entretanto, para a estimação conjunta de $c$ e $b$, DUBEY (1967) demonstrou que os melhores percentis são os relativos a $p_{1}=0,23875930$ e $p_{2}=$ 0,92656148 com aproximadamente $41 \%$ de eficiência em relação aos estimadores de máxima verossimilhança.

Para a Weibull - 3 parâmetros Zanakis (1979) (citado por ZANOCH e DELL, 1985) desenvolveu estimadores baseados nos percentis. O estimador de $a$ proposto foi:

$$
\begin{aligned}
& \hat{a}=\frac{x_{1} x_{n}-x_{2}^{2}}{x_{1}+x_{n}-2 x_{2}}, \quad \text { se } x_{2} \text { é mais próximo de } x_{1} \text { do que de } x_{n}, \mathrm{e} \\
& \hat{a}=x_{1}, \quad \text { nos demais casos }
\end{aligned}
$$

onde: $x_{i}$ é o $p_{i}{ }^{e ́ s i m o}$ percentil da amostra de tamanho $n$.

Utilizando-se a propriedade da Weibull em que $x_{p}=a+b$ é aproximadamente o percentil relativo a $p=0.63$, o estimador de $b$ proposto foi:

$$
\hat{b}=x_{p}-\hat{a}
$$


Para obter o estimador de c, Zanakis (1979) utiliza a equação (2.25) substituindo $x_{i}$ por $\left(x_{i}-a\right)$ e com os mesmos percentis recomendados por DUBEY (1967).

$$
\hat{c}=\frac{\ln \left[\ln \left(1-p_{1}\right) / \ln \left(-\ln \left(1-p_{2}\right)\right]\right.}{\ln \left[\left(x_{1}-\hat{a}\right) /\left(x_{2}-\hat{a}\right)\right]}
$$

\subsubsection{Método das Funções Lineares.}

Segundo BAILEY e DELL (1973), as funçōes lineares são obtidas através da transformação da variável aleatória $x$ (que possui distribuição Weibull) numa variável relacionada do tipo:

$$
w=\left(\frac{x}{b}\right)^{c}
$$

com distribuição independente de b e c, e com f.d.p. :

$$
\begin{aligned}
& f(w)=e^{-w}, \quad \text { para } w \geq 0, \text { e } \\
& f(w)=0, \quad \text { para } w<0
\end{aligned}
$$

Utilizando a variável $w$ busca-se obter estimadores lineares de $b$ e $c$ que minimizem a soma dos quadrados dos desvios dos valores esperados para os valores ordenados de $w$.

MENON (1963) e BAIN e ANTLE (1967) desenvolveram estimadores lineares baseados nesse princípio. Os estimadores de MENON (1963) são:

$$
\hat{c}=1 /\left\{\left(6 / \pi^{2}\right)\left[\sum_{i=1}^{n}\left(\ln \left(x_{i}\right)\right)^{2}-\left(\sum_{i=1}^{n} \ln \left(x_{i}\right)\right)^{2} / n\right] /(n-1)\right\}^{1 / 2}
$$




$$
\ln (\hat{b})=\frac{\sum_{i=1}^{n} x_{i}}{n}-\lambda_{1}\left\{\frac{6(n-1)}{\pi^{2}}\left[\sum_{i=1}^{n}\left(\ln \left(x_{i}\right)\right)^{2}-\left(\sum_{i=1}^{n} \ln \left(x_{i}\right)\right)^{2} / n\right]^{1 / 2}\right.
$$

onde: $\pi$ é o número pi $(3,1416)$, e $\lambda_{1}=-0,5772$.

Segundo BAIN e ANTLE (1967), seus estimadores são superiores aos de MENON (1967) somente no caso de amostras pequenas $(n<10)$, onde os estimadores deste se tornam tendenciosos, o que foi posteriormente confirmado por GROSS (1977).

\subsubsection{Métodos de Regressão Linear e Não Linear.}

A regressāo linear também pode ser utilizada para estimar os parâmetros da Weibull. Para isso a f.d.a. é linearizada pela aplicação sucessiva de logaritmos neperianos. WEIBULL (1951) aplicou a distribuição a diferentes situaçc̃es ajustando-a através de regressão linear da equação:

$$
\ln \left[\ln \left(\frac{1}{1-F(x)}\right)\right]=c \ln (x-a)-\ln \left(\frac{1}{b}\right)
$$

A regressão não linear também já foi utilizada para ajustar a distribuição Weibull - 2 parâmetros através da forma normal (não linearizada) da sua f.d.a. -

BERGER e LAWRENCE (1974) compararam a regressão linear contra a regressão não linear no ajuste da distribuição Weibull - 2 parâmetros. Concluíram que a regressão não linear, além de exigir seis vêzes mais tempo de computação, produz um ajuste inferior à regressão linear, pois a média dos quadrados dos desvios produzidos pela regressão não linear foi de 15 a $50 \%$ superior à regressảo linear. 


\subsubsection{Comparação dos Métodos.}

De modo geral, os estimadores de máxima verossimilhança são considerados os melhores (BAILEY e DELL, 1973). Entretanto, o estimador de máxima verossimilhança de $c$ é tendencioso, sendo que a tendenciosidade depende do tamanho da amostra, mas não do valor de c (JOHNSON e KOTZ, 1970).

ZARNOCH e DELL (1985) observaram que, em geral, os estimadores de máxima verossimilhança são mais precisos que os baseados em percentis, mas, quando $c \leq 2$, estes são iguais ou mesmo superiores aos estimadores de máxima verossimilhança.

SHIVER (1985) estudou o efeito do tamanho da amostra sobre a precisão dos estimadores de máxima verossimilhança de momentos e de percentis no ajuste da distribuição Weibull a dados simulados de distribuição de diâmetros. 0 aumento do tamanho da amostra foi mais sentido pelos estimadores de momentos e de percentis, mas o erro quadrado médio estabilizou-se para os três métodos a partir de amostras com 60 a 70 árvores.

Como as estimativas dos parâmetros da Weibull são correlacionadas e essa correlação depende do método de ajuste, o melhor método para estimar os parâmetros não é necessariamente o melhor método para representar a distribuição, pois diferentes combinações dos parâmetros podem produzir distribuições com a mesma forma (SHIVER, 1985; ZARNOCH e DELL, 1985).

Ainda segundo SHIVER (1985), amostras com 40 a 50 árvores foram suficientes para os métodos de momentos e de percentis produzirem uma distribuição de diâmetros sem diferenças estatisticamente significativas $(\alpha=0.05)$ da distribuição 
observada, enquanto que o método da máxima verossimilhança ainda apresentava diferenças significativas. ZARNOCH e DELL (1985) e SHIVER (1985) concluíram que, embora os métodos de máxima verossimilhança sejam superiores para estimar os parâmetros quando se trata de interpretá-los, os métodos dos momentos e dos percentis são superiores para representar a distribuição observada.

ZARNOCH e DELL (1985) observaram ainda que os estimadores de máxima verossimilhança da Weibull - 2 parâmetros tendem a superestimar o parâmetro c, necessitando de correção, sendo que os métodos de percentis também apresentam essa tendência.

SHIVER (1985) observou que os métodos dos momentos e dos percentis para Weibull - 3 parâmetros são altamente influenciados por estimativas tendenciosas dos valores iniciais do parâmetro a.

ZUTTER et alii (1986), comparando os diferentes estimadores de máxima verossimilhança para a Weibull - 2 parâmetros, observaram que todos apresentam pouca precisão ao estimar o diâmetro médio quadrático em distribuiçōes de diâmetro com forma de " J invertido". 0 melhor resultado foi obtido com os estimadores baseados na distribuição truncada à esquerda. 


\subsection{Metodologia Utilizada}

Das 207 espécies encontradas, apenas aquelas com 30 ou mais árvores amostradas foram estudadas (60 espécies). O limite de 30 árvores foi estabelecido arbitrariamente com o objetivo de se obter um número suficiente de espécies para o estudo e considerando que, em amostras muito pequenas, o ajuste é prejudicado.

Como vários métodos de ajuste exigem processos iterativos, utilizaram-se dados agrupados para reduzir o tempo de computação necessário ao estudo. Conseqüentemente, os estimadores foram adaptados para se trabalhar com dados agrupados. Como a amplitude das classes utilizadas pode influir significativamente no ajuste da distribuição Weibull (BARROS et alii, 1979), testaram-se, inicialmente, diferentes amplitudes de classes diamétricas.

\subsubsection{Classes diamétricas testadas}

Nesse estudo foram utilizados apenas os dados referentes aos estratos 1 e 5, portanto, das 60 espécies estudadas somente 35 foram utilizadas nessa fase inicial.

As amplitudes de classe testadas foram:

a) amplitude fixa de $5 \mathrm{~cm}$;

b) amplitude fixa de $10 \mathrm{~cm}$;

c) amplitude variável para cada espécie segundo o algoritmo de RAMSDELL (COUTO, comunicação pessoal), onde o número de classes é dado por:

$$
N C=1+3,33 \log _{10}(n)
$$


onde: $N C$ é o número de classes;

$n$ é o tamanho da amostra (número de árvores);

e a amplitude de classe é obtida arredondando-se o valor de:

$$
A=\frac{D A P_{\max }-D A P_{\min }}{N C}
$$

onde: $A$ é a amplitude de classe;

$D A P_{\max }$ e $D A P_{\min }$ são os diâmetros máximos e mínimos observados, respectivamente.

Nos três casos utilizou-se o diâmetro mínimo de $13 \mathrm{~cm}$ para todas as espécies estudadas, pois esse valor corresponde ao diâmetro mínimo do levantamento de campo.

A distribuição Weibull foi ajustada nas três amplitudes de classe para cada uma das 35 espécies utilizando o método dos percentis (vide secção 2.3.2.). A análise de variância e o teste Tukey, para as estimativas dos parâmetros $b$ e $c$, servem como uma indicação de que a amplitude de classe influencia os valores obtidos (QUADRO 2.1.).

Como o objetivo desse trabalho foi estudar a distribuição de diâmetros das espécies individualmente, decidiu-se utilizar as classes de amplitude variável. Esse sistema de agrupamento evita que espécies com pequena amplitude de variação nos diâmetros não tenha a sua distribuição restrita a 2 ou 3 classes, como acontece quando se usa classe de $10 \mathrm{~cm}$, o que prejudica o ajuste da distribuição. Por outro lado, as classes de amplitude variável evitam um número muito grande de classes com a ocorrência de flutuações no número de indivíduos em classes adjacentes, como nas classes de $5 \mathrm{~cm}$, o que também prejudica o ajuste. 
QUADRO 2.1: Teste de Tukey para comparação dos valores médios das estimativas dos parâmetros da Weibull, obtidas em dados agrupados por diferentes amplitudes de classe.

\begin{tabular}{|c|c|c|}
\hline $\begin{array}{l}\text { AMPLITUDE DE } \\
\text { CLASSE } \\
\text { (cm) }\end{array}$ & $\underset{c}{\text { PARÂMETRO }}$ & $\begin{array}{l}\text { PARÂMETRO } \\
b\end{array}$ \\
\hline $5 \mathrm{~cm}$ & $1,1839 \mathrm{C}$ & $11,167 \quad \mathrm{~B}$ \\
\hline $10 \mathrm{~cm}$ & $1,2600 \quad B$ & $13,408 \mathrm{~A}$ \\
\hline variável (segundo RAMSDELL) & $1,3417 \quad \mathrm{~A}$ & $13,402 \mathrm{~A}$ \\
\hline
\end{tabular}

OBS: Valores com letras diferentes indicam diferenças estatísticamete significativas ao nivel de $5 \%$ de probabilidade. $\mathrm{Na}$ análise de variância para o parâmetro $c \mathrm{~F}=17,96^{* *}(\mathrm{CV}=8,73 \%)$ e para o parâmetro $b \mathrm{~F}=36,20$ $* *(\mathrm{CV}=9,56 \%)$.

Utilizando os dados dos cinco estratos, as 60 espécies estudadas foram agrupadas segundo a proposta de RAMSDELL. No QUADRO 2.2. são apresentados 0 número e as amplitudes de classes para cada espécie.

\subsubsection{Métodos de ajuste testados}

Dentre os métodos apresentados, apenas os métodos de uso mais comum nos estudos de distribuição de diâmetro foram testados. Foram eles: métodos dos percentis (proposta de DUBEY 1967), método das funções lineares (MENON, 1963), métodos dos momentos (NEWBY, 1977; BURK e BURKHART, 1980) e métodos de máxima verossimilhança (estimadores para amostras completas de COHEN, 1967, e para amostras truncadas à esquerda). 
QUADRO 2.2: Número e amplitude de classes utilizadas para as 60 espécies estudadas.

\begin{tabular}{|l|c|c|c|l|c|c|c|}
\hline \multicolumn{1}{|c|}{ Espécie } & $\begin{array}{c}\text { C6́digo } \\
\text { da espécie }\end{array}$ & $\begin{array}{c}\text { Amplitude } \\
\text { (cm) }\end{array}$ & $\begin{array}{c}\text { Número de } \\
\text { classes }\end{array}$ & Espécie & $\begin{array}{c}\text { C6digo } \\
\text { da espécie }\end{array}$ & $\begin{array}{c}\text { Amplitude } \\
\text { (cm) }\end{array}$ & $\begin{array}{c}\text { Número de } \\
\text { classes }\end{array}$ \\
\hline Alho bravo & 4 & 12 & 7 & Amapá & 5 & 7 & 7 \\
Amarelinho & 7 & 1 & 10 & Amescão & 8 & 7 & 11 \\
Ariticum & 9 & 3 & 9 & Arueira brava & 15 & 9 & 7 \\
Barrote & 16 & 7 & 10 & Barracão & 18 & 5 & 8 \\
Baba de boi & 21 & 8 & 7 & Canela de viado & 25 & 2 & 6 \\
Copáiba & 28 & 10 & 9 & Cravo & 32 & 6 & 8 \\
Cumaru & 34 & 12 & 8 & Capa de bode & 38 & 6 & 7 \\
Chapéu baiano & 42 & 4 & 11 & Envira preta & 53 & 6 & 7 \\
Git6 & 64 & 3 & 14 & Goiabão & 66 & 4 & 12 \\
Guabiroba & 67 & 3 & 8 & Goiabinha & 69 & 4 & 8 \\
Inharé branco & 72 & 5 & 7 & Ingá & 73 & 3 & 10 \\
Ingá xixiba & 78 & 8 & 7 & Imbaca & 80 & 6 & 8 \\
Jatobá coruba & 83 & 8 & 10 & Jatobá lago & 84 & 9 & 6 \\
Jatobá fava & 86 & 13 & 9 & Jacarandá & 87 & 6 & 9 \\
Liinãozinho & 93 & 2 & 9 & Maria preta & 98 & 5 & 9 \\
Mamoninha & 99 & 5 & 11 & Maçaranduba & 102 & 10 & 9 \\
Olho de pombo & 106 & 4 & 9 & Puturuna & 107 & 4 & 12 \\
Pitomba de leite & 111 & 3 & 11 & Pau piranha & 112 & 4 & 10 \\
Paruru & 113 & 6 & 8 & Pau d'arco amarelo & 114 & 9 & 8 \\
Pau santo & 115 & 8 & 10 & Pau d'arco roxo & 117 & 14 & 8 \\
Morototó & 122 & 5 & 10 & Pitomba guariba & 125 & 28 & 7 \\
Quina & 133 & 13 & 8 & Toari branco & 138 & 10 & 9 \\
Tuturuba caboclo & 142 & 9 & 9 & Tuturuba verdadeira & 147 & 5 & 9 \\
Vara da mata & 149 & 2 & 10 & Visgueiro & 150 & 13 & 7 \\
Embaúba & 151 & 3 & 9 & Faveira & 152 & 15 & 7 \\
Gororoba & 153 & 6 & 7 & Gabiju & 154 & 4 & 10 \\
Inhaubá & 155 & 9 & 9 & Sucupira & 156 & 13 & 7 \\
Sacopembinha & 157 & 6 & 8 & Caneleiro & 163 & 13 & 10 \\
Violeta da mata & 164 & 7 & 8 & Jatobá & 165 & 15 & 7 \\
Embira preta & 168 & 5 & 8 & Gabiju de oco & 206 & 3 & 8 \\
\hline
\end{tabular}

Os estimadores baseados nos percentis apresentados por DUBEY (1967) foram utilizados para ajustar a Weibull - 2 parâmetros:

$$
\begin{gathered}
\hat{c}=\frac{k}{\left[\ln x_{1}-\ln x_{2}\right]} \\
\hat{b}=\frac{x_{1}}{\left[-\ln \left(1-p_{1}\right)\right]^{1 / \hat{\hat{c}}}}
\end{gathered}
$$


onde: $k=\ln \left[-\ln \left(1-p_{1}\right)\right]-\ln \left[-\ln \left(1-p_{2}\right)\right]$;

$p_{1}=0,24$ e $p_{2}=0,93$ são as probabilidades escolhidas;

$x_{1}$ e $x_{2}$ são os percentis correspondentes;

In indica logaritmo neperiano.

Os valores dos percentis $24 \%$ e $93 \%$ foram obtidos a partir dos dados agrupados, utilizando-se a fórmula apresentada por AZEVEDO e CAMPOS (1987):

$$
x_{p}=\left(\frac{F_{i-1}-O_{p}}{f_{i}}\right) A+\left(L I_{i}-13\right)
$$

onde: $x_{p}$ é o valor corrigido do percentil $p$ para distribuição de diâmetros truncada em $x=13 \mathrm{~cm}$

$O_{p}=p \cdot n$ é a ordem do percentil $p$ na amostra de tamamho $n$

$f_{i}$ é a freqüência observada na classe $i$, a qual inclue $O_{p}$;

$F_{i-1}$ é a freqüência acumulada na classe $(i-1)$;

$A$ é a amplitude de classe (já arredondada); e

$L I_{i}$ é o limite inferior da classe $i$.

Os estimadores de funçôes lineares de MENON (1963) foram adaptados para dados agrupados ficando na seguinte forma:

$$
\begin{aligned}
\hat{c} & =1 /\left\{\left(6 / \pi^{2}\right)\left[\sum_{i=1}^{n} f_{i}\left(\ln \left(x_{i}\right)\right)^{2}-\left(\sum_{i=1}^{n} f_{i} \ln \left(x_{i}\right)\right)^{2} / n\right] /(n-1)\right\}^{1 / 2} \\
\ln (\hat{b}) & =\frac{\sum_{i=1}^{n} x_{i}}{n}-\lambda_{1}\left\{\frac{6(n-1)}{\pi^{2}}\left[\sum_{i=1}^{n} f_{i}\left(\ln \left(x_{i}\right)\right)^{2}-\left(\sum_{i=1}^{n} f_{i} \ln \left(x_{i}\right)\right)^{2} / n\right]\right\}^{1 / 2}(2
\end{aligned}
$$

onde: $\pi$ é o número pi $(3,1416), \mathrm{e} \lambda_{1}=-0,5772$;

$x_{i}=C C_{i}-13$, sendo $C C_{i}$ o centro da classe $i$

$f_{i}$ é a freqüência observada na classe $i$; e 
$n=\sum_{i=1}^{n} f_{i}$ é o tamanho da amostra.

Dentre os métodos de momentos, foram testados os estimadores propostos por BURK e NEWBERRY (1984) com a adaptação de BURK e BURKHART (1984) (equações (2.20) (2.21) e (2.22)) e o método proposto por NEWBY (1980) (equação (2.23)). Somente para esses dois métodos, que utilizam o coeficiente de variação dos diâmetros $(C V)$, o diâmetro médio aritmético (DAP) e o diâmetro médio quadrático (DAPQ), os cálculos foram realizados diretamente dos dados individuais. A tabela da distribuição "Weibull Estandardizada”, necessária ao método de NEWBY (1980), encontra-se no ANEXO 2.

Para encontrar o valor de $\hat{c}$ pelo método de BURK e BURKHART (1984) utilizou-se, inicialmente, o método iterativo da secante (BERCKETT e HURT, 1967; DIXON, 1974) para solucionar a equação (2.22). As estimativas produzidas pelo método dos percentis foram tomadas como primeiro valor para iteração, sendo o segundo valor o primeiro menos 0,5. Entretanto, para algumas espécies, não houve convergência, provavelmente porque as estimativas do método dos percentis estavam bem próximas do ponto final de iteração, de modo que o decremento de 0,5 produziu um afastamento desse ponto, não permitindo a convergência. Nesses casos utilizou-se o método da falsa posição (BERCKETT e HURT, 1967; DIXON, 1974) tomando-se os mesmos valores anteriores como valores iniciais para iteração.

O critério de convergência adotado foi o de não haver alteração no valor de $\hat{c}$ (com 4 casas decimais de precisão) durante 3 passos sucessivos de iteração. O número máximo de iterações realizado foi de 60.

Os estimadores de máxima verossimilhança testados foram os de COHEN (1967) e o da Weibull - 2 parâmetros truncada à esquerda. Os estimadores de 
COHEN (1967) foram deduzidos (vide ANEXO 3) e adaptados para dados agrupados ficando:

$$
\begin{gathered}
\frac{1}{\hat{c}}-\frac{\sum_{i=1}^{n} f_{i} x_{i}^{\hat{c}} \ln \left(x_{i}\right)}{\sum_{i=1}^{n} f_{i} x_{i}^{\hat{t}}}+\frac{\sum_{i=1}^{n} f_{i} \ln \left(x_{i}\right)}{n}=0 \\
\hat{b}=\left(\frac{\sum_{i=1}^{n} f_{i} x_{i}^{\hat{c}}}{n}\right)^{1 / \hat{s}}
\end{gathered}
$$

onde: $x_{i}=C C_{i}-13 \mathrm{~cm}$, sendo $C C_{i}$ o centro da classe $i$;

$f_{i}$ é a freqüência observada na classe $i$;

$n=\sum_{i=1}^{n} f_{i}$ é o tamanho da amostra; e

In indica logaritmo neperiano

Os estimadores de máxima verossimilhança para Weibull - 2 parâmetros truncada à esquerda foram deduzidos a partir da f.d.p. apresentada por ZUTTER et alii (1982) (vide ANEXO 3) e adaptados para dados agrupados na forma de:

$$
\begin{gathered}
\frac{1}{\hat{c}}-\frac{\sum_{i=1}^{n} f_{i} x_{i}^{\hat{\hat{c}}} \ln x_{i}-n t^{\hat{c}} \ln t}{\sum_{i=1}^{n} f_{i} x_{i}^{\hat{\hat{c}}}-n t^{\hat{c}}}+\frac{\sum_{i=1}^{n} f_{i} \ln x_{i}}{n}=0 \\
\hat{b}=\left(\frac{\sum_{i=1}^{n} f_{i} x_{i}^{\hat{c}}-t^{\hat{c}}}{n}\right)^{1 / \hat{c}}
\end{gathered}
$$

onde: $t=13 \mathrm{~cm}$ é o ponto de truncagem; sendo os demais termos já conhecidos.

Como os métodos de máxima verossimilhança também necessitam de iteração para a resolução do estimador do parâmetro $c$ (equações (2.37) e (2.39)), utilizou-se o método iterativo de Newton-Raphson (BERCKETT e HURT, 1964; DIXON, 1974). Entretanto, a convergência se mostrou muito lenta. Para diminuir o número de iterações, o acréscimo (ou decréscimo) que se dava a cada passo foi multiplicado por um fator, de modo que o algoritmo utilizado passou a ser:

$$
Z_{i}=Z_{i-1}+F \frac{f(\hat{c})}{f^{\prime}(\hat{c})}
$$


onde: $Z i \dot{i}$ é valor obtido para $\hat{c}$ no passo $\dot{i}$;

$Z_{i-1}$ é o valor obtido para $\hat{c}$ no passo $(i-1)$;

$f(\hat{c})$ é a função de iteração (equações (2.37) e (2.39));

$f^{\prime}(\hat{c})=(d f(\hat{c}) / d \hat{c})$ é a primeira derivada da função de iteração; e

$F$ è o fator de multiplicação utilizado $(F=100$ na equação (2.39) e

$$
F=10 \text { na equação (2.37). }
$$

Com isso, o número de passos necessários para atingir a convergência foi sensivelmente reduzido. As estimativas obtidas pelo método dos percentis foram utilizadas como valores iniciais na iteração e o critério de convergência foi o mesmo que se utilizou para os estimadores de momentos.

O QUADRO 2.3. resume os métodos testados, apresentando um código que será utilizado para facilitar a discussão. Nota-se que, para a maioria dos métodos, o valor do parâmetro de localização foi fixado no diâmetro mínimo do levantamento $(a=13 \mathrm{~cm})$, e a variável ajustada passou a ser $x=D A P-13$, conforme a sugestão de JOHNSON e KOTZ (1970). Como a maioria das espécies possui distribuição na forma de "J invertido", o parâmetro a funcionou como um ponto de truncagem. 
QUADRO 2.3: Resumo dos métodos testados para o ajuste da distribuição Weibull

\begin{tabular}{|c|c|c|c|}
\hline MÉTODO & CóDIGo & ESTIMADORES & RESOLUÇÃO \\
\hline $\begin{array}{c}\text { Percentis } \\
\text { DUBEY (1967) }\end{array}$ & PTL & $\begin{array}{l}a=13 \mathrm{~cm} \\
\hat{b}=(2.25) \\
\hat{c}=(2.24)\end{array}$ & $\begin{array}{l}\text { Diretamente } \\
\text { Diretamente }\end{array}$ \\
\hline $\begin{array}{l}\text { Funções Lineares } \\
\text { MENON (1963) }\end{array}$ & FLN & $\begin{array}{l}a=13 \mathrm{~cm} \\
\hat{b}=(2.36) \\
\hat{c}=(2.35)\end{array}$ & $\begin{array}{l}\text { Diretamente } \\
\text { Diretamente }\end{array}$ \\
\hline $\begin{array}{c}\text { Momentos } \\
\text { BURK e BURKHART } \\
\text { (1984) }\end{array}$ & MGA & $\begin{array}{c}a=D A P_{\text {minimo }} \\
\hat{b}=(2.22) \\
\hat{c}=(2.21)\end{array}$ & $\begin{array}{l}\text { Diretamente } \\
\text { Iteração pelo } \\
\text { método da secante } \\
\text { ou falsa posição }\end{array}$ \\
\hline $\begin{array}{c}\text { Momentos } \\
\text { NEWBY (1980) }\end{array}$ & $\mathrm{MCV}$ & $\begin{array}{c}a=13 \mathrm{~cm} \\
\hat{b}=(2.23) \\
\hat{c}\end{array}$ & $\begin{array}{l}\text { Diretamente } \\
\text { Tabelado }\end{array}$ \\
\hline $\begin{array}{c}\text { Máxima } \\
\text { Verossimilhança } \\
\text { COHEN (1967) }\end{array}$ & MVN & $\begin{array}{l}a=13 \mathrm{~cm} \\
\hat{b}=(2.38) \\
\hat{c}=(2.37)\end{array}$ & $\begin{array}{c}\text { Diretamente } \\
\text { Iteração por } \\
\text { Newton - Raphson }\end{array}$ \\
\hline $\begin{array}{c}\text { Máxima } \\
\text { Verossimilhança }\end{array}$ & MVT & $\begin{array}{l}t=13 \mathrm{~cm} \\
\hat{b}=(2.40) \\
\hat{c}=(2.39)\end{array}$ & $\begin{array}{c}\text { Diretamente } \\
\text { Iteração por } \\
\text { Newton - Raphson }\end{array}$ \\
\hline
\end{tabular}




\subsection{Resultados e Discussão}

\subsubsection{Ajustamento em relação às distribuições originais.}

A qualidade do ajustamento produrido pelos métodos testados foi medida através do desvio médio, da soma dos desvios absolutos, do índice de ajustamento e do teste de Komolgorov - Smirnov (MASSEY, 1951), que foram computados para cada espécie estudada. Entendeu-se por desvio a diferença entre a freqüência esperada e a observada em cada classe de DAP para cada uma das espécies. $O$ índice de ajustamento (KNOEBEL et alii, 1986) foi calculado por:

$$
I A=100\left(1-\frac{\sum_{i=1}^{n}\left(y_{i}-\hat{y}_{i}\right)^{2}}{\sum_{i=1}^{n}\left(y_{i}-\bar{y}_{i}\right)^{2}}\right)
$$

onde: $y_{i}$ é a freqüência observada na classe $i$;

$\hat{y}_{i}$ é a freqüência esperada na classe $i ; \mathrm{e}$

$\bar{y}_{i}$ é a freqüência média nas $n$ classes.

O QUADRO 2.4. apresenta os valores máximos, mínimos e médios dos critérios de ajustamento encontrados para cada um dos métodos. Nota-se que pelo teste de Komolgorov - Smirnov todos os métodos apresentaram um bom ajuste em relação às distribuições observadas. À exceção do método das funçōes lineares (FLN), todos os demais nảo apresentaram diferenças estatisticamente signficativas para todas as espécies. Entretanto, os métodos produziram estimativas estatisticamente diferentes para os parâmetros, como pode ser visto pela análise de variância e teste de médias apresentados no QUADRO 2.5. . Confirmam-se as observações de SHIVER (1985) 
QUADRO 2.4: Valores médios (MED), mínimos (MIN) e máximos (MAX) dos critérios de ajustamento encontrados entre as 60 espécies estudadas

\begin{tabular}{cccccc}
\hline MÉTODO & & $\begin{array}{c}\text { Desvio } \\
\text { Médio }\end{array}$ & $\begin{array}{c}\text { Soma dos } \\
\text { Desvios } \\
\text { Absolutos }\end{array}$ & $\begin{array}{c}\text { f́ndice de } \\
\text { ajustamento }\end{array}$ & $\begin{array}{c}\text { Número de } \\
\text { espécies sem } \\
\text { ajustamento }\end{array}$ \\
\hline \multirow{3}{*}{ PTL } & MED & 0,0895 & 21,16 & 90,49 & \\
& MIN & 0,0000 & 4,68 & 29,85 & - \\
& MAX & 0,4300 & 128,61 & 99,85 & \\
FLN & MED & 0,0305 & 36,85 & 88,98 & \\
& MIN & 0,0000 & 2,00 & 42,62 & 2 \\
& MAX & 0,3389 & 251,34 & 99,92 & \\
MGA & MED & 0,1729 & 26,92 & 84,80 & \\
& MIN & 0,0021 & 3,80 & 22,15 & - \\
& MAX & 5,6420 & 222,59 & 99,93 & \\
MCV & MED & 0,0696 & 26,11 & 90,34 & \\
& MIN & 0,0000 & 4,62 & 38,79 & - \\
& MAX & 0,2828 & 126,89 & 99,72 & \\
\hline \multirow{2}{*}{ MVN } & MED & 0,0538 & 24,68 & 89,68 & \\
& MIN & 0,0000 & 5,76 & 46,35 & - \\
& MAX & 0,2467 & 130,51 & 99,54 & \\
\hline \multirow{2}{*}{ MVT } & MED & 0,0459 & 28,01 & 89,07 & \\
& MIN & 0,0000 & 5,18 & 47,14 & - \\
& MAX & 0,2282 & 208,83 & 99,51 & \\
\hline
\end{tabular}

OBSERVAÇÃO : As espécies sem ajustamento foram aquelas que apresentaram teste de Komolgorov - Smirnov significativo ao nível de $5 \%$ de probabilidade

e ZARNOCH e DELL (1985) de que a distribuição Weibull permite que diferentes combinações dos parâmetros produzam distribuições semelhantes.

Os demais critérios de ajustamento do QUADRO 2.4. também mostram que não há diferenças marcantes entre os métodos. Os métodos FLN, MGA e MVT apresentam amplitude maior para a soma dos desvios absolutos que os demais. Apesar das diferenças de ajustamento não serem marcantes, a qualidade do ajuste desses métodos variou mais de espécie para espécie que a dos demais métodos. 
A distribuição de todos os desvios, independentemente das espécies (FIGURA 2.4.), confirma a maior constância na qualidade do ajuste dos estimadores PTL, MCV e MVN. A dispersão dos desvios é claramente maior para FLN e MVT, e o método MGA, embora possua uma dispersão pequena, produziu num dos casos uma freqüência muito abaixo da esperada, embora isso não comprometa o desempenho desse método em termos globais.

Observa-se que os métodos PTL, MCV e MVN, que foram muito próximos em termos de distribuição dos desvios, não produziram diferenças estatisticamente significativas na estimativa do parâmetro da forma $c$ (QUADRO 2.5.).

QUADRO 2.5: Teste t (mínima diferença significativa) para comparação dos métodos de ajuste da Weibull através dos valores médios das estimativas dos parâmetros nas 60 espécies estudadas.

\begin{tabular}{|ccc|ccc|}
\hline \multicolumn{3}{|c|}{ PARÂMETRO $c$} & \multicolumn{3}{c|}{ PARÂMETRO b } \\
\hline Método & Médias & Comparação & Método & Médias & Comparação \\
\hline MVT & 2,0204 & A & MVT & 23,072 & B \\
FLN & 1,6033 & B & MVN & 15,460 & B C \\
MVN & 1,4121 & C & PTL & 15,136 & B C \\
PTL & 1,3423 & C & MCV & 14,684 & C \\
MCV & 1,3263 & C & FLN & 14,675 & C \\
MGA & 1,1481 & D & MGA & 12,826 & D \\
\hline
\end{tabular}

OBSERVACOES : (a) Médias com letras diferentes representam diferencas estatisticamente significativas ao nf́vel de $5 \%$ de probabilidade. (b) $\mathrm{Na}$ análise de variância obteve-se para o parâmetro $c$ teste $\mathrm{F}=40,43(\alpha=0,0001 ; C V=$ $25,16 \%)$ e para o parâmetro $b$ teste $\mathrm{F}=202,06(\alpha=0,0001 ; C V=12,26 \%)$.

Em termos de índice de ajustamento, os métodos de máxima verossimilhança (MVN e MVT) apresentaram uma constância maior na qualidade do ajustamento nas diferentes espécies. Contudo, esse índice parece ser pouco sensível pois o 


\subsubsection{Influência do tamanho da amostra}

O número de árvores amostradas para cada uma das 60 espécies estudadas variou bastante (de 30 a 1480 árvores), pois trata-se de uma floresta tropical pluvial com grande diversidade de espécies.

Embora não se tenha encontrado diferenças marcantes entre os métodos em termos globais, o ajuste produzido pelos métodos é bastante diferente no que tange às amostras de tamanhos diferentes.

Para se observar o efeito do tamanho da amostra sobre o ajuste da Weibull pelos diferentes métodos as espécies foram agrupadas conforme o número de árvores amostradas. Dentro de cada grupo os métodos de ajuste foram comparados através do teste de Kruskal - Wallis utilizando-se o valor absoluto dos desvios como variável de análise. O resultado dessas análises é apresentado no QUADRO 2.6.. Os métodos se mostraram estatisticamente diferentes para os grupos com mais de 100 árvores amostradas. Essa diferença, entretanto, se deve principalmente ao método FLN, pois a exclusão desse método produziu um teste de Kruskal - Wallis não significativo.

No mesmo quadro pode-se observar que, para os grupos de espécies com mais de 60 árvores amostradas, os valores da soma das ordens para o método PTL é sempre menor do que para os demais. Uma vez que a variável analisada é o valor absoluto dos desvios, um valor menor representa uma maior proximidade entre as freqüências esperada e observada e, portanto, um melhor ajuste.

Para verificar se o ajuste do método PTL nos grupos de espécies com mais árvores amostradas era significativamente melhor que o ajuste dos demais foi realizado o teste das ordens assinaladas. Esse teste permite uma comparação mais 
QUADRO 2.6: Comparação dos métodos de ajuste da Weibull para grupos de espécies com diferentes números de árvores amostradas. Analisou-se o desvio absoluto de cada classe de diâmetro através do teste da Soma das Ordens ( Wilcoxon ) e qui-quadrado aproximado do teste de KRUSKALL - WALLIS.

\begin{tabular}{|c|c|c|c|c|c|c|c|c|}
\hline \multirow{2}{*}{$\begin{array}{l}\text { Grupos de } \\
\text { Tamanho de } \\
\text { Amostra }\end{array}$} & \multirow{2}{*}{$\begin{array}{l}\text { Número de } \\
\text { Classes } \\
\text { Diamétrica }\end{array}$} & \multicolumn{6}{|c|}{ MÉTODOS } & \multirow{2}{*}{$\begin{array}{l}\text { Qui-Quadrado } \\
(\alpha)\end{array}$} \\
\hline & & PTL & FLN & MCV & MGA & MVN & MVT & \\
\hline 30 a 40 & 46 & 6319 & 6877 & 5923 & 6023 & 6528 & 6516 & $\begin{array}{c}2,1851 \\
(0,8230)\end{array}$ \\
\hline 40 a 50 & 49 & 7123 & 6798 & 7167 & 7365 & 7457 & 7455 & $\begin{array}{c}0,1903 \\
(0,9695)\end{array}$ \\
\hline 50 a 60 & 30 & 2690 & 3108 & 2393 & 2622 & 2701 & 2776 & $\begin{array}{c}3,3312 \\
(0,6491)\end{array}$ \\
\hline 60 a 70 & 24 & 1512 & 1964 & 1618 & 1829 & 1694 & 1823 & $\begin{array}{c}3,2081 \\
(0,6679)\end{array}$ \\
\hline 70 a 80 & 30 & 2466 & 3319 & 2732 & 2509 & 2680 & 2584 & $\begin{array}{c}5,9905 \\
(0,3071)\end{array}$ \\
\hline 80 a 90 & 30 & 2299 & 3127 & 2867 & 2537 & 2822 & 2638 & $\begin{array}{c}5,0947 \\
(0,4044)\end{array}$ \\
\hline 90 а 100 & 15 & 585 & 848 & 704 & 632 & 641 & 685 & $\begin{array}{c}4,0672 \\
(0,5398)\end{array}$ \\
\hline 100 a 200 & 70 & 12920 & 17460 & 13952 & 14422 & 14336 & 15320 & $\begin{array}{c}11,569 \\
(0,0412)\end{array}$ \\
\hline$>200$ & 181 & 86726 & 116405 & 98499 & 93400 & 96865 & 98396 & $\begin{array}{c}27,397 \\
(0,0001)\end{array}$ \\
\hline
\end{tabular}

OBSPRVACÃO : Os valores entre parênteses na coluna do Qui-Quadrado são os níveis de significância para o teste de KRUSKALL - WALLIS.

rigorosa, uma vez que ele compara duas amostras independentes pareadas (CAMPOS, 1979).

Nesse caso, o pareamento foi realizado para cada classe dentro de cada espécie, sendo a variável de análise o valor absoluto dos desvios. O QUADRO 2.7. apresenta os valores de $\mathrm{T}$ do teste das ordens assinaladas. Como o teste foi realizado para comparar a diferença dos métodos testados em relação ao método PTL, valores negativos de T indicam um menor desvio absoluto para o método PTL. Observa-se, de fato, que o método PTL é superior aos demais quando se trata de espécies com 
grande número de árvores amostradas. Confirmam-se as conclusões de SHIVER (1985) e ZARNOCH e DELL (1985) de que os métodos baseados em percentis são superiores aos demais quando se trata de representar a distribuição observada.

QUADRO 2.7. Valores do $\mathrm{T}$ do teste das Ordens Assinaladas ( Wilcoxon ) na comparação do método dos percentis (PTL) com os demais, em termos de desvios absolutos nas classes diamétricas.

\begin{tabular}{|c|c|c|c|c|c|c|}
\hline \multirow{2}{*}{$\begin{array}{l}\text { Grupos de } \\
\text { Tamanho de } \\
\text { Amostra }\end{array}$} & \multirow{2}{*}{$\begin{array}{l}\text { Número de } \\
\text { Classes } \\
\text { Diamétrica }\end{array}$} & \multicolumn{5}{|c|}{ MÉTODOS } \\
\hline & & FLN & $\mathrm{MCV}$ & MGA & MVN & MVT \\
\hline 30 a 40 & 46 & $-1,28$ & 0,91 & 0,92 & $-1,69 *$ & $-0,51$ \\
\hline 40 a 50 & 49 & 0,80 & 1,02 & $-0,72$ & $-0,41$ & 0,27 \\
\hline 50 a 60 & 30 & $-2,19 *$ & 0,85 & $-0,24$ & $-0,36$ & $-0,55$ \\
\hline 60 a 70 & 24 & $-2,29 *$ & $-0,91$ & $-1,06$ & $-2,43^{* *}$ & $-2,37^{* *}$ \\
\hline 70 a 80 & 30 & $-2,25 *$ & $-0,59$ & 0,73 & 0,07 & 0,48 \\
\hline 80 a 90 & 30 & $-2,42^{* *}$ & $-1,35$ & $-0,55$ & - 1,41 & $-2,36^{* *}$ \\
\hline 90 a 100 & 15 & $-2,44^{* *}$ & $-1,87^{*}$ & $-0,97$ & $-0,74$ & $-2,44 * *$ \\
\hline 100 a 200 & 70 & $-4,74 * *$ & $-1,76^{* *}$ & $-1,34$ & $-2,66 * *$ & $-3,77 * *$ \\
\hline$>200$ & 181 & $-6,67^{* *}$ & $-3,05^{* *}$ & $-2,64^{* *}$ & $-3,05^{* *}$ & - $3,94^{* *}$ \\
\hline
\end{tabular}

OBSERVAÇAO: * Valores significativos para $\alpha=0,05$. ** Valores significativos para $\alpha=0,01$.

2.4.3. Intervalo de confiança das estimativas dos parâmetros

A comparação da precisão na estimativa dos parâmetros, medida em termos de intervalo de confiança (a nível de $95 \%$ de probabilidade) das estimativas dos parâmetros, foi realizada apenas para os três métodos que se apresentaram mais semelhantes em termos de comparação global: PTL, MCV e MVN. 
A variância das estimativas obtidas pelo método dos percentis (PTL) foi calculada segundo DUBEY(1967) sendo as fórmulas:

$$
\begin{aligned}
& \operatorname{Var}(\hat{c})=\frac{\hat{c}^{2}}{n k^{2}}\left[\frac{q_{1}}{k_{1}^{2}}+\frac{q_{2}}{k_{2}^{2}}-2 \frac{q_{1}}{k_{1} k_{2}}\right] \\
& \operatorname{Var}(\hat{b})=\frac{\hat{b}^{2}}{n \hat{c}^{2}}\left(\frac{p_{1}}{1-p_{1}}\right) \ln ^{2}\left(1-p_{1}\right)
\end{aligned}
$$

onde: $q_{i}=p_{i} /\left(1-p_{i}\right), \quad(i=1,2)$;

$k_{i}=-\ln \left(1-p_{i}\right), \quad(i=1,2)$;

$n$ é o tamanho da amostra; e

$p_{1}=0,24$ e $p_{2}=0,93$ são os mesmos percentis

utilizados no cálculo de $\hat{c}$ e $\hat{b}$.

A variância das estimativas do método dos momentos (MCV) (segundo NEWBY, 1980) foi obtida por:

$$
\begin{gathered}
\operatorname{Var}(\hat{c})=\frac{h_{11}}{n} \\
\operatorname{Var}(\hat{b})=\frac{\hat{b}^{2} h_{22}}{n}
\end{gathered}
$$

onde: $n$ é o tamanho da amostra; e

$h_{11}$ e $h_{22}$ são coeficientes da matriz assintótica de variância - covariância da distribuição Weibull estandardizada (vide ANEXO 2).

No método da máxima verossimilhança (MVN) a variância das estimativas dos parâmetros foi obtida segundo DUBEY (1967), sendo:

$$
\begin{gathered}
\operatorname{Var}(\hat{c})=\frac{\hat{c}^{2}}{n \Psi(1)(1)} \\
\operatorname{Var}(\hat{b})=\frac{\hat{b}^{2}}{\hat{c}^{2} \eta}\left(1+\frac{[\Psi(2)]^{2}}{\Psi(1)(1)}\right)
\end{gathered}
$$


onde: $n$ é o tamanho da amostra;

$$
\begin{aligned}
& \Psi(2)=0,4227843351 \text { é a função digama; e } \\
& \Psi^{(1)}(1)=1,644934066848 \text { é a função trigama. }
\end{aligned}
$$

O intervalo de confiança foi calculado através de

$$
\begin{aligned}
& I C_{\hat{\mathrm{c}}}=t \sqrt{\frac{\operatorname{Var}(\hat{c})}{n}} \\
& I C_{\hat{b}}=t \sqrt{\frac{\operatorname{Var}(\hat{\hat{b}})}{n}}
\end{aligned}
$$

onde $t$ é o valor da variável "Studentizada" para $n-1$ graus de liberdade.

Observou-se que os intervalos de confiança das estimativas do parâmetro $c$ nos métodos PTL e MCV foram significativamente maiores que os obtidos pelo método MVN. No caso do parâmetro $b$ a diferença só é significativa entre os métodos PTL e MCV (QUADRO 2.8.). Conclui-se que o método da máxima verossimilhança (MVN), embora menos exato na representação das distribuições observadas, é mais preciso na estimativa dos parâmetros. Novamente as conclusões de SHIVER (1984) e ZARNOCH e DELL (1985) foram confirmadas.

QUADRO 2.8: Teste t pareado comparando o intervalo de confiança (em porcentagem) dos parâmetros da Weibull obtidos pelos métodos dos percentis (PTL), momentos (MCV) e máxima verossimilhança (MVN) ( $n=60$ espécies).

\begin{tabular}{|c|cc|cc|}
\hline & \multicolumn{2}{|c|}{ MCV } & \multicolumn{3}{|c|}{ MVN } \\
\hline PTL & 0,385 & $-0,706$ & 10,445 & 6,937 \\
& $(0,7014)$ & $(0,4832)$ & $(0,0001)$ & $(0,0001)$ \\
\hline MVN & 3,129 & 1,391 & & \\
& $(0,0027)$ & $(0,1696)$ & & \\
\hline
\end{tabular}

OBSWRVAÇAO : Os valores entre parênteses são os níveis de significância do teste $t$. 
2.4.4. Comparação dos métodos de ajuste que necessitam de iteração

Três dos métodos testados necessitam de processos iterativos para obter as estimativas dos parâmetros: método da máxima verossimilhança para Weibull - 2 parâmetros com amostras completas (MVN) e com amostras truncadas à esquerda (MVT), e o método dos momentos proposto por BURK e BURKHART (1984).

No ANEXO 4 apresenta-se o quadro contendo o número de iterações necessárias para atingir a convergência em cada uma das espécies estudadas. Os métodos de máxima verossimilhança, nos quais o método iterativo foi o de Newton - Rapshon, foram de convergência mais lenta que o método dos momentos, onde se utilizaram os métodos da secante e da falsa posição.

Apesar de apresentar convergência mais rápida, o método da secante não foi capaz de convergir no caso de algumas espécies. Isso provavelmente foi devido ao valor inicial da iteração em algumas espécies estar bem próximo do valor de convergência, de modo que o decremento de 0,5 no valor inicial afastou a iteração do ponto de convergência. Dentre os métodos de máxima verossimilhança, o método baseado na Weibull - 2 parâmetros em amostras completas (MVN) teve convergência mais rápida que o método baseado em amostras truncadas à esquerda, provavelmente porque o fator de multiplicação era maior.

\subsubsection{Escolha das melhores estimativas}

Para interpretação do significado biológico dos parâmetros da distribuição Weibull, decidiu-se utilizar as estimativas obtidas pelo método dos percentis. 
Embora as estimativas de máxima verossimilhança sejam mais precisas, ZARNOCH e DELL (1985) demonstraram que quando o parâmetro da forma é menor que dois $(c \leq 2)$ os estimadores de percentis são tão bons, ou mesmo superiores, aos estimadores de máxima verossimilhança.

Outra grande vantagem dos estimadores de percentis é a simplicidade e rapidez na sua computação, que não necessita de processos iterativos, de fórmulas complexas ou de tabelas. Quando se utilizam dados agrupados, entretanto, deve-se fazer cuidadosamente a escolha do número e amplitude das classes, pois estas variáveis influenciam de modo marcante o valor calculado para os percentis e, conseqüentemente, as estimativas dos parâmetros da distribuição Weibull.

Os valores das estimativas dos parâmetros pelo método dos percentis para as espécies estudadas, e os seus respectivos intervalos de confiança, estão no ANEXO 5. Estes valores foram utilizados para os estudos sobre o significado biológico dos parâmetros da distribuição. 


\section{INTERPRETAÇÃO BIOLÓGICA DOS PARÂMETROS DA DISTRIBUIÇÃO WEIBULL}

"Contra o positivismo, que pára perante os fenômenos e diz: 'Há apenas fatos', eu digo: 'Ao contrário, fatos é o que não há; hâ apenas interpretações?"

Nietzsche 


\section{INTERPRETAÇÃO BIOLÓGICA DOS PARÂMETROS DA DISTRIBUIÇÃO WEIBULL}

Nesta seção procurou-se relacionar a distribuição de diâmetros, representada pela distribuição Weibull, com as características fitossociológicas e com algumas características reprodutivas e vegetativas de cada espécie.

As características reprodutivas e vegetativas foram utilizadas para agrupar as espécies em quatro fases da sucessão secundária (pioneira, secundária inicial, secundária tardia e clímax), tentando seguir a proposta de BUDOWSKI $(1963,1965)$.

$\mathrm{Na}$ tentativa de estabelecer relações entre a distribuição de diâmetros e as características fitossociológicas e "sucessionais" de cada espécie, a distribuição Weibull foi deduzida como uma distribuição representativa da sobrevivência das árvores em função de seu diâmetro. Procurou-se interpretar biologicamente os parâmetros da distribuição para compreender a sua relação com as características das espécies estudadas. 
A sobrevivência normalmente é observada em relação à idade dos indivíduos. Embora exista uma relação geral entre o diâmetro e a idade das árvores, essa relação deve ser demonstrada antes de ser assumida (WHITE, 1980). Como não foi possível demostrar a existência dessa relação, estudou-se a sobrevivência das árvores como uma função do diâmetro (diâmetro à altura do peito - DAP).

\subsection{Dedução da Distribuição Weibull}

Apesar de ter sido apresentada inicialmente como uma distribuição empírica (WEIBULL, 1951), a distribuição Weibull pode ser deduzida a partir de considerações sobre a sobrevivência dos indivíduos de uma população, conforme os conceitos apresentados por ELANDT-JOHNSON e JOHNSON (1980).

Dada uma população com ${ }^{\propto}$ Curva de Mortalidade» em função do tamanho dos indivíduos $(\mathrm{x}$ ) na forma:

$$
F(x)=\operatorname{Pr}[X \leq x]
$$

onde: $\operatorname{Pr}[X \leq x]$ é a probabilidade de um indivíduo morrer até atingir o tamanho $x$. Pode-se considerar a "Curva de Sobrevivência” dessa população como sendo:

$$
S(x)=1-F(x)=\operatorname{Pr}[X>x]
$$

onde: $\operatorname{Pr}[X>x]$ é a probabilidade de um indivíduo sobreviver até atingir

o tamanho $x$; 
assumindo-se que para $x=0$, têm-se $F(x)=0$ e $S(x)=0$, ou seja não há mortes nem sobrevivência para indivíduos de tamanho $x=0$.

Para obter a "Taxa Instantânea Absoluta de Mortalidade" $f(x)$, basta derivar a função da curva de mortalidade, encontrando-se:

$$
f(x)=\frac{d F(x)}{d x}=-\frac{d S(x)}{d x}
$$

A “Taxa Instantânea Relativa de Mortalidade» $M(x)$, que será chamada “Função de Mortalidade”, é obtida pela razão entre a taxa instantânea absoluta de mortalidade e a sobrevivência:

$$
M(x)=\frac{f(x)}{S(x)}=\frac{-[d S(x) / d x]}{S(x)}=\frac{-d \ln [S(x)]}{d x}
$$

Em termos biológicos, o que se espera de uma função de mortalidade é que ela seja positiva podendo ser crescente, constante ou decrescente, dependendo da população em estudo. A função mais simples que satisfaz essas condições é:

$$
M(x)=k x^{m}
$$

onde: $k>0$ e $m$ são constantes que dependem da população estudada.

Assumindo a função (3.5) como a função de mortalidade a curva de sobrevivência resultante é:

$$
\begin{aligned}
& S(x)=\exp \left[\int M(x) d x\right] \\
& S(x)=\exp \left[\int k x^{m} d x\right] \\
& S(x)=\exp \left[-\frac{k x^{m+1}}{m+1}\right]
\end{aligned}
$$


Para fins de simplificação, pode-se assumir que $\gamma=m+1$ e $\theta=k / m+1$ e, portanto, a curva de sobrevivência fica:

$$
S(x)=\exp \left[-\theta x^{\gamma}\right]
$$

A curva de mortalidade obtida é:

$$
F(x)=1-S(x)=1-\exp \left[-\theta x^{\gamma}\right]
$$

Comparando-se a equação (3.7) com a equação (2.4) nota-se que ambas representam a função de densidade acumulada da distribuição Weibull - 2 parâmetros, sendo $c=\gamma$ e $b=1 / \theta^{(1 / \gamma)}$, enquanto que a função de densidade probabilística é:

$$
f(x)=\frac{d F(x)}{d x}=\theta \gamma x^{\gamma-1} \exp \left[-\theta x^{\gamma}\right]
$$

Portanto, ao assumir a taxa instantânea relativa de mortalidade, em função do tamanho (função de mortalidade), como sendo do tipo $M(x)=k x^{m}$, a distribuição do tamanho dos indivíduos dessa população seguirá a distribuição Weibull - 2 parâmetros. Para obter a Weibull - 3 parâmetros basta assumir que $x=y-t$ representa o tamanho dos indivíduos a partir de um tamanho mínimo $t$.

O significado dos parâmetros da distribuição Weibull pode ser entendido analisando o seu efeito sobre a função de mortalidade assumida. Essa pode ser apresentada na forma:

$$
M(x)=\theta \gamma x^{\gamma-1}
$$

ou então, na forma mais utilizada nos estudos de distribuição de diâmetros como nas equaçōes (2.1) a (2.4):

$$
M(x)=\left(c / b^{c}\right) x^{c-1}
$$


PINDER et alii (1978) relacionaram os três tipos básicos de curvas de sobrevivência com o valor do pârametro $c$ da Weibull. Quando a taxa de mortalidade específica da idade (no nosso caso do tamanho) é crescente, a curva de sobrevivência foi chamada de tipo I, o que é obtida na equação (3.10) para $c>1$. A curva tipo II é obtida nos casos de taxa de mortalidade constante, isto é, para $c=1$, e a curva de sobrevivência tipo III resulta de uma taxa de mortalidade decrescente, valores de $c$ menores que 1 (FIGURA 3.1.).

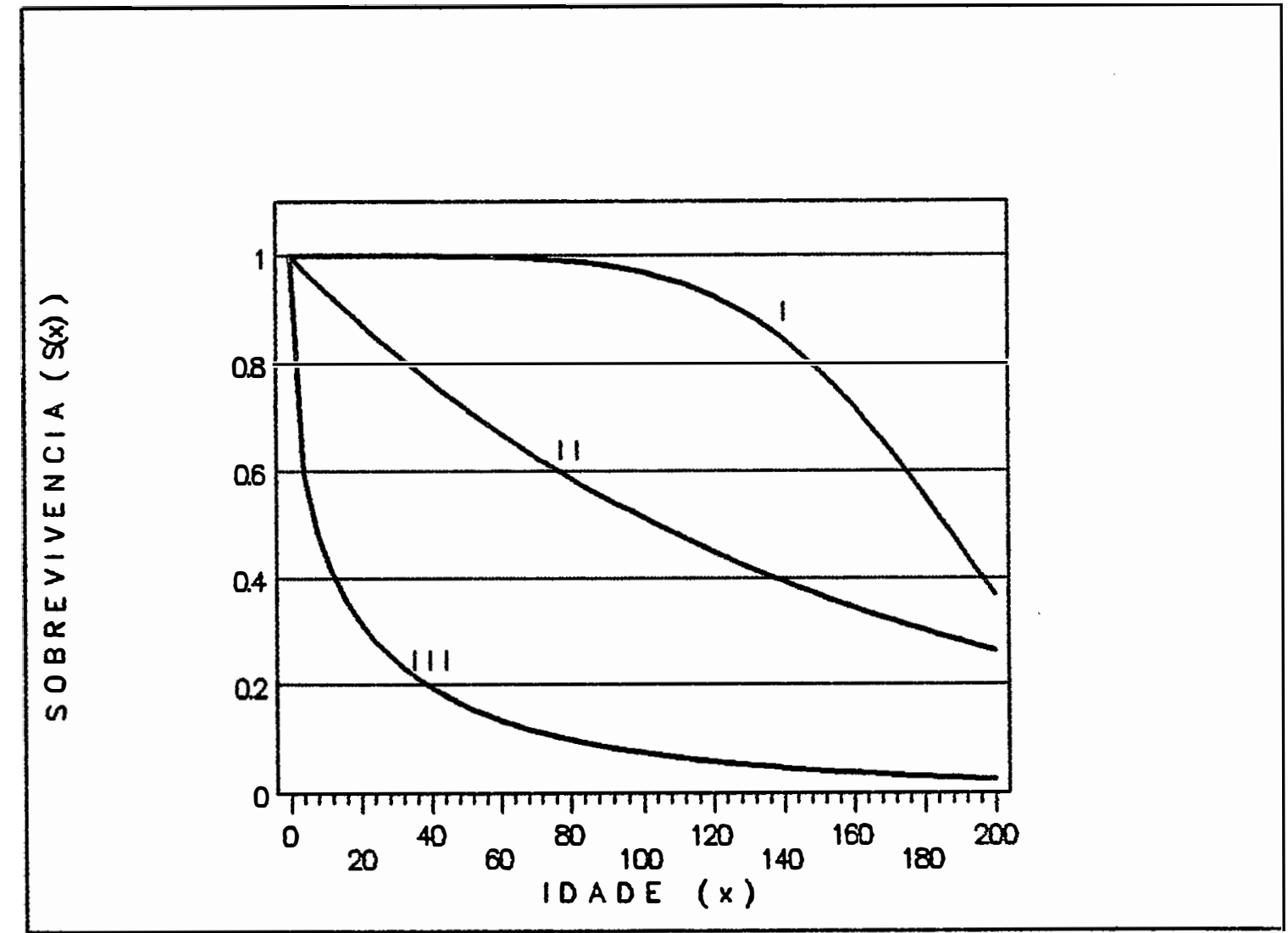

FIGURA 3.1.: Tipos básicos de curva de sobrevivência segundo PINDER et alii (1978). Curva tipo I representa taxa de mortalidade especifica da idade crescente. Na curva tipo II a taxa de mortalidade é constante e na tipo III é decrescente. 
Portanto, o parâmetro $c$ indica o padrão da curva de sobrevivência, sendo uma medida quantitativa de um fenômeno contínuo, onde os tipos I, II e III representam apenas uma simplificação.

A influência do parâmetro $b$ pode ser melhor visualizada através da equação (2.6), que constitue a propriedade da distribuição Weibull, onde a média é dada por:

$$
\mu=b \Gamma(1+1 / c)
$$

onde: $\Gamma$ é a função gama.

Observa-se que duas populações com o mesmo valor de $c$, e portanto com as mesmas características em termos de tipo de curva de sobrevivência, podem apresentar tamanhos médios diferentes em função do valor do parâmetro $b$. Conseqüentemente, esse parâmetro está diretamente ligado ao tamanho médio que os indivíduos da população tendem a assumir. No caso particular de $c=10$ parâmetro $b$ é a própria média da população, e a distribuição Weibull passa a ser idêntica à distribuição exponencial. 


\subsection{Caracterização das Espécies Arbóreas Tropicais}

As florestas tropicais são caracterizadas pela presença de um grande número de espécies, formando um sistema muito complexo com uma enorme quantidade de inter-relações. Ao se procurar entender tal sistema surgem algumas questões como: qual a importância de cada uma das espécies para a dinâmica e estabilidade do sistema? cada espécie possui características totalmente particulares ou exitem grupos de espécies que se comportam de forma semelhante, desempenhando praticamente o mesmo papel dentro do sistema?

Os primeiros estudos da floresta tropical foram taxonômicos e procuravam conhecer individualmente cada espécie, classificando-as dentro de um sistema taxonômico. Posteriormente, aliou-se aos estudos taxonômicos uma abordagem fitossociológica, onde se buscava compreender a relação entre as espécies individuais e a floresta como um todo. Alguns métodos fitossociológicos desenvolvidos foram a identificação de estratos verticais na floresta, o Indice de Valor de Importância, que define a importância de cada espécie em função da sua freqüência, densidade e dominância, e os f́ndices de dispersão que buscam reconhecer padrões de distribuição dos indivíduos de uma espécie no espaço horizontal. Exemplos recentes desses estudos são: GIBSS e LEITÃO (1978), GIBBS et alii (1980), OLIVEIRA e ROTTA (1982), SILVA e LOPES (1982) e BARROS (1986).

Sendo mais florística que ecológica, a abordagem fitossociológica tradicional tem sido pouco esclarecedora quanto ao papel de cada espécie na dinâmica da floresta e quanto ao comportamento das espécies individuais. 
Durante o desenvolvimento da Silvicultura nos trópicos alguns conceitos práticos a respeito do comportamento das espécies arbóreas foram utilizados. Inicialmente se reconheciam dois grupos de espécies: as "tolerantes" e as “intolerantes” à sombra (WHITMORE, 1975), conforme os conceitos da Silvicultura tradicional praticada na Europa. Posteriormente, reconheceu-se um terceiro grupo de espécies chamadas "oportunistas de clareira" (FAO, s.i.). E, finalmente, reconheceu-se que existe praticamente uma infinidade de respostas possíveis entre as espécies tropicais em relação ao grau de luminosidade que se pode produzir no piso florestal através dos tratamentos silviculturais (WHITMORE, 1978 e 1982).

A variedade de respostas quanto à luminosidade, que se observa entre as espécies tropicais, é o resultado natural do processo de regeneração das florestas tropicais. O fenômeno de abertura de clareiras na floresta (aberturas no dossel) e a sua posterior reocupação (sucessão secundária) é reconhecido hoje como o fenômeno primordial para a regeneração das espécies arbóreas tropicais (SILVERTOWN, 1987; WHITMORE, 1978 e 1982; HARTSHORN, 1980).

BUDOWSKI (1963 e 1965) foi quem, inicialmente, caracterizou as espécies arbóreas tropicais em função do estágio que elas ocupavam na sucessão secundária. Ele reconheceu quatro fases na sucessão: pioneira, secundária inicial, secundária tardia e clímax. As fases foram estabelecidas a partir de parâmetros como: composição florística, número de estratos, velocidade de crescimento das espécies presentes, longevidade das espécies dominantes, presença de epíftas, cipós, arbustos e gramíneas, regeneração das espécies dominantes, viabilidade das sementes, tamanho das sementes e frutos, dispersores de sementes, tolerância à sombra. Dessa forma é 
possível inferir o estágio da sucessão secundária a que uma dada espécie pertence a partir das suas características reprodutivas e vegetativas.

NINOMIYA e OGINO (1984) apresentaram o "diagrama M-w” como uma forma de identificar o estágio sucessional das florestas e de espécies arbóreas individuais. O diagrama $\mathrm{M}-\mathrm{w}$ é um gráfico com ambos os eixos em escala logarítmica, onde o indice M (razão do produto da freqüência das árvores com o seu tamanho, pela sua freqüência) é colocado contra o tamanho das árvores (w). No diagrama, o número de estratos de altura é facilmente identificado, tornando-se possível inferências quanto à continuidade da regeneração natural das espécies.

KNIGHT (1975) e PIRES (1976), estudando a distribuição diamétrica de espécies arbóreas da floresta tropical, chegaram a reconhecer padrões básicos de distribuição. O primeiro autor reconheceu 5 padrões, sendo que os dois mais comuns são o da forma de "J invertido", característico de espécies com regeneração contínua, e um padrão descontínuo, característico de espécies com regeneração intermitente. Esses dois padrões também foram observados por PIRES (1976), que atribuiu o primeiro a espécies tolerantes e o segundo a espécies intolerantes. 


\subsection{Sucessão Secundária e Padrões de Distribuição de Diâmetros}

Com o auxilio de mateiros do Centro de Pesquisa do Trópico Úmido (CPATU) da EMBRAPA, em Belém, foi possível obter informações sobre algumas características de 18, dentre as 60 espécies estudadas. Os QUADROS 3.1.a e 3.1.b apresentam as espécies com as informações obtidas. As informações sobre densidade da madeira foram obtidas nos trabalhos de BRITO (1981) e PIO-CORRÊA (1926).

\subsubsection{Estágios da sucessão secundária}

Com as informações obtidas procurou-se classificar as espécies em quatro estágios da sucessão secundária, seguindo as características apresentadas por BUDOWSKI (1963 e 1965) (QUADRO 3.2.). A importância dada a cada característica é bastante subjetiva, de modo que a classificação serve antes para definir a posição relativa das espécies em termos de ińcio, meio e final da sucessão, que para definir claramente as espécies pertencentes às quatro fases da sucessão. Por outro lado, o fato da sucessão ser um fenômeno contínuo determina que a própria definição de quatro fases feita por BUDOWSKI (1963) já é em si arbitrária.

Nota-se no QUADRO 3.2. uma tendência, dos estágios iniciais para os estágios finais da sucessão, de diminuição do valor do parâmetro c, estabilizando ao redor de 1 , e de aumento do valor do parâmetro $b$. Em termos de distribuição de diâmetro, essa tendência significa que as espécies com distribuição na forma de ${ }^{a} \mathrm{~J}$ invertido" vão sendo substituídas por espécies com distribuição de curvatura mais suave, tendendo quase a uma reta (FIGURA 3.2.). Em termos de curva de sobrevivência, 
QUADRO 3.1.a: Características reprodutivas de algumas das 60 espécies estudadas.

\begin{tabular}{|c|c|c|c|c|c|}
\hline \multirow{3}{*}{\begin{tabular}{|l} 
ESPÉCIE \\
Amapá
\end{tabular}} & \multirow{3}{*}{\begin{tabular}{|c|} 
CÓDIGO \\
5 \\
\end{tabular}} & \multicolumn{4}{|c|}{ CARACTERISTICAS REPRODUTIVAS } \\
\hline & & \multirow[t]{2}{*}{$\begin{array}{l}\text { Tipo de } \\
\text { Fruto }\end{array}$} & \multirow{2}{*}{$\begin{array}{l}\text { Dispersor } \\
\text { pássaros }\end{array}$} & \multicolumn{2}{|c|}{$\begin{array}{c}\text { Semente } \\
\text { dormência longevidade }\end{array}$} \\
\hline & & & & กล̃o & curta \\
\hline Araticum & 9 & baga & $\begin{array}{l}\text { macaco, } \\
\text { rato, cutia }\end{array}$ & & curta \\
\hline Arueira brava & 15 & drupa & vento & não & curta \\
\hline Canela de viado & 25 & & $\begin{array}{l}\text { gravidade, } \\
\text { rato, cutia }\end{array}$ & & curta \\
\hline Cravo & 32 & & gravidade & & curta \\
\hline Cumaru & 34 & vagem & gravidade, & não & curta \\
\hline Envira preta & 53 & & passaros & & curta \\
\hline Goiabinha & 69 & & $\begin{array}{l}\text { gravidade, cutia, paca } \\
\text { macaco, viado }\end{array}$ & & longa \\
\hline Ingá & 73 & $\begin{array}{c}\text { vagem } \\
\text { indeiscente }\end{array}$ & pássaros & não & curta \\
\hline Ingá xixiba & 78 & vagem & pássaros & não & curta \\
\hline Jatobá fava & 86 & $\begin{array}{l}\text { ragem seca } \\
\text { indeiscente }\end{array}$ & $\begin{array}{l}\text { gravidade, paca, } \\
\text { viado, cutia, porco }\end{array}$ & sim & longa \\
\hline Jacarandá & 87 & vagem & vento & $\operatorname{sim}$ & longa \\
\hline Maçaranduba & 102 & baga & $\begin{array}{l}\text { pássaros, porco } \\
\text { viado, paca, cutia }\end{array}$ & $\operatorname{sim}$ & longa \\
\hline Pau d'arco amarelo & 114 & cápsula & vento & não & curta \\
\hline Pau d'arco roxo & 117 & cápsula & vento & não & curta \\
\hline Morotot6 & 122 & drupa & pássaros & sim & longa \\
\hline Embaúba & 151 & noz & pássaros & sim & longa \\
\hline
\end{tabular}

essa tendência se traduz em curvas progressivamente menos inclinadas que atingem diâmetros maiores (FIGURA 3.3.). 
QUADRO 3.1.b: Características vegetativas de algumas das 60 espécies estudadas.

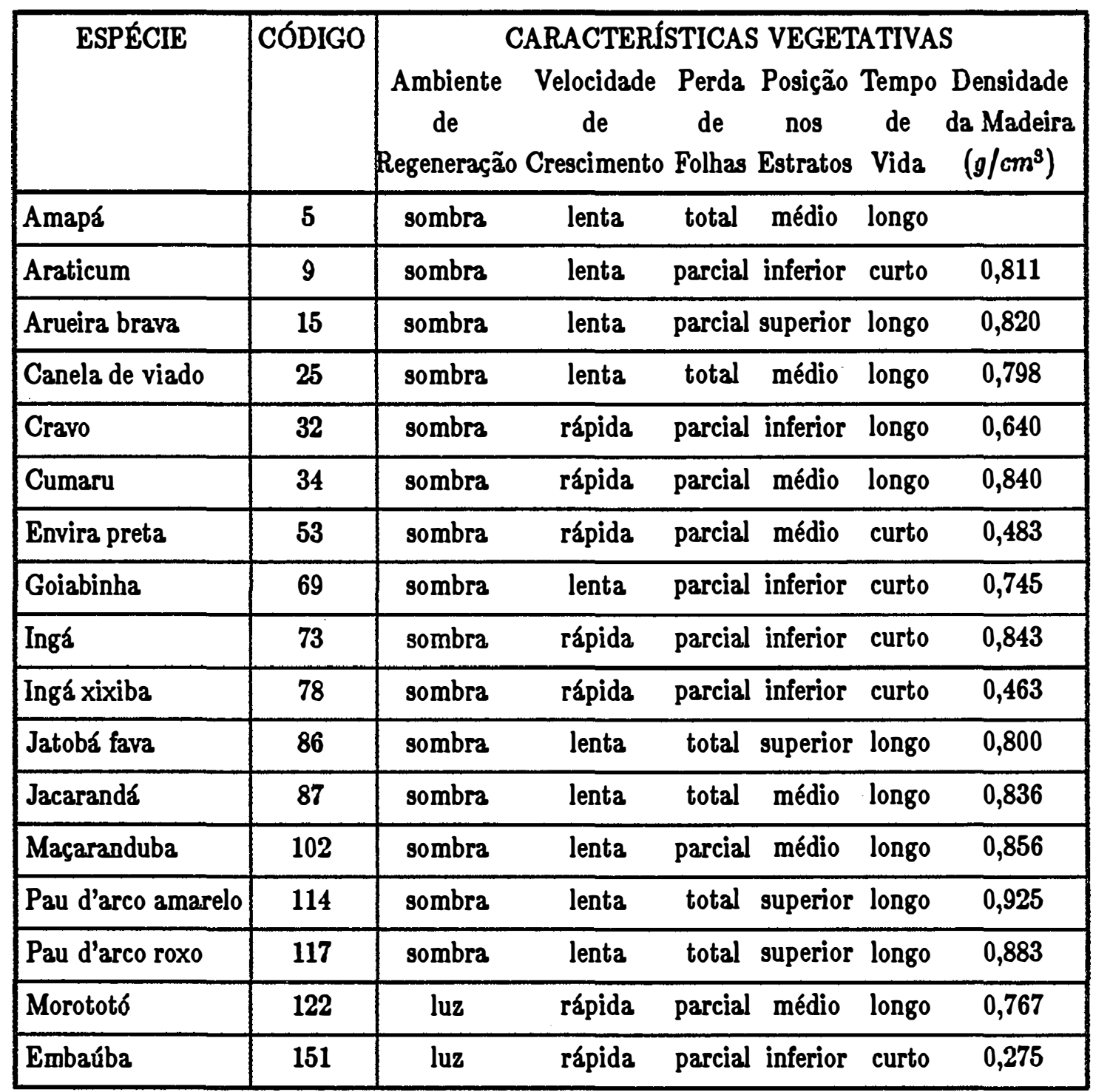

Do ponto de vista biológico, a diminuição no valor do parâmetro $c$ no decorrer da sucessão significa que espécies com taxas de mortalidade (específicas do tamanho) crescentes (pioneiras) são substituídas por espécies com taxas menos crescentes (secundárias), tendendo para espécies com taxas de mortalidade constantes 
QUADRO 3.2.: Classificação das espécies nos quatro estágios da sucessão propostos por BUDOWSKI (1963).

\begin{tabular}{|c|c|c|c|c|}
\hline \multirow[t]{2}{*}{ ESTAGIO } & \multirow[t]{2}{*}{ ESPÉCIES } & \multirow{2}{*}{$\begin{array}{c}\text { AMOSTRA } \\
\text { (no de árvores) }\end{array}$} & \multicolumn{2}{|c|}{ PARÂMETROS } \\
\hline & & & & \\
\hline \multirow[t]{2}{*}{ Pioneira } & Morototó & 315 & 1,3522 & 5,9250 \\
\hline & Embaúba & 43 & 1,9975 & 11,0295 \\
\hline \multirow[t]{7}{*}{ Secundária Inicial } & Canela de viado & 34 & 2,1172 & 5,9527 \\
\hline & Ingá xixiba & 39 & 1,6448 & 23,9392 \\
\hline & Ingá & 183 & 1,3308 & 8,4651 \\
\hline & Amapá & 45 & 1,3827 & 11,3295 \\
\hline & Ariticum & 257 & 1,2982 & 6,0358 \\
\hline & Goiabinha & 75 & 1,2119 & 7,4736 \\
\hline & Envira Preta & 47 & 1,2081 & 13,1580 \\
\hline \multirow[t]{5}{*}{ Secundária Tardia } & Arueira brava & 36 & 1,1999 & 9,9318 \\
\hline & Cravo & 133 & 1,2775 & 10,7549 \\
\hline & Jacarandá & 90 & 1,3530 & 10,5320 \\
\hline & Pau d'arco roxo & 70 & 1,2102 & 36,0329 \\
\hline & Pau d'arco amarelo & 75 & 0,9651 & 19,3291 \\
\hline \multirow[t]{4}{*}{ Clímax } & Cumaru & 63 & 0,8909 & 23,4718 \\
\hline & Copaíba & 203 & 1,2804 & 30,2118 \\
\hline & Maçaranduba & 144 & 1,1144 & 19,3468 \\
\hline & Jatobá fava & 178 & 1,0549 & 26,2757 \\
\hline
\end{tabular}

(clímax). Em relação à mudança conjunta dos parâmetros $c \mathrm{e} b$, a tendência se dá no sentido de espécies que possuem indivíduos de grandes diâmetros.

Esses dois processos não são necessariamente ligados, havendo espécies com taxa de mortalidade crescente que atingem grandes diâmetros, mas o resultado geral parece representar o fato de espécies de ciclo de vida mais longo sucederem espécies de ciclo de vida curto durante a sucessão secundária (GÓMEZ-POMPA e VÁZQUEZYANES, 1981). 


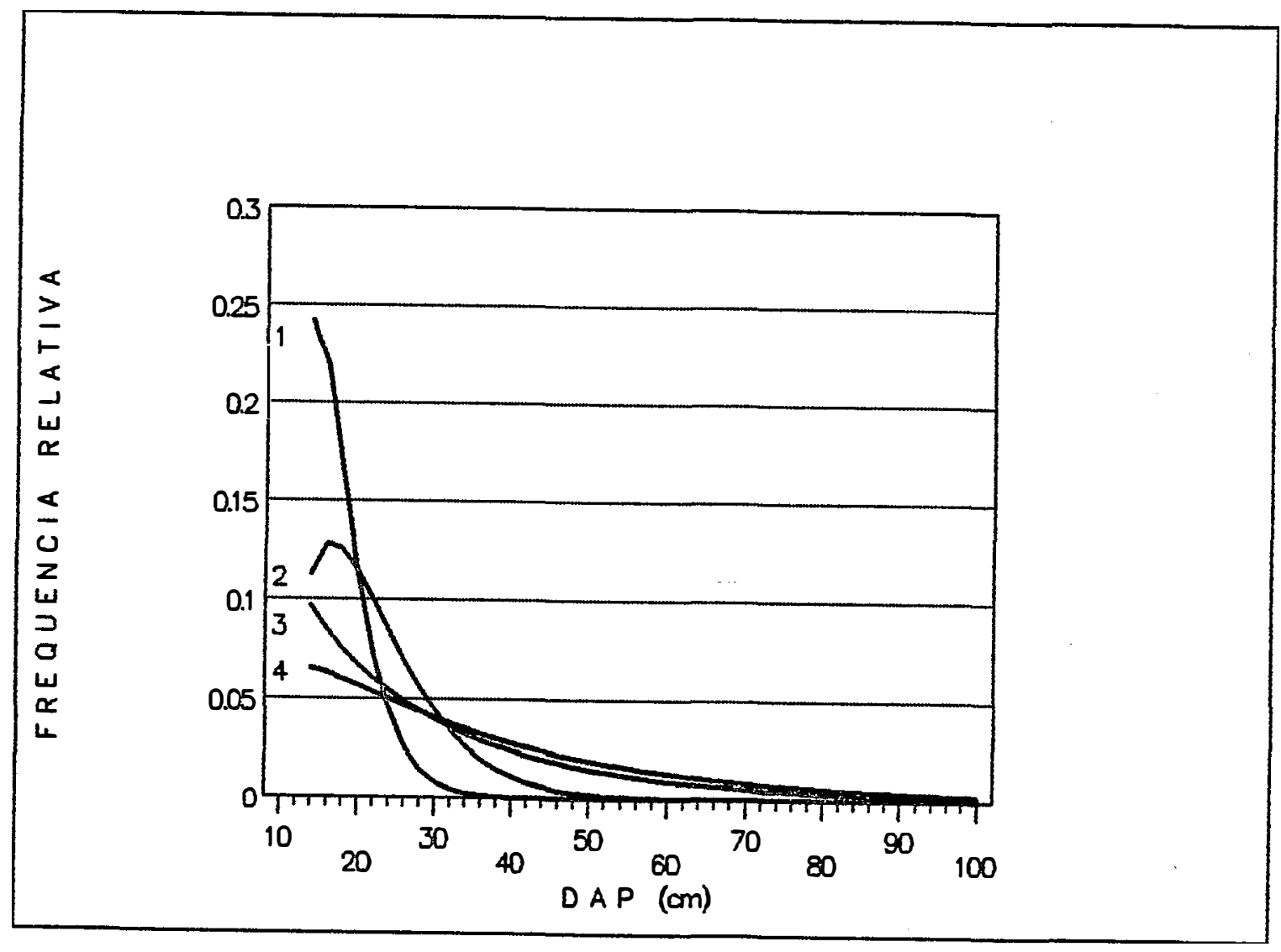

FIGURA 3.2.: Curvas de distribuição de diâmetros para espécies características dos estágios da sucessão. Espécies: (1) morototó, (2) amapá, (3) pau d'arco amarelo e (4) jatobá fava.

Embora não haja uma compatibilidade perfeita entre a classificação realizada pelos critérios de BUDOWSKI (1963 e 1965) e o valor dos parâmetros da distribuição Weibull, os parâmetros produzem curvas de diâmetro e sobrevivência com uma continuidade que representa melhor o processo de sucessão que a formação de classes bem delimitadas. Em última análise, a visualização de "estágios" na sucessão secundária é uma simplificação para facilitar a compreensão de um fenômeno contínuo. 


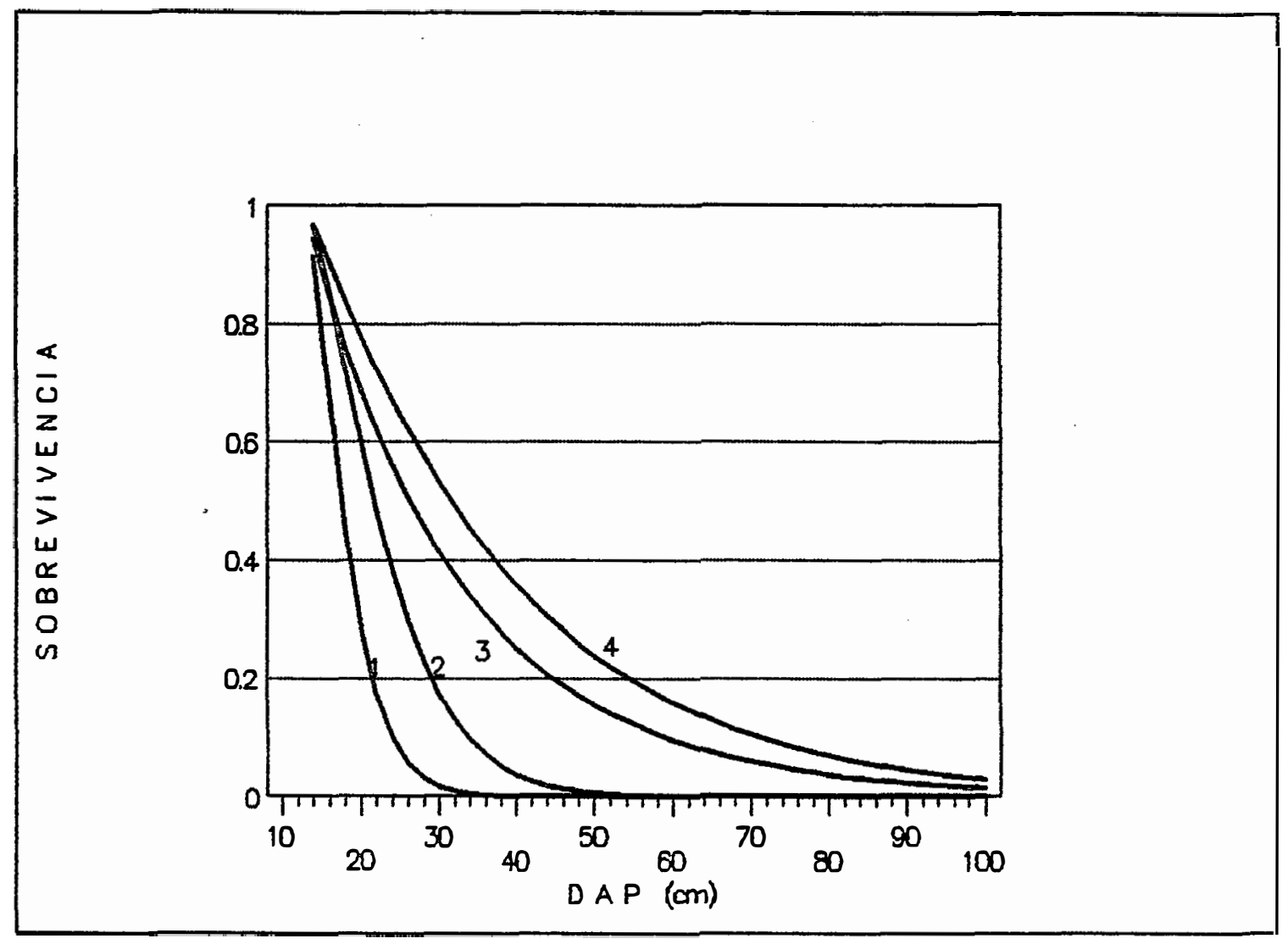

FIGURA 3.3.: Curvas de sobrevivência para espécies características dos estágios da sucessão. Espécies: (1) morototó, (2) amapá, (3) pau d'arco amarelo e (4) jatobá fava.

A "continuidade do processo de sucessão" não é a sucessão contínua de indivíduos de espécies diferentes na ocupação de uma clareira na floresta tropical. Ela significa que existe um "continuum" de estratégias de regeneração, onde as espécies arbóreas pioneiras, que só colonizam áreas abertas de grande luminosidade, e as espécies clímax, capazes de regenerar sob o dossel da floresta, representam os extremos. 


\subsubsection{Padrões de distribuição de diâmetro}

Como o estabelecimento de estágios ou classes facilita a compreensão de um fenômeno contínuo, procurou-se identificar padrões básicos de distribuição de diâmetro e sobrevivência dentro do "continuum" produzido pelos parâmetros da distribuição Weibull. Para isso, as espécies foram agrupadas através de análise de agrupamentos, utilizando como variáveis de análise as estimativas dos parâmetros $c \mathrm{e} b$, e como método de agrupamento o método Ward ou método da mínima variância dentro dos grupos (ROMESBURG, 1984; SAS, 1985). Escolheu-se arbitrariamente um número de 4 grupos para que estes fossem comparados com os 4 estágios da sucessão propostos por BUDOWSKI (1963 e 1965). O dendrograma produzido pela análise de agrupamento é apresentado no ANEXO 6.

Na FIGURA 3.4. pode-se observar a posição dos quatro grupos em relação aos valores das estimativas do parâmetros. Nota-se uma clara distinção entre os quatro grupos obtidos pela análise de agrupamento. Entretanto, não há uma correspondência perfeita entre esses grupos e os quatro estágios da sucessão.

Em linha geral os grupos 3,1 e 2 parecem representar espécies em início, meio e final de sucessão, respectivamente. 0 grupo 4, representato por apenas 2 espécies (sucupira e alho bravo), parece ter um comportamento pouco comum entre as espécies mais freqüentes na floresta tropical. No ANEXO 7 são apresentadas as 60 espécies estudadas, conforme o grupo a que pertencem, com as respectivas estimativas dos parâmetros.

Os quatro grupos encontrados representam padrões bem definidos em termos de curva de distribuição de diâmetros (FIGURA 3.5.). Os grupos 1 e 2 apresentam curvas na forma de " $\mathrm{J}$ invertido", enquanto que os grupos 3 e 4 apresentam a 


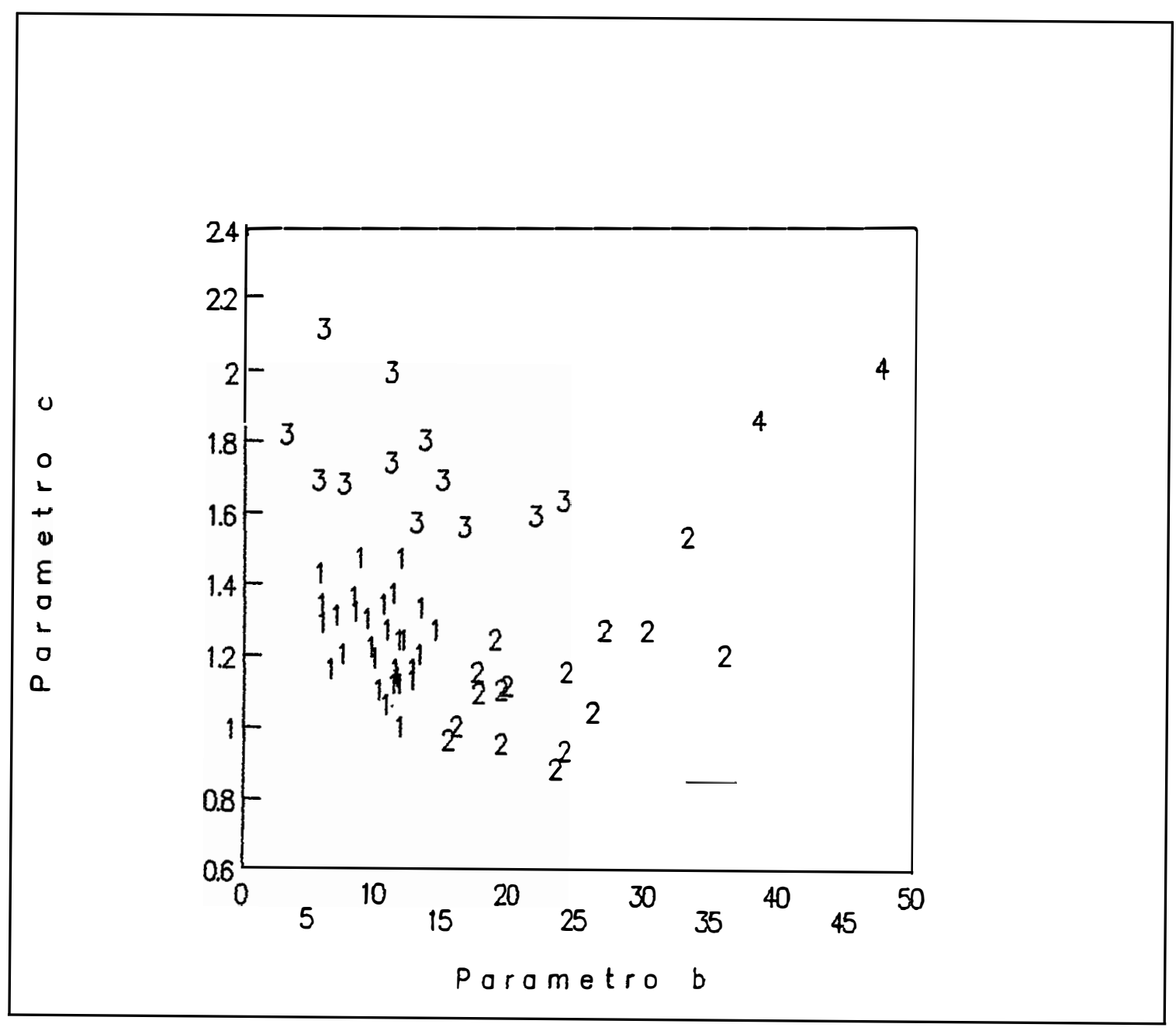

FIGURA 3.4.: Posição dos grupos de padrão de distribuição de diâmetro em relação aos parâmetros $c$ e $b$ da distribuição Weibull.

forma de uma curva normal positivamente assimétrica. A forma de "J invertido" parece estar relacionada com a regeneraçáo contínua, e a forma normal assimétrica relacionase com a regeneração intermitente. PIRES (1976) e KNIGHT (1975) atribuem esse último comportamento a espécies intolerantes, e o primeiro a espécies tolerantes.

As curvas da sobrevivência e da taxa instantânea relativa de mortalidade (FIGURAS 3.6. e 3.7. respectivamente) também mostram essa semelhança entre 


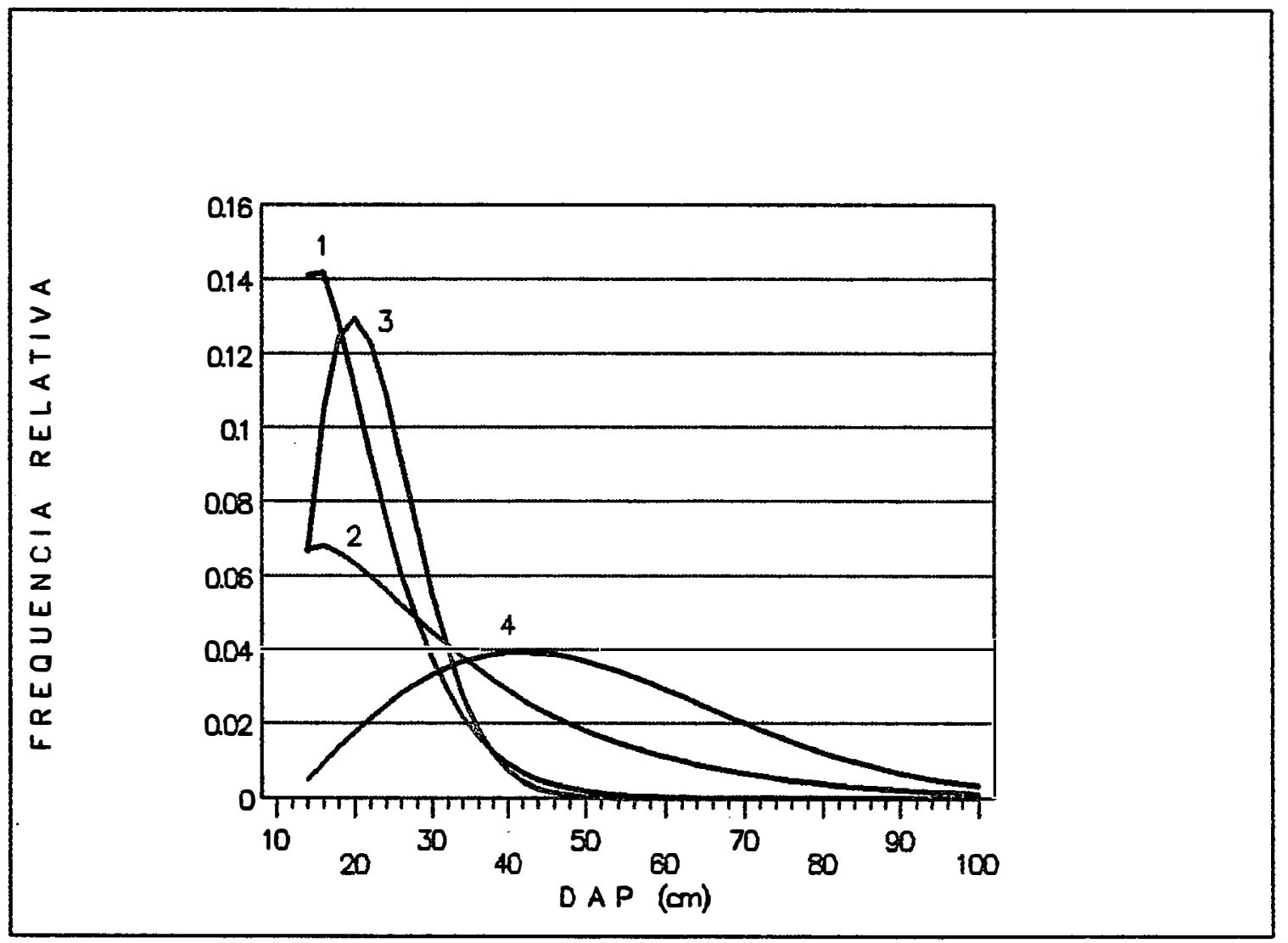

FIGURA 3.5.: Curvas de distribuição de diâmetros para os grupos representativos de padrões de distribuição de diâmetros. Os números das curvas indicam os grupos.

os grupos 1 e 2 e os grupos 3 e 4 . A curva da taxa de mortalidade assume uma forma potencial para os grupos 1 e 2 e uma forma de reta para os grupos 3 e 4 . 0 que diferencia o grupo 1 do 2, e o grupo 3 do 4, é a inclinação das curvas.

Os grupos 2 e 4, apesar de possuírem formas diferentes de curva, apresentam taxa de mortalidade praticamente constante em relação ao diâmetro, o que explica o fato das epécies desses grupos atingirem grandes diâmetros. 


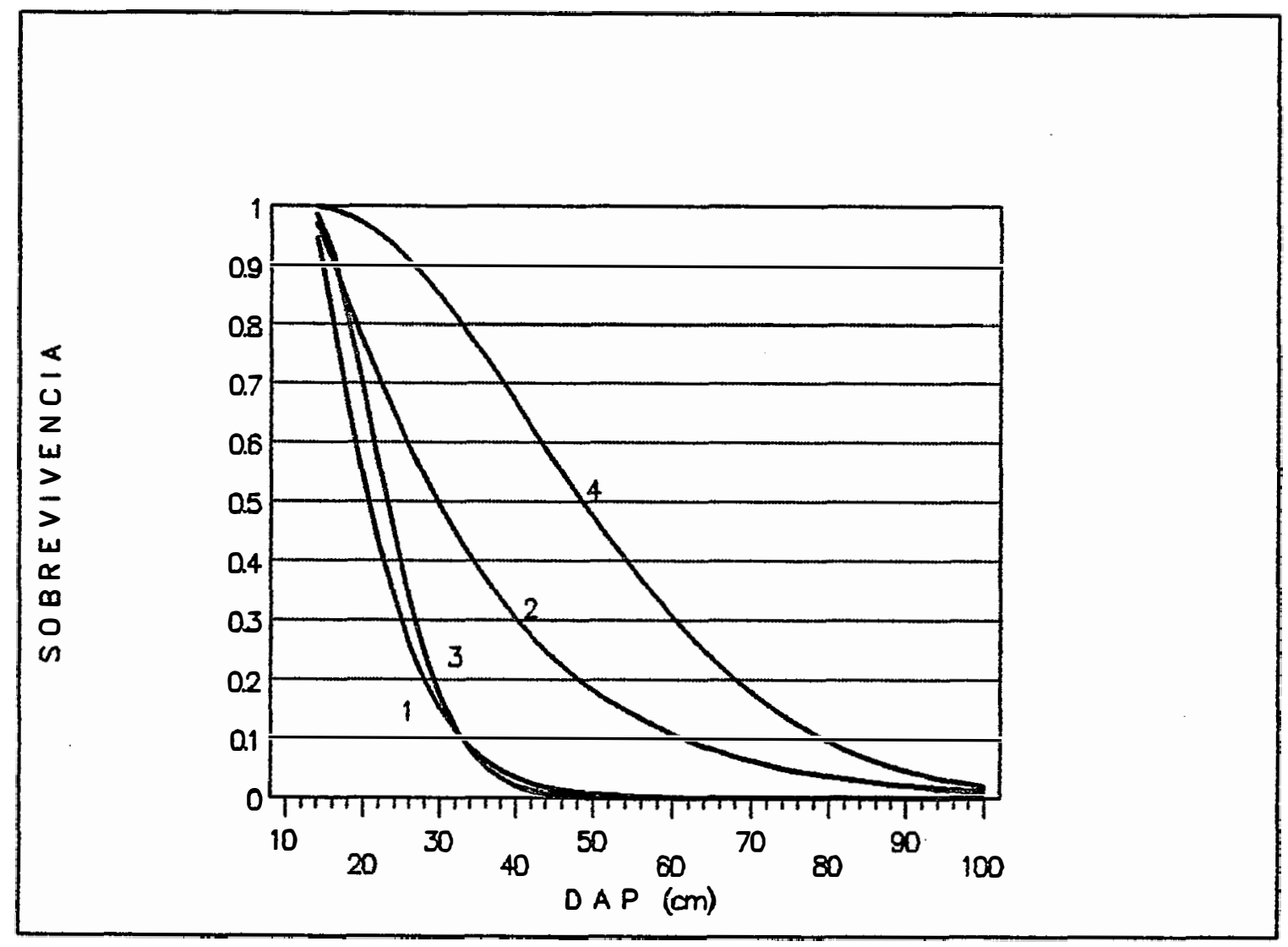

FIGURA 3.6.: Curvas de sobrevivência para os grupos representativos de padrões de distribuição de diâmetros. Os números das curvas indicam os grupos.

Já os grupos 1 e 3 possuem taxa de mortalidade crescente com o diâmetro, embora no grupo 1 o ritmo de crescimento seja decrescente (tendência a uma assíntota), enquanto no grupo 3 a taxa de mortalidade possui um aumento constante.

Em relação a esses quatro grupos pode-se afirmar que: 


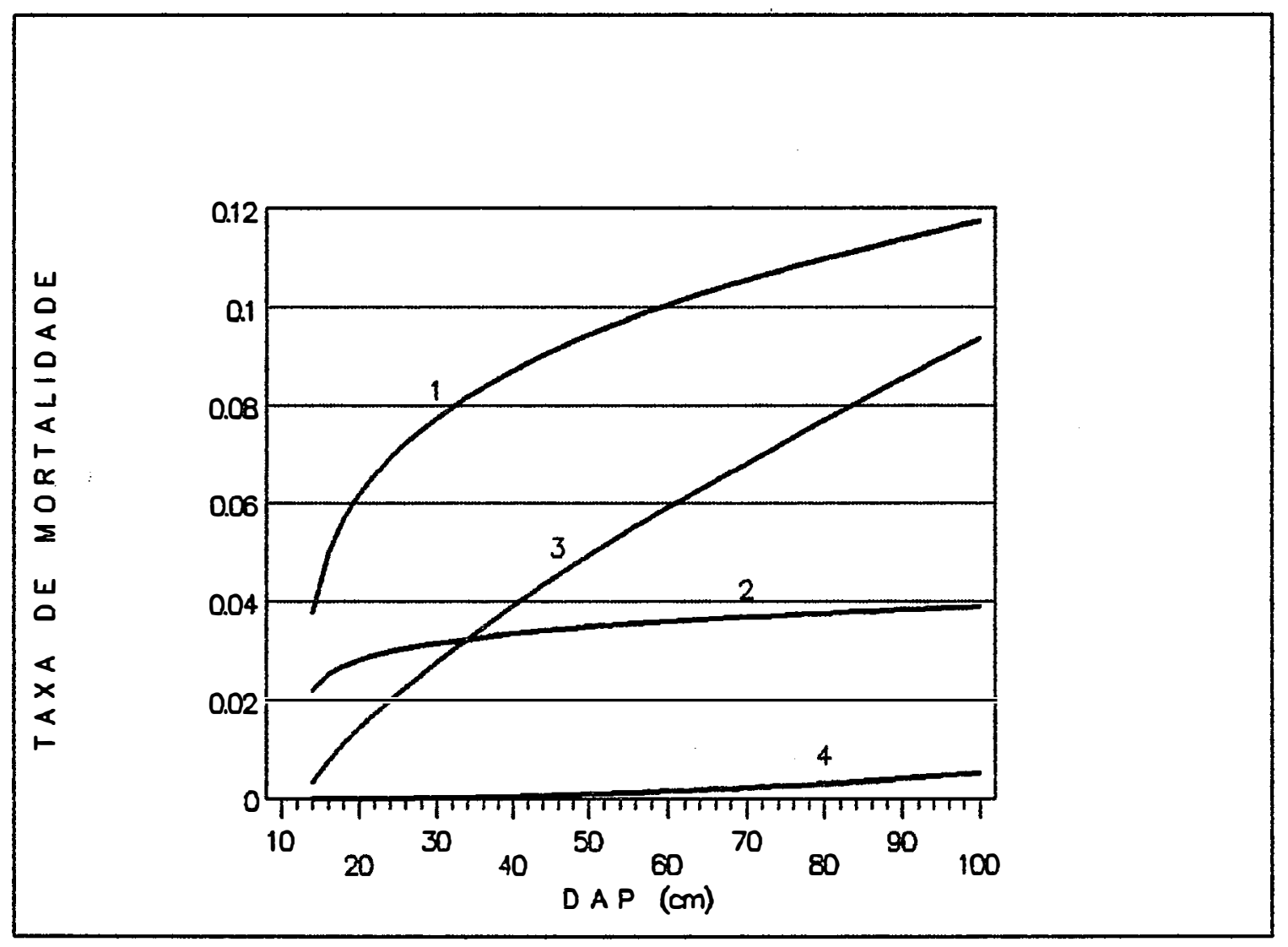

FIGURA 3.7.: Curvas da taxa de mortalidade instantânea para os grupos representativos de padrões de distribuição de diâmetros. Os números das curvas indicam os grupos.

A) $\bigcirc$ grupo 1 é composto por espécies com taxa de mortalidade crescente com tendência a estabilização nos diâmetros maiores. Provavelmente, tais espécies têm regeneração contínua e comportamento intermediário entre espécies tolerantes e intolerantes (final e início de sucessão), tendendo para espécies tolerantes, e atingem o dossel da floresta. 
B) As espécies do grupo 2 têm taxa de mortalidade praticamente constante em relação ao diâmetro e possuem árvores com grandes diâmetros. É provável que sejam espécies com regeneração contínua, que dominem o dossel e que sejam de final de sucessão (clímax).

C) As características básicas do grupo 3 são distribuição de diâmetro na forma de uma curva normal com forte assimetria positiva, e taxa de mortalidade crescente. As espécies desse grupo apresentam regeneração descontínua e ciclo de vida curto (atingem apenas pequenos diâmetros), sendo provavelmente espécies intolerantes de início de sucessão (pioneiras).

D) O grupo 4 é o grupo menos numeroso, mas constitui um padrão bem definido e distinto dos demais. A distribuição de diâmetros na forma próxima à normal (com certa assimetria positiva) e a taxa de mortalidade praticamente constante, parece indicar espécies com regeneração descontínua, mas com árvores de grandes diâmetros, que atingem o dossel da floresta. 


\subsection{Identificação do Padrão de Distribuição de Diâmetro de uma Espécie}

Procurou-se desenvolver um método no qual a partir dos valores das estimativas dos parâmetros $c$ e $b$ da distribuição Weibull, ajustada à distribuição de diâmetros de uma espécie qualquer, fosse possível determinar a qual dos quatro grupos definidos na secção 3.3.2. essa espécie pertenceria. Para isso, utilizou-se a análise discriminante para se estimar uma função discriminante e das probabilidades de cada espécie pertencer aos quatro grupos. A metodologia usada foi a apresentada pelo sistema SAS (SAS, 1985).

A função discriminante é uma função que produz, a partir dos valores de $c$ e $b$, de uma dada espécie, um valor para cada um dos quatro grupos. A espécie em estudo é classificada no grupo que apresentar o maior valor da função. A função discriminante é do tipo:

$$
Y=X^{\prime} \beta
$$

onde:

$Y$ é um vetor linha com os valores $y_{j}(j=1,2,3,4)$ para cada grupo $j$;

$X^{\prime}=\left[\begin{array}{lll}1 & c & b\end{array}\right]$ é o vetor linha com os parâmetros da distribuição de diâmetros da espécie a ser classificada; e

$\beta$ é a matriz de coeficientes da função discriminante.

Para utilizar essa função é necessário conhecer $\beta$, que nesse caso foi:

$$
\beta=\left(\begin{array}{cccc}
-41,29071 & -43,42358 & -79,08346 & -135,00462 \\
62,12524 & 55,80097 & 86,60362 & 96,09535 \\
0,45697 & 1,03879 & 0,54991 & 1,93966
\end{array}\right)
$$


Utilizando como exemplo a espécie pau-santo, em que as estimativas dos parâmetros foram $\hat{c}=1,1613$ e $\hat{b}=17,4845$, a função discriminante (3.11) fica:

$$
\begin{aligned}
Y & =\left(\begin{array}{llll}
y_{1} & y_{2} & y_{3} & y_{4}
\end{array}\right)= \\
& =\left(\begin{array}{lll}
1 & 1,1613 & 17,4845
\end{array}\right)\left(\begin{array}{cccc}
-41,29071 & -43,42358 & -79,08346 & -135,00462 \\
62,12524 & 55,80097 & 86,60362 & 96,09535 \\
0,45697 & 1,03879 & 0,54991 & 1,93966
\end{array}\right)
\end{aligned}
$$

resultando em:

$$
Y=\left(\begin{array}{llll}
y_{1} & y_{2} & y_{3} & y_{4}
\end{array}\right)=\left(\begin{array}{llll}
38,8452 & 39,5408 & 31,1042 & 10,5049
\end{array}\right)
$$

Como o maior valor da função foi $y_{2}=39,5408$ essa espécie foi classificada no grupo 2. Os valores da função discriminante, entretanto, não possuem qualquer significado biológico direto, sendo difícil a sua interpretação. Por outro lado, tais valores também não indicam a posição da espécie estudada em relação aos grupos de classificação, assim, apesar do valor $y_{1}=38,8452$ ser bem próximo ao valor obtido para o grupo $2\left(y_{2}\right)$ é diff́cil saber se o pau-santo é uma espécie intermediária aos grupos 1 e 2 , ou se é uma espécie bem característica do grupo 2 .

Uma outra forma de classificar uma dada espécie em um dos quatro grupos é calculando a probabilidade da espécie em estudo pertencer a cada um dos grupos. Essa probabilidade é calculada através de:

$$
\operatorname{Pr}(j \mid X)=\frac{\exp \left[-0,5 D_{j}^{2}(X)\right]}{\sum_{j=1}^{k} \exp \left[-0,5 D_{j}^{2}(X)\right]}
$$

onde:

$\operatorname{Pr}(j \mid X)$ é a probabilidade da espécie estudada pertencer ao grupo $j$;

$D_{j}^{2}$ é o quadrado da distância generalizada de MAHALANOBIS, obtida por:

$$
D_{j}^{2}=\left(X-X_{j}\right)^{\prime} \Sigma^{-1}\left(X-X_{j}\right)
$$


sendo:

$X$ o vetor coluna com o valor dos parâmetros da espécie em estudo;

$X_{j}$ o vetor coluna com o valor médio dos parâmetros no grupo $j$; e

$\Sigma$ a matriz de variância - covariância dos parâmetros $c$ e $b$.

No cálculo do quadrado da distância, para cada um dos grupos, os vetores dos valores médios dos parâmetros dos quatro grupos foram:

$$
X_{1}=\left(\begin{array}{c}
1,25419 \\
10,20830
\end{array}\right) \quad X_{2}=\left(\begin{array}{c}
1,12791 \\
23,01592
\end{array}\right) \quad X_{3}=\left(\begin{array}{c}
1,74816 \\
12,31084
\end{array}\right) \quad X_{4}=\left(\begin{array}{c}
1,94272 \\
42,95780
\end{array}\right)
$$

e a matriz de variância - covariância obtida foi:

$$
\Sigma=\left(\begin{array}{cc}
0,02017166 & 0,00222369 \\
0,00222369 & 22,03693659
\end{array}\right)
$$

Utilizando novamente o pau-santo como exemplo, o quadrado da distância dessa espécie para cada um dos quatro grupos obtido usando-se a equação (3.13) e os vetores acima é:

$$
\begin{aligned}
& D_{1}^{2}=\left(\begin{array}{ll}
-0,09289 & 7,7620
\end{array}\right)\left(\begin{array}{ll}
0,02017166 & 0,00222369 \\
0,00222369 & 22,03693659
\end{array}\right)^{-1}\left(\begin{array}{c}
-0,09289 \\
7,7620
\end{array}\right)=2,83702 \\
& D_{2}^{2}=\left(\begin{array}{ll}
0,03339 & -5,53142
\end{array}\right)\left(\begin{array}{ll}
0,02017166 & 0,00222369 \\
0,00222369 & 22,03693659
\end{array}\right)^{-1}\left(\begin{array}{c}
0,03339 \\
-5,53142
\end{array}\right)=1,44556 \\
& D_{3}^{2}=\left(\begin{array}{ll}
-0,58686 & 5,17366
\end{array}\right)\left(\begin{array}{cc}
0,02017166 & 0,00222369 \\
0,00222369 & 22,03693659
\end{array}\right)^{-1}\left(\begin{array}{c}
-0,58686 \\
5,17366
\end{array}\right)=18,42984 \\
& D_{4}^{2}=\left(\begin{array}{lll}
-0,78142 & -25,47330
\end{array}\right)\left(\begin{array}{cc}
0,02017166 & 0,00222369 \\
0,00222369 & 22,03693659
\end{array}\right)^{-1}\left(\begin{array}{c}
-0,78142 \\
-25,47330
\end{array}\right)=59,51807
\end{aligned}
$$


A partir do valor do quadrado da distância as probabilidades da espécie pertencer a cada um dos grupos é facilmente obtida através da equação (3.12). No caso do pau-santo essas probabilidades foram:

$$
\begin{aligned}
& \operatorname{Pr}(1 \mid X)=0,3327 \\
& \operatorname{Pr}(2 \mid X)=0,6672 \\
& \operatorname{Pr}(3 \mid X)=0,0001 \\
& \operatorname{Pr}(4 \mid X)=0,0000
\end{aligned}
$$

Nota-se que a maior probabilidade se refere ao grupo 2, no grupo no qual a função discriminante já havia classificado essa espécie. Existe, contudo, uma certa probabilidade dessa espécie pertencer ao grupo $1(33,27 \%)$, embora o grupo 2 seja de fato o grupo de origem da espécie pau-santo.

A função discriminante foi aplicada d̀s 60 espécies estudadas. Apenas uma (visgueiro) foi classificada fora do seu grupo de origem, todas as demais apresentaram sempre probabilidades acima de 60\% de pertencerem aos seus grupos de origem. Entretanto, o uso da função discriminante na forma de probabilidade deve ser cauteloso pois exige que os parâmetros possua distribuição normal e que se conheça as probabilidades a priori de cada grupo. No caso desse estudo assuimiu-se a normalidade da distribuição dos parâmetros e a probabilidade a priori como sendo igual para todos os grupos.

O uso da função discriminante aqui apresentada para a classificação de outras espécies arbóreas tropicais, não estudadas nesse trabalho, pode servir de auxalio no estudo do comportamento ecológico dessas espécies. 


\subsection{Distribuição de Diâmetros e Características Fitossociológicas}

As características fitossociológicas calculadas para as espécies estudadas foram:

a) densidade (DAI),

b) freqüência (FAI),

c) dominância (DoAI),

d) f́ndice de valor de importância (IVI),

e) f́ndice de dispersão de Morisita,

f) desvio do índice de Morisita em relação à dispersão aleatória.

As fórmulas utilizadas estão no QUADRO 3.3. e os resultados obtidos para cada uma das espécies no ANEXO 8. A DAI, FAI, DoAI e IVI são as características mais comumente utilizadas nos estudos fitossociológicos. O índice de Morisita e o seu desvio foram utilizados devido a sua facilidade de cálculo a partir de dados de parcelas, onde a distância entre os indivíduos de uma mesma espécie não é computada. Infelizmente, esse índice é bastante influenciado pelo tamanho das parcelas (GREIGSMITH, 1964).

Das espécies estudadas, apenas o pau d'arco roxo, quina, cumaru, alho bravo, sucupira, visgueira, inharé branco e gororoba se apresentaram com dispersão aleatória. Todas as demais se mostraram com dispersão agrupada (desvio do índice de Morisita significativo ao nível de $5 \%$ de probabilidade).

Outras características observadas nos índices fitossociológicos foram:

1) a baixa densidade das espécies, $43 \%$ das espécies possuem menos de 2 indivíduos por hectare; 
QUADRO 3.3.: Fórmulas utilizadas nos cálculos dos índices fitossociológicos.

\begin{tabular}{ccc}
\hline CARACTERÍSTICA & ÍNDICE ABSOLUTO & ÍNDICE RELATIVO \\
\hline $\begin{array}{c}\text { Densidade (DAI) } \\
\text { (nọ de indivíduos /ha) }\end{array}$ & $D A_{i}=n_{i} / S$ & $D R_{i}=D A_{i} / \sum_{i=1}^{E} D A_{i}$ \\
\hline $\begin{array}{c}\text { Freqüência (FAI) } \\
\text { (nọ de ocorrências) }\end{array}$ & $F A_{i}=m_{i} / M$ & $F R_{i}=F A_{i} / \sum_{i=1}^{E} F A_{i}$ \\
\hline $\begin{array}{c}\text { Dominância (DoAI) } \\
\left(m^{2} / h a\right)\end{array}$ & $D o A_{i}=A B_{i} / S$ & $D o R_{i}=D o A_{i} / \sum_{i=1}^{E} D o A_{i}$ \\
\hline $\begin{array}{c}\text { Indice de Valor de } \\
\text { Importância (IVI) }\end{array}$ & $N V I_{i}=D R_{i}+F R_{i}+D o R_{i}$ \\
\hline $\begin{array}{c}\text { Indice de Dispersão de } \\
\text { Morisita (MORISITA) } \\
\text { (GREIG-SMITH, 1964) }\end{array}$ & $I_{\delta i}=M\left[\sum_{k=1}^{M} n_{i k}\left(n_{i k}-1\right)\right] /[N(N-1)]$ \\
\hline $\begin{array}{c}\text { Desvio do f́ndice de } \\
\text { Morisita em relação à } \\
\text { dispersão aleatória }\end{array}$ & $D E S V I O_{i}=\left[I_{\delta i}\left(n_{i}-1\right)+M-n_{i}\right] /(M-1)$ \\
(GREIG-SMITH, 1964)
\end{tabular}

\section{OBSERVAÇŌES:}

$n_{i}$ é o número de indivíduos da espécie $i(i=1,2, \ldots, E)$;

$m_{i}$ é o número de ocorrências da espécie $i$;

$n_{i k}$ é o número de índividuos da espécie $i$ na parcela $k(k=1,2, \ldots, M)$;

$S$ é a área total amostrada (em ha);

$M$ é o número de parcelas amostradas;

$N$ é o número total de árvores amostradas;

$A B_{i}$ é a área basal da espécie $i\left(\mathrm{em} \mathrm{m}^{2}\right)$; e

$\operatorname{DESVIO} \mathrm{i}_{i}$ segue a distribuição de F com graus de liberdade $n_{1}=M-1$ e $n_{2}=\infty$.

2) algumas espécies se destacam com uma alta freqüência, como o gitó $(37,4$ ind./ha), amescão $(19,1$ ind./ha), chapéu baiano (17,2 ind./ha), goiabão (14,6 ind./ha), puturuna $(13,6$ ind./ha) e barrote $(10,0$ ind./ha);

3) apenas três espécies apresentam mais de $1 \mathrm{~m}^{2} / h a$ de área basal: amescão, gitó e caneleiro; 
4) muitas espécies possuem uma baixa freqüência, pois 25 espécies estiveram presentes em menos de $50 \%$ das parcelas.

Procurou-se correlacionar as características fitossociológicas com a distribuiçảo de diâmetros, calculando-se o coeficiente de correlação de Kendall entre as estimativas dos parâmetros da Weibull, os indices fitossociológicos e os diâmetros médio aritmético (DAP) e médio quadrático (DAPQ). O QUADRO 3.4. apresenta os resultados obtidos.

A estimativa do parâmetro da forma $(\hat{c})$ não apresentou correlação com nenhum dos índices testados, mas apresentou correlação estatisticamente significativa (nível de 5\% de probabilidade) com o $\overline{D A P}$ e o $\overline{D A P Q}$, embora o valor dos coeficientes seja baixo. Essa correlação era esperada, pois o parâmetro $c$ controlando a forma da distribuição de diâmetros influencia diretamente o valor dos momentos da distribuição, os quais podem ser representados pelo DAP (primeiro momento central) e $\overline{D A P Q}$ (segundo momento central).

Já a estimativa do parâmetro $b$ (parâmetro da escala) apresentou uma al ta correlação com os $\overline{D A P}$ e $\overline{D A P} \bar{Q}$, o que é uma conseqüência do significado biológico desse parâmetro. Por outro lado, a estimativa de $b$ também apresentou correlação estatisticamente signficativa com o índice de Morisita e seu desvio. $O$ fato dessa correlação ser negativa sugere que espécies com um maior valor de $b$ tendem a uma dispersão mais agrupada.

As variâncias das estimativas de ambos os parâmetros se mostraram negativamente correlacionadas com FAI, DAI, DoAI, IVI e o desvio do índice de 
QUADRO 3.4.: Coeficiente de correlação de Kendall e níveis de probabilidade para correlação entre os parâmetros da distribuição Weibull e os índices fitossociológicos e os diâmetros médio aritmético (DAP) e médio quadrático (DAPQ).

\begin{tabular}{|l|cc|cc|}
\hline \multirow{2}{|c|}{ INDICES } & \multicolumn{2}{|c|}{ PARÂMETRO $c$} & \multicolumn{2}{c|}{ PARÂMETRO b } \\
FITOSSOCIOLÓGICOS & Estimativa & Variância & Estimativa & Variância \\
\hline Freqüência & $-0,0023$ & $-0,7500$ & $-0,0307$ & $-0,3955$ \\
Absoluta (FAI) & $(0,9796)$ & $(0,0000)$ & $(0,7304)$ & $(0,0001)$ \\
\hline $\begin{array}{l}\text { Densidade } \\
\text { Absoluta (DAI) }\end{array}$ & $-0,0402$ & $-0,7614$ & $-0,0979$ & $-0,4772$ \\
\hline Dominância & $(0,6509)$ & $(0,0000)$ & $(0,2698)$ & $(0,0001)$ \\
Absoluta (DoAI) & $-0,0520$ & $-0,6237$ & 0,2825 & $-0,1073$ \\
\hline fndice de Valor de & $(0,5574)$ & $(0,0001)$ & $(0,0014)$ & $(0,2256)$ \\
Importância (IVI) & 0,0000 & $-0,7186$ & 0,0723 & $-0,3017$ \\
\hline f́ndice de Morisita & $(1,0000)$ & $(0,0001)$ & $(0,4143)$ & $(0,0007)$ \\
(MORISITA) & 0,0667 & 0,2610 & $-0,2655$ & $-0,0746$ \\
\hline Desvio do índice & $(0,4517)$ & $(0,0032)$ & $(0,0027)$ & $(0,3999)$ \\
de Morisita (DESVIO) & 0,1130 & $-0,3299$ & $-0,2960$ & $-0,4667$ \\
\hline Diâmetro Médio & $(0,2021)$ & $(0,0002)$ & $(0,0008)$ & $(0,0001)$ \\
Aritmético (DAP) & $-0,1977$ & 0,0328 & 0,9164 & 0,5876 \\
\hline Diâmetro Médio & $(0,0256)$ & $(0,7114)$ & $(0,0000)$ & $(0,0001)$ \\
Quadrático (DAPQ) & -0.2271 & 0,0599 & 0,8983 & 0,6260 \\
& $(0,0103)$ & $(0,4990)$ & $(0,0000)$ & $(0,0001)$ \\
\hline
\end{tabular}

OBSERVAÇÃO: Os valores entre parênteses são os níveis de probabilidade.

Morisita, o que pode ser explicado pela amostragem. Quanto maior o valor das características fitossociológicas de uma dada espécie, maior será a sua participação nas parcelas amostradas e conseqüentemente menor a variância das estimativas dos parâmetros.

Quando a correlação entre os parâmetros da Weibull e as características fitossociológicas foi estudada, em separado para cada um dos grupos de padrões de distribuição de diâmetros, observou-se que essa correlação pode ser particular para cada grupo (QUADRO 3.5.). 
QUADRO 3.5.: Coeficiente de correlação de Kendall e níveis de probabilidade para correlação entre os parâmetros da distribuição Weibull e os índices fitossociológicos para cada um dos grupos de espécie.

\begin{tabular}{|c|c|c|c|c|c|c|c|}
\hline \multirow[t]{2}{*}{ GRUPO } & & \multicolumn{6}{|c|}{ ÍNDICES FITOSSOCIOLÓGICOS } \\
\hline & & FAI & DAI & DoAI & IVI & MORISITA & DESVIO \\
\hline \multirow[t]{2}{*}{$\begin{array}{c}1 \\
n=30\end{array}$} & $c$ & $\begin{array}{c}0,3356 \\
(0,0096)\end{array}$ & $\begin{array}{c}0,4115 \\
(0,0014)\end{array}$ & $\begin{array}{c}0,3241 \\
(0,0119)\end{array}$ & $\begin{array}{c}0,3747 \\
(0,0036)\end{array}$ & $\begin{array}{c}0,0023 \\
(0,9858)\end{array}$ & $\begin{array}{c}0,4621 \\
(0,0003)\end{array}$ \\
\hline & $b$ & $\begin{array}{l}-0,0671 \\
(0,6045)\end{array}$ & $\begin{array}{l}-0,1172 \\
(0,3629)\end{array}$ & $\begin{array}{c}0,0069 \\
(0,9573)\end{array}$ & $\begin{array}{c}-0,0713 \\
(0,5802)\end{array}$ & $\begin{array}{r}-0,1770 \\
(0,1695)\end{array}$ & $\begin{array}{c}-0,2506 \\
(0,0518)\end{array}$ \\
\hline \multirow[t]{2}{*}{$\stackrel{2}{n=16}$} & $c$ & $\begin{array}{c}0,2929 \\
(0,1147)\end{array}$ & $\begin{array}{c}0,3500 \\
(0,0586)\end{array}$ & $\begin{array}{c}0,3333 \\
(0,0717)\end{array}$ & $\begin{array}{c}0,3667 \\
(0,0476)\end{array}$ & $\begin{array}{c}-0,2333 \\
(0,2074)\end{array}$ & $\begin{array}{c}0,0000 \\
(1,0000)\end{array}$ \\
\hline & $b$ & $\begin{array}{c}0,0418 \\
(0,8217)\end{array}$ & $\begin{array}{c}0,1000 \\
(0,5890)\end{array}$ & $\begin{array}{c}0,3500 \\
(0,0586)\end{array}$ & $\begin{array}{c}0,2167 \\
(0,2418)\end{array}$ & $\begin{array}{c}-0,2167 \\
(0,2418)\end{array}$ & $\begin{array}{c}-0,0833 \\
(0,6525)\end{array}$ \\
\hline \multirow[t]{2}{*}{$\begin{array}{c}3 \\
n=12\end{array}$} & $c$ & $\begin{array}{c}-0,3206 \\
(0,1489)\end{array}$ & $\begin{array}{c}-0,2424 \\
(0,2726)\end{array}$ & $\begin{array}{l}-0,4545 \\
(0,0397)\end{array}$ & $\begin{array}{c}-0,3333 \\
(0,1314)\end{array}$ & $\begin{array}{c}0,6364 \\
(0,0040)\end{array}$ & $\begin{array}{c}0,1212 \\
(0,5833)\end{array}$ \\
\hline & $b$ & $\begin{array}{c}0,1374 \\
(0,5362)\end{array}$ & $\begin{array}{l}0,0000 \\
(1,000)\end{array}$ & $\begin{array}{c}0,5758 \\
(0,0092)\end{array}$ & $\begin{array}{c}0,2121 \\
(0,3370)\end{array}$ & $\begin{array}{c}-0,5152 \\
(0,0197)\end{array}$ & $\begin{array}{c}-0,3636 \\
(0,0998)\end{array}$ \\
\hline
\end{tabular}

OBSERVAÇÕES: os valores entre parênteses são os níveis de probabilidade, e $n$ representa o número de espécies em cada grupo.

No grupo 1, constituído de espécies de meio de sucessão, a estimativa do parâmetro $c$ apresentou correlação positiva estatisticamente significativa com todos os índices, exceto o índice de Morisita. Portanto, as variações na forma da distribuição de diâmetro dentro desse grupo estão correlacionadas com o comportamento fitossociológico das espécies. As espécies do grupo 1 com maior importância fitossociológica (maior valor para FAI, DAI, DoAI e IVI) e mais agrupadas (maior valor para o desvio do ́́ndice de Morisita) são espécies que tendem a um comportamento de início de sucessão (maior valor do parâmetro c) característico do grupo 3.

Já no grupo 2, composto por espécies de final de sucessão, a estimativa do parâmetro da forma $(c)$ só apresentou correlação estatisticamente significativa 
com o IVI. De modo análogo ao grupo 1, pode-se afirmar que as espécies com maior importância fitossociológica do grupo 2 tendem a uma distribuição com forma de "J invertido" com maior inclinação (maior valor de c) e, portanto, a um comportamento de meio de sucessão secundária.

No grupo 3, a estimativa do parâmetro $c$ apresentou correlação negativa com a dominância (DoAI). Espécies com menor valor de $\varepsilon$ tendem a atingir maiores diâmetros e, portanto, a apresentar maior dominância. Por outro lado, o índice de Morisita se mostrou positivamente correlacionado com $\hat{c}$ e negativamente com $\hat{b}$. O grupo 3 é composto por espécies de início de sucessão, um maior índice de Morisita significa maior tendência ao agrupamento e talvez maior dependência de clareiras para regeneração. Isso resulta que espécies com alto valor de $\hat{c}$ e baixo valor de $\hat{b}$ tendem a ser espécies pioneiras, cuja regeneração é muito dependente da existência de clareiras.

No caso do grupo 4, não foi possível explorar as correlações entre os índices fitossociológicos e os parâmetros da Weibull, pois apenas duas espécies fizeram parte desse grupo. 


\section{CONCLUSÕES}

“Nós não sabemos. Nós só podemos dar palpites”.

K. Popper 


\section{CONCLUSÕES}

A respeito do uso da distribuição Weibull para representar a distribuição dos diâmetros das espécies arbóreas tropicais pode- se concluir que:

1) Devido à sua grande flexibilidade, a distribuição Weibull se ajusta bem à distribuição de diâmetros de diferentes espécies arbóreas presentes na floresta tropical.

2) Todos os métodos de ajuste testados produzem um bom ajuste em relação aos valores observados, exceto o método das funções lineares proposto por MENON (1963).

3) $O$ método dos percentis é o mais indicado para representar a distribuição original, pois as freqüências calculadas por classe de diâmetro são as mais próximas das freqüências observadas. 
4) Quando o objetivo é obter estimativas dos parâmetros com uma boa precisão, o método da máxima verossimilhança é o mais indicado, pois produz estimativas com menor intervalo de confiança.

5) Para amostra com menos de 90 árvores, os métodos dos momentos e da máxima verossimilhança são praticamente iguais ao método dos percentis na representação das distribuições originais.

6) Dentre os métodos que utilizam processos iterativos, os métodos de máxima verossimilhança, usando o método iterativo de NewtonRaphson, são os mais seguros para obter a convergência. Esses métodos sảo, entretanto, mais lentos que o método dos momentos utilizando os métodos iterativos da secante e da falsa posição.

7) $O$ número e amplitude das classes de diâmetro influenciam significativamente as estimativas dos parâmetros obtidas pelo método dos percentis, utilizando-se dados agrupados.

Sobre o significado biológico dos parâmetros da Weibull conclui-se que:

8) Embora inicialmente proposta como distribuição empírica, a distribuição Weibull pode ser deduzida biologicamente quando se assume que a taxa instantânea relativa de mortalidade de uma população segue uma função do tipo $M(x)=\theta \gamma x^{(\gamma-1)}$. 
9) O parâmetro c, quando a Weibull é ajustada a uma distribuição de diâmetros, traduz o comportamento da taxa instantânea relativa de mortalidade com o aumento do diâmetro. Para $c<1$ a taxa é decrescente, para $c=1$ ela se torna constante e para $c>1$ passa a ser crescente.

10) $O$ parâmetro $b$, para distribuições com o mesmo valor de $c$, controla os diâmetros médios aritmético e quadrático da distribuição de diâmetros.

11) Ao longo da sucessão secundária, a distribuição de diâmetros das espécies arbóreas muda da forma em “J invertido" com alta inclinação, nas espécies pioneiras, para a forma exponencial bem suave, tendendo a uma reta, nas espécies clímax.

12) Essa mudança na forma da distribuição de diâmetros pode ser representada pela diminuição do valor do parâmetro $c$, que varia de valores próximos a 2 para as espécies pioneiras diminuindo gradativamente para valores ao redor de 1 para as espécies clímax. Portanto, a taxa instantânea relativa de mortalidade muda gradativamente de uma função crescente com o diâmetro nas espécies pioneiras para uma função constante nas espécies clímax. 
13) A diminuição do parâmetro $c$ e o aumento do parâmetro $b$, no decorrer dos estágios da sucessão, representam o aumento dos diâmetros atingidos pelas espécies arbóreas de diferentes estágios da sucessão.

14) Com base nos parâmetros $c$ e $b$ foi possível identificar quatro padrões de distribuição de diâmetro. Embora a variação dos parâmetros seja praticamente contínua, cada um dos grupos representa um padrão bem definido.

15) Em linhas gerais há uma compatibilidade entre os grupos identificados e os estágios da sucessão, sendo que o grupo 3 representa espécies de início de sucessão, o grupo 1 de espécies de meio de sucessão e o grupo 2 espécies de final de sucessão. 0 grupo 4 foi constituído por apenas duas espécies de modo que representa um comportamento menos comum na floresta tropical.

16) A classificação de uma dada espécie em um desses quatro grupos, com base nos parâmetros da Weibull, pode ser facilmente obtida a partir de uma função discriminante. 
17) Em linhas gerais não há correlação entre o parâmetro $c$ e o comportamento fitossociológico das espécies estudadas. Já o parâmetro $b$ apresentou correlação negativa com os índices de dispersão, sugerindo que as espécies que atingem maiores diâmetros tendem a uma dispersão menos agregada. A maioria das espécies apresentou dispersão claramente agregada. 
5. BIBLIOGRAFIA CITADA 


\section{BIBLIOGRAFIA CITADA}

ALEXANDER, R.R., 1985 Diameter and basal area distribuitions in old-growth Spruce-fir stands in Colorado. USDA, Forest Service, Research Note, Fort Collins, RM - 451: 1 -4.

ALEXANDER, R.R. e C.B. EDMINSTER, 1977 Uneven-aged management of oldgrowth Spruce-fir forests: cutting method and stand structure, goals for the initial entry. USDA, Forest Service, Research Paper, Fort Collins, RM - 186:1 - 12.

ARMESTO, J.J. et alii, 1986 A comparison of spatial patterns of trees in some tropical and temperate forests. Biotropica, 18(1): 1 -11.

AZEVEDO, A.G. e P.H.B. CAMPOS, 1987 Estatística básica. Rio de Janeiro, Livros Técnicos e Científicos, 283p.

BAILEY, R.L., 1973 Weibull model for Pinus radiata diameter distribuitions. In: "Statistics in Forestry Research" Proceedings of the meeting of IUFRO subject group S6.02, Vancouver, p.51 -59.

BAILEY, R.L. e T.R. DELL, 1973 Quantifying diameter distributions with the Weibull function. Forest Sciences, 19(2): 97 - 104.

BAIN, L.J.e C.E. ANTLE, 1967 Estimation of parameters in the Weibull distribution. Technometrics, 9(4): 621 - 627 .

BARROS, P.L.C. de, 1986 Estudos fitossociológicos de uma floresta tropical úmida no planalto de Curuá-Una, amazônia brasileira. Viçosa, UFV, 147p. (Tese - Mestrado - UFV). 
BARROS, P.L.C. de et alii, 1979 Comparação de modelos descritivos da distribuição diamétrica em uma floresta tropical. Revista Arvore, Viçosa, 10(2): 19 - 32.

BERCKETT, R. e J. HURT, 1967 Numerical calculations and algorithms. New York, McGraw-Hill, 298p.

BERGER, R.W. e K. LAWRENCE, 1974 Estimating Weibull parameters by linear and nonlinear regression. Technometrics, 16(4): 617 - 619.

BONNER, F.T. e T.R. DELL, 1976 The Weibull function: a new method of comparing seed vigor. Journal of Seed Technology, 1(1): 96 - 103.

BOURGERON, P.S., 1983 Spacial aspects of vegetation structure. In: GOLLEY, F.B. Tropical Rain Forest Ecossistems. Amsterdam, Elsevier Scientific. p.29 - 47.

BRASIL, 1973a Departamento Nacional de Produção Mineral. Projeto RADAM. Folha SA.23 São Luís e parte da folha SA.24 Fortaleza. Rio de Janeiro. v3.

BRASIL, 1973b Departamento Nacional de Produção Mineral. Projeto RADAM. Folha SB.23 Teresina e parte da folha SB.24 Jaguaribe. Rio de Janeiro. v2.

BRITO, J.O., 1981 Comportamento de madeiras nativas do Maranhão frente ao processo de destilação seca. Brasil Florestal, Braślia, 11(45): 47 - 56.

BRUNIG, E.F., 1983 Vegetation structure and growth. In: GOLLEY, F.B. Tropical Rain Forest Ecossystems. Amsterdam, Elsevier Scientific. p.49 - 75.

BRUNIG, E.F. e J. HEUVELDOP, 1976 Structure and functions in natural and man-made forests in the humid tropics. In: IUFRO Word Congress, 16, Oslo, Proceedings, v1., p.500 - 511.

BUDOWSKI, G. 1963 Forest succession in tropical lowland. Turrialba, Turrialba, $13(1): 43-44$.

BUDOWSKI, G. 1965 Distribution of tropical American rain forest species in the light of successional processes. Turrialba, Turrialba, 15(1): 40 - 42 .

BUDOWSKI, G. 1984 Sustainable use of species and ecossystems. In: THIBODEAU, F.R. e H.H. FIELD Sustaining Tomorrow. Hanover, University Press of New England.

BURK, T.E. e H.E. BURKHART, 1984 Diameter distribution and yields of natural stands of Loblolly Pine. School of Forestry and Wildlife Resources, Virginia Polytechnic Institute and State University, Blacksburg, Publication FWS - 1 84. 
BURK, T.E. e J.D. NEWBERRY, 1984 A simple algorithm for moment- based recovery of Weibull distribution parameters. Forest Sciences, 30(2): 329 - 332.

BURKHART, H.E. et alii, 1981 A comparison of growth and yield prediction models for Loblolly Pine. School of Forestry and Wildlife Resources, Virginia Polytechnic Institute and State University, Blacksburg, Publication FWS-2-81.

CAMPOS, H. de, 1979 Estatística experimental não-paramétrica. Piracicaba, ESALQ/USP. 343p.

CARVALHO, J.O.P. de 1981 Distribuição diamétrica de espécies comerciais potenciais em floresta tropical úmida natural da amazônia. Boletim de Pesquisa, EMBRAPA/CPATU, Belém, (23): 1 - 34.

COHEN, A.C., 1965 Maximum likelihood estimation in the Weibull distribution based on complete and censored samples. Technometrics, (7): $570-601$.

COUTO, H.T.Z. do, 1980 Distribuição de diâmetros em plantaçōes de Pinnus caribaea var. caribaea. Piracicaba, ESALQ / USP. (Tese - Livre-Docência - ESALQ)

DIXON, C. 1974, Numerical analysis. Glasgow, Blackie \& Chambers. 182p.

DOUROJEANNI, M.J., 1983 Conceituação em ecologia. Silvicultura, São Paulo, 8(28): 30 - 35 .

DUBEY, S.D., 1967 Some percentile estimators for Weibull parameters. Technometrics, 9(1): $119-129$.

ELANDT-JOHNSON, R.C. e N.L. JOHNSON, 1980 Survival models and data analysis. New York, John Wiley.

FAO, s.d. Report to Brazilian Government, s.i., 194p. 1v.

FEARNSIDE, P.M. 1984 A floresta vai acabar? Ciência Hoje, Rio de Janeiro, 2(10): $42-52$.

GIBBS, P.E. et alii, 1980 Aplicação do método dos quadrantes no levantamento florístico de uma mata ciliar em Mogi-Guaçu, SP, Brasil. Revista Brasileira de Botânica, 3(1/2): 17 - 22.

GIBBS, P.E. e H.F. LEITÃO, 1978 Composição Florística de uma mata ciliar nas proximidades de Mogi-Guaçu, Estado de São Paulo, Brasil Sudeste. Revista Brasileira de Botânica, 1(2): 151 - 7.

GILBERT, L.E., 1980 Food web organization and the conservation of Neotropical diversity. In: SOULÉ, M.E. e B.A. WILCOX Conservation Biology: an EvolutionaryEcological Perspective. Sunderland, Sinauer Associates. 
GÓMEZ-POMPA, A. et alii, 1972 The tropical rain forest: a nonrenewable resource. Science, 177: 762 - 765.

GÓMEZ-POMPA, A. e C. VÁSQUEZ-YANES, 1981 Successional studies of a rain forest. In: WEST, D.C. et alii. Forest Succession. New York, Springer-Verlag. p.246 $-266$.

GREIG-SMITH, P., 1964 Quantitative plant ecology. London, Butterworth. 256p.

GROSS, A.J. 1977 Monte Carlo comparisons of parameter estimators of the 2 parameter Weibull distribution. IEEE Transactions on Reliability, R - 26(5): 356 - 358 .

GROSS, A.J. e V.A. CLARK, 1975 Survival distributions: reliability applications in the biomedical sciences. New York, John Wiley. 331p.

GUILLAUMET, J.L. e F. KAHN, 1982 Structure e dynamisme de la forêt. Acta Amazonica, 12(3)suplemento: 61 - 77.

HALLE, F. et alii, 1978 Tropical trees and forests: an architectural analysis. Berlim, Springer-Verlag. 441p.

HARTER, H.L. e A.H. MOORE, 1965 Maximum-likelihood estimation of the parameters of gamma and Weibull population from complete and from censored samples. Technometrics, 7(4): 639 - 643.

HARTSHORN, G.S. 1975 A matrix model of tree population dynamics. In: GOLLEY, F.B. e E. MEDINA Tropical Ecological Systems: Trends in Terrestrial and Aquatic Research. New York, Spring-Verlag. p.41 - 51.

HARTSHORN, G.S. 1980 Neotropical forest dynamics. Biotropica, 12(suplemento): $23 \cdot 39$.

HOSOKAWA, R.T. e J.E. GLADE, 1986 Prognose de rendimentos de bitolas comerciais para múltiplos fins em povoamentos florestais. In: $V$ Congresso Florestal Brasileiro, Olinda, p.150 - 163.

JOHNSON, N.L. e S. KOTZ, 1970 Continous univariate distributions. Boston, Houghton Mififn. v2.

KNIG HT, D.H., 1975 An analysis of late secondary succession in species-rich tropical forest. In: GOLLEY, F.B. e E. MEDINA, Tropical Ecological Systems: Trends in Terrestrial and Aquatic Research. New York, Spring-Verlag. p.53 - 59.

KNOEBEL, B.R. et alii, 1986 A growth and yield model for thinned stands of Yellow-poplar. Forest Science Monograph (27): 1 -62. 
KRUG, A.G. et alii, 1984 Determining initial values for parameter of Weibull model: a case study. Forest Science, 30(3): 573 -581.

LEAK, W.B., 1964 An expression of diameter distribution for unbalanced, unevenaged stands and forests. Forest Science, 10(1): $39-50$.

LENHART, J.D., 1986 Estimating the amount of wood per acre in Loblolly Pine and Slash Pine plantations in East Texas. In: Biennal Southern Silvicultural Research Conference, 4, Atlanta, Proceedings, p.485 - 488.

LENHART, J.D. e J.L. CLUTTER, 1971 Cubic-foot yield tables for old-field Loblolly Pine plantations in the Georgia Piedmont. Georgia Forest Research Council, Report 22(3): $1-13$.

LITTLE, S.N., 1983 Weibull diameter distributions for mixed stands of Western conifers. Canadian Journal of Forest Research, 13(1): 85 - 88.

MASSEY, F.J. Jr., 1951 The Kolmogorov-Smirnov test for goodness of fit. Journal of American Statistical Association, 46(523): 68 - 78.

MENON, M.V. 1963 Estimation of the shape and scale parameters of the Weibull distribution. Technometrics, 5(2): 175 - 182.

NELSON, T.C. 1964 Diameter distribution and growth of Loblolly Pine. Forest Science, 10(1): 105 - 114.

NEWBY, M.J., 1980 The properties of moment estimator for the Weibull distribution based on the sample coeficient of variation. Technometrics, 22(2): 187 - 194.

NONOMIYA, N. e K. OGINO, 1984 Size structure analysis by M-w diagram. In: HOTTA. Forest Ecology and Flora of G. Gadut West Sumatra. p.17 - 27.

OLIVEIRA, Y.M.M. de e E. ROTTA, 1982 Levantamento da estrutura horizontal de uma mata de araucária do Primeiro Planalto Paranaense. Boletim de Pesquisa Florestal, EMBRAPA/CNPF, Curitiba, (4): 1 - 46.

PINDER, J.E. et alii, 1978 The Weibull distribution: a new method of summarizing survivorship data. Ecology, 59(1): 175 - 179.

PIO-CORRÊA, M., 1926 Dicionário das plantas úteis do Brasil e das exóticas cultivadas. Rio de Janeiro, Ministério da Agricultura, Serviço de Informação Agrícola, $6 \mathrm{vA}$.

PIRES, J.M., 1976 Aspectos ecológicos da floresta amazônica. In: Congresso Brasileiro de Florestas Tropicais, 2, Mossoró, Anais, p.235 - 287. 
RANKIN, J.M., 1979 A floresta tropical como modelo para desenvolvimento ecológico na amazônica. Publicações ACIESP, São Paulo, (19): 112 - 121.

ROMESBURG, H.C., 1984 Cluster analysis for researchers. Belmont, Lifetime Learning Publication. 334p.

SARUKHÁN, J. 1976 Studies on the demography of tropical trees. In: TOMLINSON, P.B. e M.H. ZIMMERMANN Tropical Trees as Living Systems. Cambridge University Press.

SARUKHÁN, J. 1980 Demographic problems in tropical systems. In: SOLBRIG, O.T. Demography and Evolution in plant populations. Berkeley, University of California Press.

SAS, 1985 SAS/STAT Guide for personal computer, 6 version. Cary, SAS Institute. 1028p.

SCHREUDER, H.T. e W.T. SWANK, 1974 Coniferous stands characterized with the Weibull distribution. Canadian Journal of Forest Research,4(4): 518 - 523.

SHAPIRO, S.S. e A.J. GROSS, 1981 Statistical modeling techniques. New York, Marcel Dekker. 367p.

SHIVER, B.D., 1985 Sample size for estimating Weibull function parameters for Slash Pine plantations diameter distributions. Plantation Management Research Cooperative, Technical Report, 1985 - 4, 21p.

SILVA, J.A.A., 1986 Dynamics of stand structure in fertilized slash pine plantations. Athens, University of Georgia. 139p. (Tese - Doutoramento - UG).

SILVA, J.N.M. e J. de C.A. LOPES, 1982 Distribuição espacial de árvores na Floresta Nacional do Tapajós. Circular Técnica, EMBRAPA/CPATU, Belém, (26):1 - 14.

SILVERTOWN, J., 1987 Introdution to plant population ecology. New York, Longman Scientific e Technical. 229p.

SOMERS, G.L. et alii, 1980 Predicting mortality with a Weibull distribution. Forest Science,26(2): 291 - 300.

TERBORGH, J. The vertical component of plant species diversity in temperate and tropical forest. The American Naturalist, 126(6): 760 - 776.

TOMAZELLO, M. et alii, 1983 Madeira de espécies florestais do Estado do Maranhão. I Identificação e aplicações. Silvicultura, São Paulo, 8(28): 891 - 896.

VAN SCHAIK, C.P. e E. MIRMANTO, 1985 Spatial variation in the structure and litterfall of a sumatran rain forest. Biotropica, 17(3): $196-205$. 
VELOSO, H.P. e L. GÓES-FILHO, 1982 Fitogeografia Brasileira: classificação fisionômica-ecológica da vegetação neotropical. RADAM Brasil, Boletim Técnico Série Vegetação, Salvador, (1): 1 - 80.

WEIBULL, W., 1951 A statistical distribution function of wide applicability. Journal of Applied Mechanics, 18: 293 - 297.

WHITE, J., 1980 Demographic factors in population of plants. In: SOLBRIG, O.T. Demography an evolution in plant populations. Berkeley, University of California Press.

WHITMORE, T.C., 1975 Tropical rain forest of Far East. Oxford, Clarendon Press. 282p.

WHITMORE, T.C., 1978 Gaps in forest canopy. In: TOMLINSON, P.B. e M.H. ZIMMERMANN, Tropical trees as living systems. Cambridge, Cambridge University Press.

WHITMORE, T.C., 1982 On pattern and process in forests. In: NEWMAN, E.I., The plant community as a working mechanism. Oxford, Blackwell Scientific Publications.

WHYTE, A.G. 1986 Modelos de crescimento e de produção para plantações florestais. EMBRAPA, março: 1 - 38.

ZARNOCH, S.J. e T.R. DELL, 1985 An evaluation of percentile and maximum likelihood estimators of Weibull parameters. Forest Science,31(1): 260 - 268.

ZEIDE, B., 1984 Exponencial diameter distribution: interpretation of coefficients. Forest Science, 30(4): 907 - 912.

ZUTTER, B.R. et alii, 1982 Weibull - a program to estimate parameters of forms of Weibull distribution using complete, censored and truncated data. Virginia Polytechnic Institute and State University, Blacksburg, Publication FWS-3-82. 
ANEXO 1

Nomes Populares e Nomes Científicos das Espécies Estudadas 


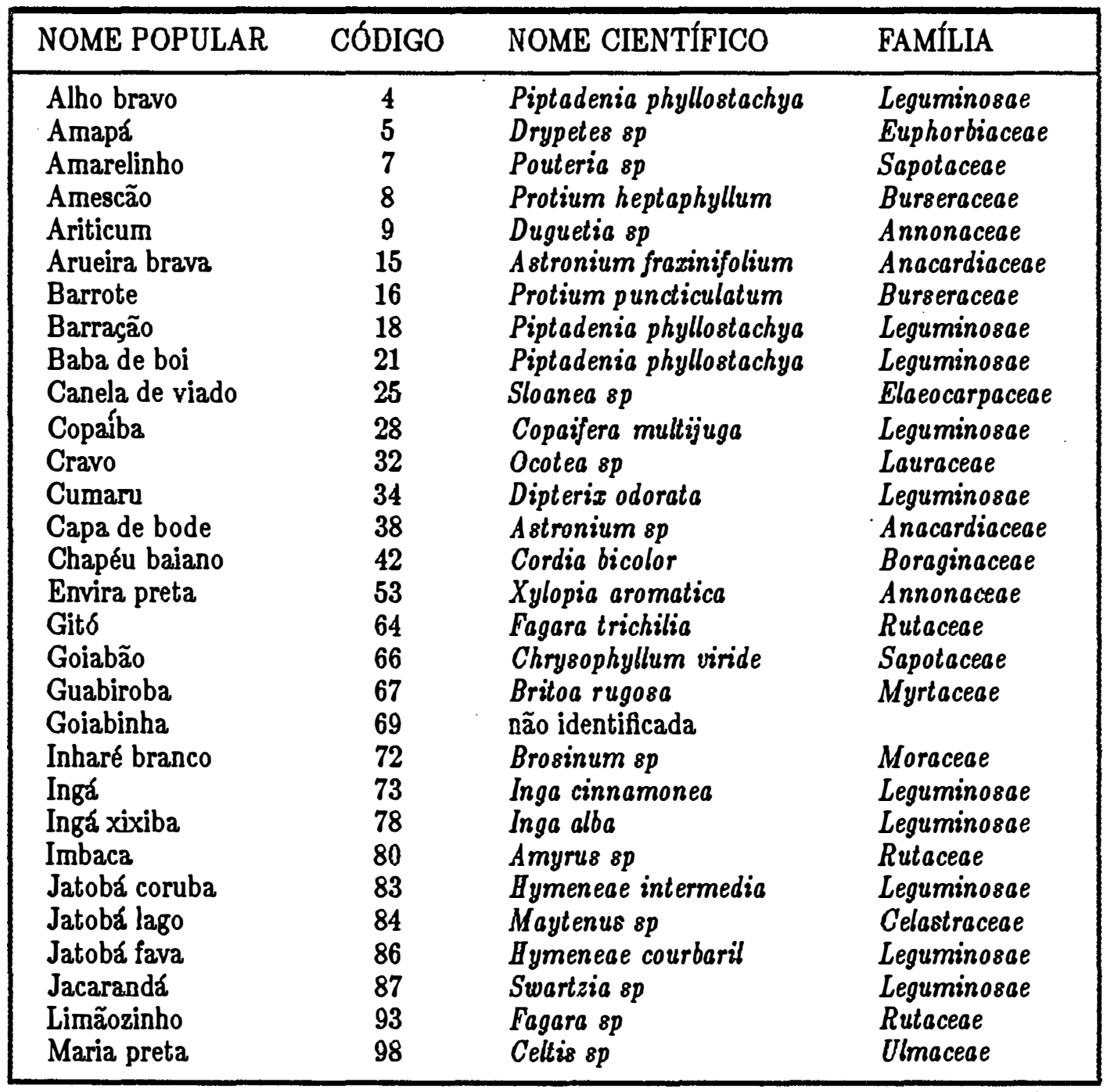

continua 
continuação

\begin{tabular}{|lcll|}
\hline NOME POPULAR & CÓDIGO & NOME CIENTÍFICO & FAMÍLIA \\
\hline Mamoninha & 99 & Pouteria sp & Sapotaceae \\
Maçaranduba & 102 & Manilkara huberi & Sapotaceae \\
Olho de pombo & 106 & Trichilia guianensis & Meliaceae \\
Puturuna & 107 & Cassia sp & Leguminosae \\
Pitomba de leite & 111 & Pouteria sp & Sapotaceae \\
Pau piranha & 112 & não identificada & \\
Paruru & 113 & Elizabetha sp & Leguminosae \\
Pau d'arco amarelo & 114 & Tabebuia serratifolia & Bignoniaceae \\
Pau santo & 115 & Zollernia paraensis & Leguminosae \\
Pau d'arco roxo & 117 & Tabebuia sp & Bignoniaceae \\
Morototó & 122 & Didymopanax morototoni & Araliaceae \\
Pitomba guariba & 125 & Talisia sp & Sapindaceae \\
Quina & 133 & Geissospermum sericeum & Apocynaceae \\
Toari branco & 138 & Platymiscium sp & Leguminosae \\
Tuturuba caboclo & 142 & Pouteria sp & Sapotaceae \\
Tuturuba verdadeira & 147 & Ecclinusa ucuquirana & Sapotaceae \\
Vara da mata & 149 & Trichilia sp & Meliaceae \\
Visgueiro & 150 & Didymopanax sp & Araliaceae \\
Embaúba & 151 & não identificada & \\
Faveira & 152 & Roupaa brasiliensis & Proteaceae \\
Gororoba & 153 & não identificada & \\
Gabiju & 154 & não identificada & \\
Inhaubá & 155 & não identificada & \\
Sucupira & 156 & não identificada & \\
Sacopembinha & 157 & não identificada & \\
Caneleiro & 163 & Lindackeria paraensis & Fracourtiaceae \\
Violeta da mata & 164 & Swartzia sp & Leguminosae \\
Jatobá & 165 & Hymeneae sp & Leguminosae \\
Embira preta & 168 & não identificada & \\
Gabiju de oco & 206 & não identificada & \\
\hline
\end{tabular}




\section{ANEXO 2}

\section{TABELA DA DISTRIBUIÇÃO \\ WEIBULL ESTANDARDIZADA}




\begin{tabular}{|c|c|c|c|c|c|c|}
\hline \multicolumn{4}{|c|}{$\begin{array}{l}\text { Estatísticas da Weibull } \\
\text { Estandardisada }\end{array}$} & \multicolumn{3}{|c|}{$\begin{array}{c}\text { Matrix Assintótica } \\
\text { de Variância - Covariância }\end{array}$} \\
\hline $\begin{array}{l}\text { Parâmetro da } \\
\text { forma } \\
\text { (c) }\end{array}$ & $\begin{array}{c}\text { Média } \\
(\bar{x})\end{array}$ & $\begin{array}{l}\text { Variância } \\
\qquad\left(s^{2}\right)\end{array}$ & $\begin{array}{l}\text { Coeficiente de } \\
\text { Variação } \\
\text { (CV) }\end{array}$ & $h_{11}$ & $h_{22}$ & $h_{12}$ \\
\hline 0.4 & 3,3234 & 108,9553 & 3,1409 & 2,7056 & 164,9387 & $-20,5729$ \\
\hline 0,6 & 1,5046 & 6,9968 & 1,7581 & 1,1332 & 10,4154 & $-2,9169$ \\
\hline 0,8 & 1,1330 & 2,0397 & 1,2605 & 0,9459 & 2,5910 & $-0,9832$ \\
\hline 1,0 & 1,0000 & 1,0000 & 1,0000 & 1,0000 & 1,1787 & $-0,4228$ \\
\hline 1,2 & 0,9407 & 0,6197 & 0,8369 & 1,1603 & 0,7195 & $-0,1690$ \\
\hline 1,4 & 0,9114 & 0,4351 & 0,7238 & 1,3957 & 0,5109 & $-0,0209$ \\
\hline 1,6 & 0,8966 & 0,3292 & 0,6399 & 1,6973 & 0,3946 & 0,0802 \\
\hline 1,8 & 0,8893 & 0,2614 & 0,5749 & 2,0626 & 0,3216 & 0,1565 \\
\hline 2,0 & 0,8862 & 0,2146 & 0,5227 & 2,4918 & 0,2691 & 0,2179 \\
\hline 2,2 & 0,8856 & 0,1806 & 0,4798 & 2,9858 & 0,2310 & 0,2696 \\
\hline 2,4 & 0,8865 & 0,1548 & 0,4438 & 3,5459 & 0,2016 & 0,3145 \\
\hline 2,6 & 0,8882 & 0,1347 & 0,4131 & 4,1736 & 0,1736 & 0,3542 \\
\hline 2,8 & 0,8905 & 0,1185 & 0,3866 & 4,8703 & 0,1592 & 0,3900 \\
\hline 3,0 & 0,8930 & 0,1053 & 0,3634 & 5,6371 & 0,1433 & 0,4225 \\
\hline 3,2 & 0,8957 & 0,0944 & 0,4524 & 6,4756 & 0,1299 & 0,4524 \\
\hline 3,4 & 0,8984 & 0,0852 & 0,3248 & 7,3867 & 0,1184 & 0,4801 \\
\hline 3,6 & 0,9011 & 0,0773 & 0,3085 & 8,3715 & 0,1085 & 0,5058 \\
\hline 3,8 & 0,9038 & 0,0705 & 0,2939 & 9,4311 & 0,0999 & 0,5299 \\
\hline 4,0 & 0,9064 & 0,0647 & 0,2805 & 10,5663 & 0,0923 & 0,5524 \\
\hline 4,2 & 0,9089 & 0,0595 & 0,2684 & 11,7780 & 0,0856 & 0,5737 \\
\hline 4,4 & 0,9114 & 0,0550 & 0,2573 & 13,0668 & 0,0796 & 0,5937 \\
\hline
\end{tabular}

Fonte: NEWBY (1980). 


\section{ANEXO 3}

Dedução dos Estimadores de

Máxima Verossimilhança para

Distribuição Weibull - 2 parâmetros 


\section{I) AMOSTRAS COMPLETAS}

Função de densidade probabilística:

$$
f(x)=\left(\frac{c}{b}\right)\left(\frac{x}{b}\right)^{c-1} \exp \left(-(x / b)^{c}\right)
$$

Dedução da função de Máxima Verossimilhança $(L)$

$$
\begin{gathered}
L=\prod f(x)=\left(\frac{c}{b}\right)^{n} \prod\left(\frac{x}{b}\right)^{c-1} \exp \left(-\sum(x / b)^{c}\right) \\
L=\frac{c^{n}}{b^{n}}\left(\frac{1}{b^{c-1}}\right)^{n} \prod\left(x^{c-1}\right) \exp \left(-\left(1 / b^{c}\right) \sum x^{c}\right) \\
L=\frac{c^{n}}{b^{n}} \frac{1}{b^{n(c-1)}} \prod\left(x^{c-1}\right) \exp \left(-\left(1 / b^{c}\right) \sum x^{c}\right) \\
L=\frac{c^{n}}{b^{n c}} \prod\left(x^{c-1}\right) \exp \left(-\left(1 / b^{c}\right) \sum x^{c}\right)
\end{gathered}
$$

Logaritmo da função de máxima verossimilhança $(\ln (L))$ :

$$
\begin{gathered}
\ln (L)=\ln \left(\frac{c^{n}}{b^{n c}}\right)+\ln \left(\prod\left(x^{c-1}\right)\right)-\frac{1}{b^{c}} \sum x^{c} \\
\ln (L)=\ln \left(c^{n}\right)-\ln \left(b^{n c}\right)+\sum \ln \left(x^{c-1}\right)-\frac{1}{b^{c}} \sum x^{c} \\
\ln (L)=n \ln (c)-n c \ln (b)+(c-1) \sum \ln (x)-\frac{1}{b^{c}} \sum x^{c} \\
\ln (L)=n \ln (c)-n c \ln (b)+c \sum \ln (x)-\sum \ln (x)-\frac{1}{b^{c}} \sum x^{c}
\end{gathered}
$$

Primeira derivada do logaritmo da função de máxima verossimilhança em relação ao parâmetro $b$

$$
\frac{\partial \ln (L)}{\partial b}=-\frac{n c}{b}-\left(\frac{-c}{b^{c+1}}\right) \sum x^{c}
$$

Condição necessária para máximo relativo:

$$
\begin{gathered}
\frac{\partial \ln (L)}{\partial b}=-\frac{n c}{b}+\frac{c}{b^{c+1}} \sum x^{c}=0 \\
\frac{c}{b}\left(-n+\frac{\sum x^{c}}{b^{c}}\right)=0 \\
-n+\frac{\sum x^{c}}{b^{c}}=0
\end{gathered}
$$




$$
\frac{\sum x^{c}}{b^{c}}=n
$$

Estimador do parâmetro b:

$$
\hat{b}=\left(\frac{\sum x^{c}}{n}\right)^{1 / \varepsilon}
$$

Primeira derivada do logaritmo da função de máxima verossimilhança em relação ao parâmetro c

$$
\begin{gathered}
\ln (L)=n \ln (c)-n c \ln (b)+c \sum \ln (x)-\sum \ln (x)-\sum\left(\frac{x}{b}\right)^{c} \\
\frac{\partial \ln (L)}{\partial c} \frac{(L)}{c}=\frac{n}{c}-n \ln (b)+\sum \ln (x)-\sum\left(\frac{x}{b}\right)^{c} \ln \left(\frac{x}{b}\right) \\
\frac{\partial \ln (L)}{\partial c}=\frac{n}{c}-n \ln (b)+\sum \ln (x)-\sum\left(\frac{x}{b}\right)^{c}(\ln (x)-\ln (b)) \\
\frac{\partial \ln (L)}{\partial c}=\frac{n}{c}-n \ln (b)+\sum \ln (x)-\frac{1}{b^{c}} \sum\left(x^{c} \ln (x)-x^{c} \ln (b)\right) \\
\frac{\partial \ln (L)}{\partial c}=\frac{n}{c}-n \ln (b)+\sum \ln (x)-\frac{1}{b^{c}} \sum x^{c} \ln (x)+\frac{1}{b^{c}} \sum x^{c} \ln (b)
\end{gathered}
$$

Condição necessária para máximo relativo:

$$
\begin{gathered}
\frac{n}{c}-n \ln (b)+\sum \ln (x)-\frac{1}{b^{c}} \sum x^{c} \ln (x)+\ln (b) \frac{\sum x^{c}}{b^{c}}=0 \\
\frac{n}{c}-n \ln (b)+\sum \ln (x)-\frac{1}{b^{c}} \cdot \sum x^{c} \ln (x)+\ln (b) n=0 \\
\frac{n}{c}+\sum \ln (x)-\frac{1}{b^{c}} \cdot \sum x^{c} \ln (x)=0
\end{gathered}
$$

Estimador do parâmetro c:

$$
\hat{c}=\frac{n}{\left(\overline{1} / \overline{b^{c}}\right) \sum \bar{x}^{c} \ln (\bar{x})-\sum \ln (\bar{x})}
$$




\section{II) AMOSTRAS TRUNCADAS À ESQUERDA}

Função de densidade probabilistica ( $t$ é o ponto de truncagem):

$$
f(x)=\left(\frac{c}{b}\right)\left(\frac{x}{b}\right)^{c-1} \exp \left[(t / b)^{c}-(x / b)^{c}\right]
$$

Dedução da função de Máxima Verossimilhança (L)

$$
\begin{aligned}
& L=\prod f(x)=\left(\frac{c}{b}\right)^{n} \prod\left(\frac{x}{b}\right)^{c-1} \exp \left[\sum\left((t / b)^{c}-(x / b)^{c}\right)\right] \\
& L=\frac{c^{n}}{b^{n}}\left(\frac{1}{b^{c-1}}\right)^{n} \prod\left(x^{c-1}\right) \exp \left[n\left(\frac{t}{b}\right)^{c}-\sum(x / b)^{c}\right] \\
& L=\frac{c^{n}}{b^{n}} \frac{1}{b^{n(c-1)}} \prod^{\left(x^{c-1}\right)} \exp \left[\frac{n t^{c}}{b^{c}}\right] \exp \left[-\left(1 / b^{0}\right) \sum x^{c}\right] \\
& L=\frac{c^{n}}{b^{n c}} \prod\left(x^{c-1}\right) \exp \left[\frac{n t^{c}}{b^{c}}\right] \exp \left[-\left(1 / b^{c}\right) \sum x^{c}\right]
\end{aligned}
$$

Logaritmo da função de máxima verossimilhança $(\ln (L))$ :

$$
\begin{gathered}
\ln (L)=\ln \left(\frac{c^{n}}{b^{n c}}\right)+\ln \left(\prod\left(x^{c-1}\right)\right)+\frac{n t^{c}}{b^{c}}-\frac{1}{b^{c}} \sum x^{c} \\
\ln (L)=\ln \left(c^{n}\right)-\ln \left(b^{n c}\right)+\sum \ln \left(x^{c-1}\right)+\frac{n t^{c}}{b^{c}}-\frac{1}{b^{c}} \sum x^{c} \\
\ln (L)=n \ln (c)-n c \ln (b)+(c-1) \sum \ln (x)+\frac{n t^{c}}{b^{c}}-\frac{1}{b^{c}} \sum x^{c} \\
\ln (L)=n \ln (c)-n c \ln (b)+c \sum \ln (x)-\sum \ln (x)+\frac{n t^{c}}{b^{c}}-\frac{1}{b^{c}} \sum x^{c}
\end{gathered}
$$

Primeira derivada do logaritmo da função de máxima verossimilhança em relação ao parâmetro b

$$
\frac{\partial \ln (L)}{\partial b}=-\frac{n c}{b}+\frac{(-c) n t^{c}}{b c+1}-\left(\frac{-c}{b c+1}\right) \sum x^{c}
$$

Condição necessária para máximo relativo:

$$
\begin{gathered}
\frac{\partial \ln (L)}{\partial b}=-\frac{n c}{b}-\frac{c n t^{c}}{b^{c+1}}+\frac{c}{b^{c+1}} \sum x^{c}=0 \\
\frac{\partial \ln (L)}{\partial b}=-\frac{n c}{b}+\frac{c}{b c+1}\left(\sum x^{c}-n t^{c}\right)=0 \\
\frac{c}{b}\left[\frac{1}{b c}\left(\sum x^{c}-n t^{c}\right)-n\right]=0
\end{gathered}
$$




$$
\begin{gathered}
\frac{1}{b^{c}}\left(\sum x^{c}-n t^{c}\right)-n=0 \\
\frac{\sum x^{c}-n t^{c}}{b^{c}}=n
\end{gathered}
$$

Estimador do parâmetro b:

$$
\hat{b}=\left[\frac{\sum x^{\varepsilon}-n t^{\varepsilon}}{n}\right]^{1 / \varepsilon}
$$

Primeira derivada do logaritmo da função de máxima verossimilhança em relação ao parâmetro c

$$
\begin{gathered}
\ln (L)=n \ln (c)-n c \ln (b)+c \sum \ln (x)-\sum \ln (x)+\frac{n t^{c}}{b^{c}}-\frac{1}{b^{c}} \sum x^{c} \\
\frac{\partial \ln (L)}{\partial c}=\frac{n}{c}-n \ln (b)+\sum \ln (x)+n\left(\frac{t}{b}\right)^{c} \ln \left(\frac{t}{b}\right)-\sum\left(\frac{x}{b}\right)^{c} \ln \left(\frac{x}{b}\right) \\
\frac{\partial \ln (L)}{\partial c}=\frac{n}{c}-n \ln (b)+\sum \ln (x)+n\left(\frac{t}{b}\right)^{c}[\ln (t)-\ln (b)]-\sum\left(\frac{x}{b}\right)^{c}[\ln (x)-\ln (b)\} \\
\frac{\partial \ln (L)}{\partial c}=\frac{n}{c}-n \ln (b)+\sum \ln (x)+n\left(\frac{t}{b}\right)^{c} \ln (t)-n\left(\frac{t}{b}\right)^{c} \ln (b)-\frac{1}{b^{c}} \sum x^{c} \ln (x)+\frac{1}{b^{c}} \sum x^{c} \ln (b) \\
\frac{\partial \ln (L)}{\partial c}=\frac{n}{c}-n \ln (b)+\sum \ln (x)+\frac{n t^{c}}{b^{c}} \ln (t)-\frac{n t^{c}}{b^{c}} \ln (b)-\frac{1}{b^{c}} \sum x^{c} \ln (x)+\frac{\sum x^{c}}{b c} \ln (b) \\
\frac{\partial \ln (L)}{\partial c}=\frac{n}{c}-n \ln (b)+\sum \ln (x)+\frac{n t^{c}}{b^{c}} \ln (t)-\frac{1}{b^{c}} \sum x^{c} \ln (x)+\ln (b)\left[\frac{\sum x^{c}-n t^{c}}{b^{c}}\right] \\
\frac{\partial \ln (L)}{\partial c}=\frac{n}{c}-n \ln (b)+\sum \ln (x)+\frac{n t^{c}}{b^{c}} \ln (t)-\frac{1}{b^{c}} \sum x^{c} \ln (x)+\ln (b)\left[\frac{\sum x^{c}-n t^{c}}{\left(\sum x^{c}-n t^{c}\right) / n}\right] \\
\frac{\partial \ln (L)}{\partial c}=\frac{n}{c}-n \ln (b)+\sum \ln (x)+\frac{n t^{c}}{b^{c}} \ln (t)-\frac{1}{b^{c}} \sum x^{c} \ln (x)+\ln (b) n
\end{gathered}
$$

Condição necessária para máximo relativo:

$$
\frac{n}{c}+\sum \ln (x)+\frac{n t^{c}}{b^{c}} \ln (t)-\frac{1}{b^{c}} \sum x^{c} \ln (x)=0
$$

Estimador do parâmetro c:

$$
\hat{c}=n /\left\{\left(1 / b^{\varepsilon}\right)\left[\sum x^{\varepsilon} \ln (x)-n t^{\varepsilon} \ln (t)\right]-\sum \ln (x)\right\}
$$




\section{$\mathrm{ANEXO} 4$}

Número de passos de iteração

necessários para a convergência para cada método testado 


\begin{tabular}{|c|c|c|c|c|c|c|c|}
\hline ESPÉCIE & $\begin{array}{l}\text { Newton } \\
\text { MVN }\end{array}$ & $\begin{array}{c}\text { Raphson } \\
\text { MVT }\end{array}$ & $\begin{array}{l}\text { Secante } \\
\text { MCV }\end{array}$ & ESPÉCIE & $\begin{array}{l}\text { Newtor } \\
\text { MVN }\end{array}$ & $\begin{array}{l}\text { Raphson } \\
\text { MVT }\end{array}$ & $\begin{array}{c}\text { Secante } \\
\text { MCV }\end{array}$ \\
\hline $\begin{array}{l}\text { Alho bravo } \\
\text { Amarelinho } \\
\text { Ariticum } \\
\text { Barrote } \\
\text { Baba de boi } \\
\text { Copaíba } \\
\text { Cumaru } \\
\text { Chapéu baiano } \\
\text { Gitó } \\
\text { Guabiroba } \\
\text { Inharé branco } \\
\text { Ingá xixiba } \\
\text { Jatobá coruba } \\
\text { Jatobá fava } \\
\text { Limãozinho } \\
\text { Mamoninha } \\
\text { Olho de pombo } \\
\text { Pitomba de leite } \\
\text { Paruru } \\
\text { Pau santo } \\
\text { Morototó } \\
\text { Quina } \\
\text { Tuturuba caboclo } \\
\text { Vara da mata } \\
\text { Embaúba } \\
\text { Gororoba } \\
\text { Inhaubá } \\
\text { Sacopembinha } \\
\text { Violeta da mata } \\
\text { Embira preta }\end{array}$ & $\begin{array}{c}24 \\
26 \\
24 \\
14 \\
8 \\
13 \\
8 \\
6 \\
5 \\
10 \\
8 \\
15 \\
6 \\
7 \\
5 \\
7 \\
9 \\
23 \\
7 \\
6 \\
35 \\
7 \\
5 \\
8 \\
14 \\
6 \\
8 \\
6 \\
15 \\
7\end{array}$ & $\begin{array}{l}15 \\
60^{*} \\
33 \\
15 \\
13 \\
11 \\
7 \\
23 \\
28 \\
26 \\
19 \\
14 \\
12 \\
8 \\
46 \\
16 \\
23 \\
27 \\
15 \\
12 \\
21 \\
9 \\
9 \\
47 \\
36 \\
17 \\
10 \\
15 \\
12 \\
21\end{array}$ & $\begin{array}{c}5 \\
(6) \\
8 \\
6 \\
7 \\
5 \\
7 \\
7 \\
8 \\
7 \\
6 \\
7 \\
6 \\
5 \\
8 \\
7 \\
8 \\
11 \\
8 \\
7 \\
12 \\
8 \\
7 \\
10 \\
9 \\
7 \\
6 \\
7 \\
9 \\
7\end{array}$ & $\begin{array}{l}\text { Amapa } \\
\text { Amescão } \\
\text { Arueira brava } \\
\text { Barração } \\
\text { Canela de viado } \\
\text { Cravo } \\
\text { Capa de bode } \\
\text { Envira preta } \\
\text { Goiabão } \\
\text { Goiabinha } \\
\text { Ingá } \\
\text { Imbaca } \\
\text { Jatobá lago } \\
\text { Jacarandá } \\
\text { Maria preta } \\
\text { Maçaranduba } \\
\text { Puturuna } \\
\text { Pau piranha } \\
\text { Pau d'arco amarelo } \\
\text { Pau d'arco roxo } \\
\text { Pitomba guariba } \\
\text { Toari branco } \\
\text { Tuturuba verdadeira } \\
\text { Visgueiro } \\
\text { Faveira } \\
\text { Gabiju } \\
\text { Sucupira } \\
\text { Caneleiro } \\
\text { Jatobá } \\
\text { Gabiju de oco }\end{array}$ & $\begin{array}{c}5 \\
9 \\
14 \\
8 \\
9 \\
6 \\
25 \\
6 \\
5 \\
18 \\
7 \\
9 \\
8 \\
8 \\
6 \\
4 \\
9 \\
14 \\
7 \\
15 \\
13 \\
9 \\
10 \\
14 \\
19 \\
6\end{array}$ & $\begin{array}{c}14 \\
13 \\
10 \\
19 \\
60^{*} \\
18 \\
19 \\
19 \\
19 \\
22 \\
25 \\
18 \\
12 \\
15 \\
18 \\
10 \\
21 \\
26 \\
9 \\
11 \\
13 \\
12 \\
19 \\
10 \\
6 \\
19 \\
14 \\
8 \\
5 \\
32\end{array}$ & $\begin{array}{c}8 \\
8 \\
(15) \\
6 \\
9 \\
8 \\
(6) \\
6 \\
7 \\
8 \\
8 \\
7 \\
7 \\
8 \\
6 \\
7 \\
10 \\
8 \\
6 \\
6 \\
(8) \\
8 \\
7 \\
7 \\
(7) \\
8 \\
7 \\
7 \\
8 \\
8\end{array}$ \\
\hline MÉDIA & 10,77 & 18,93 & 7,42 & DESVIO PADRÃO & 6,61 & 11,56 & 1,36 \\
\hline
\end{tabular}

\section{OBSERVAÇÕES :}

a) 0 asterisco indica espécies/métodos que não atingiram o critério de convergência em 60 passos.

b) Os valores entre parênteses indicam espécies em que o método da secante não convergiu, utilizando-se 0 método da falsa posição como substituto, cuja média e o desvio padrão foram de 8,40 e 3,78 respectivamente . 


\section{ANEXO 5}

Estimativas e Intervalo de Confiança dos Parâmetros da Distribuição Weibull ajustada pelo Método dos Percentis 
OBSERVAÇÃO: Intervalo de Confiança a nível de 5\% de probabilidade.

\begin{tabular}{|c|c|c|c|c|c|}
\hline ESPECIES & CÓDIGO & $\begin{array}{l}\text { PARÂ } \\
\text { Estimativa }\end{array}$ & $\begin{array}{l}\text { METRO c } \\
\text { Intervalo de } \\
\text { Confiança }\end{array}$ & $\begin{array}{l}\text { PARÂA } \\
\text { Estimativa }\end{array}$ & $\begin{array}{l}\text { IETRO b } \\
\text { Intervalo de } \\
\text { Confiança }\end{array}$ \\
\hline $\begin{array}{l}\text { Alho bravo } \\
\text { Amapá } \\
\text { Amarelinho } \\
\text { Amescão } \\
\text { Ariticum } \\
\text { Arueira brava } \\
\text { Barrote } \\
\text { Barração } \\
\text { Baba de boi } \\
\text { Canela de viado } \\
\text { Copaíba } \\
\text { Cravo } \\
\text { Cumaru } \\
\text { Capa de bode } \\
\text { Chapéu baiano } \\
\text { Envira preta } \\
\text { Gitó } \\
\text { Goiabão } \\
\text { Guabiroba } \\
\text { Goiabinha } \\
\text { Inharé branco } \\
\text { Ingá } \\
\text { Ingá xixiba } \\
\text { Imbaca } \\
\text { Jatobá coruba } \\
\text { Jatobá lago } \\
\text { Jatobá fava } \\
\text { Jacarandá } \\
\text { Limãozinho } \\
\text { Maria preta }\end{array}$ & $\begin{array}{c}4 \\
5 \\
7 \\
8 \\
9 \\
15 \\
16 \\
18 \\
21 \\
25 \\
28 \\
32 \\
34 \\
38 \\
42 \\
53 \\
64 \\
66 \\
67 \\
69 \\
72 \\
73 \\
78 \\
80 \\
83 \\
84 \\
86 \\
87 \\
93 \\
98\end{array}$ & $\begin{array}{l}2,1068 \\
1,3827 \\
1,8326 \\
1,2518 \\
1,2982 \\
1,1999 \\
1,6006 \\
1,1329 \\
1,0146 \\
2,1172 \\
1,2804 \\
1,2775 \\
0,8909 \\
1,1686 \\
1,4781 \\
1,2081 \\
1,4783 \\
1,3396 \\
1,2260 \\
1,2119 \\
1,0117 \\
1,3308 \\
1,6448 \\
1,1230 \\
1,1013 \\
0,9740 \\
1,0546 \\
1,3530 \\
1,6911 \\
1,2537\end{array}$ & $\begin{array}{l}0,1010 \\
0,0629 \\
0,0528 \\
0,0033 \\
0,0100 \\
0,0689 \\
0,0080 \\
0,0229 \\
0,0566 \\
0,1291 \\
0,0125 \\
0,0192 \\
0,0286 \\
0,0691 \\
0,0043 \\
0,0525 \\
0,0020 \\
0,0046 \\
0,0500 \\
0,0326 \\
0,0471 \\
0,0145 \\
0,0868 \\
0,0282 \\
0,0106 \\
0,0678 \\
0,0118 \\
0,0302 \\
0,0552 \\
0,0114\end{array}$ & $\begin{array}{r}47,4804 \\
11,3295 \\
3,2400 \\
11,7064 \\
6,0358 \\
9,9318 \\
21,8613 \\
11,2716 \\
15,8804 \\
5,9527 \\
30,2118 \\
10,7549 \\
23,4718 \\
6,6256 \\
11,7732 \\
13,1580 \\
8,8393 \\
13,2705 \\
9,6262 \\
7,4736 \\
11,8467 \\
8,4651 \\
23,9392 \\
11,7531 \\
17,6134 \\
15,2764 \\
26,2757 \\
10,5320 \\
7,4757 \\
12,0293\end{array}$ & $\begin{array}{l}1,4845 \\
0,4690 \\
0,0642 \\
0,0306 \\
0,0451 \\
0,5980 \\
0,0854 \\
0,2534 \\
1,0987 \\
0,2157 \\
0,2905 \\
0,1589 \\
1,0652 \\
0,4219 \\
0,0291 \\
0,5958 \\
0,0100 \\
0,0425 \\
0,4029 \\
0,2085 \\
0,6860 \\
0,0870 \\
0,9670 \\
0,3313 \\
0,1931 \\
1,3732 \\
0,3501 \\
0,2185 \\
0,1817 \\
0,1099\end{array}$ \\
\hline
\end{tabular}

continua 
Continuação

\begin{tabular}{|l|c|cc|cc|}
\hline \multicolumn{1}{|c|}{ ESPÉCIES } & \multicolumn{2}{|c|}{ PARÂMETRO c } & \multicolumn{2}{c|}{ PARÂMETRO b } \\
& CÓDIGO & Estimativa & Intervalo de & Estimativa & Intervalo de \\
& & & Confiança & & Confiança \\
\hline Mamoninha & 99 & 1,1533 & 0,0060 & 11,4653 & 0,0646 \\
Maçaranduba & 102 & 1,1144 & 0,0154 & 19,3468 & 0,3024 \\
Olho de pombo & 106 & 1,8113 & 0,0326 & 13,4898 & 0,1689 \\
Puturuna & 107 & 1,3672 & 0,0050 & 8,2595 & 0,0279 \\
Pitomba de leite & 111 & 1,4440 & 0,0099 & 5,7893 & 0,0346 \\
Pau piranha & 112 & 1,3260 & 0,0094 & 6,9876 & 0,0469 \\
Paruru & 113 & 1,5711 & 0,0385 & 16,5163 & 0,3245 \\
Pau d'arco amarelo & 114 & 0,9651 & 0,0259 & 19,3291 & 0,6772 \\
Pau santo & 115 & 1,1613 & 0,0071 & 17,4845 & 0,1151 \\
Pau d'arco roxo & 117 & 1,2102 & 0,0349 & 36,0329 & 1,0804 \\
Morototón & 122 & 1,3522 & 0,0085 & 5,9250 & 0,0347 \\
Pitomba guariba & 125 & 1,6766 & 0,0698 & 14,8339 & 0,4636 \\
Quina & 133 & 1,2503 & 0,0285 & 18,8364 & 0,4327 \\
Toari branco & 138 & 1,1755 & 0,0113 & 11,3933 & 0,1170 \\
Tuturuba caboclo & 142 & 1,1183 & 0,0173 & 19,6774 & 0,3426 \\
Tuturuba verdadeira & 147 & 1,1107 & 0,0117 & 10,1785 & 0,1219 \\
Vara da mata & 149 & 1,7081 & 0,0211 & 5,5562 & 0,0506 \\
Visgueiro & 150 & 1,5356 & 0,0833 & 33,2458 & 1,4779 \\
Embaúba & 151 & 1,9975 & 0,0952 & 11,0295 & 0,3313 \\
Faveira & 152 & 1,1389 & 0,0543 & 12,6785 & 0,6680 \\
Gororoba & 153 & 1,2794 & 0,0418 & 14,4286 & 0,4635 \\
Gabiju & 154 & 1,3119 & 0,0088 & 9,3366 & 0,0603 \\
Inhaubá & 155 & 1,1574 & 0,0106 & 24,2809 & 0,2415 \\
Sucupira & 156 & 1,8686 & 0,0891 & 38,4352 & 1,2342 \\
Sacopembinha & 157 & 1,1745 & 0,0278 & 12,6915 & 0,3215 \\
Caneleiro & 163 & 1,2827 & 0,0066 & 27,1203 & 0,1360 \\
Violeta da mata & 164 & 1,0663 & 0,0409 & 10,6926 & 0,4845 \\
Jatobá & 165 & 0,9350 & 0,0608 & 24,1711 & 2,1140 \\
Embira preta & 168 & 1,1509 & 0,0543 & 12,8580 & 0,3518 \\
Gabiju de oco & 206 & 1,7462 & 0,0657 & 10,9775 & 0,2979 \\
\hline
\end{tabular}




\section{ANEXO 6}

Dendrograma Resultante da Análise de

Agrupamento Utilizando os Parâmetros da

Distribuição Weibull como Variáveis de Análise 


\section{DEMDHOGRAMA ANALISE DE AGROPERADOS}

\section{METODO DE WARD OU DA MINIMA UARIAHCIA}

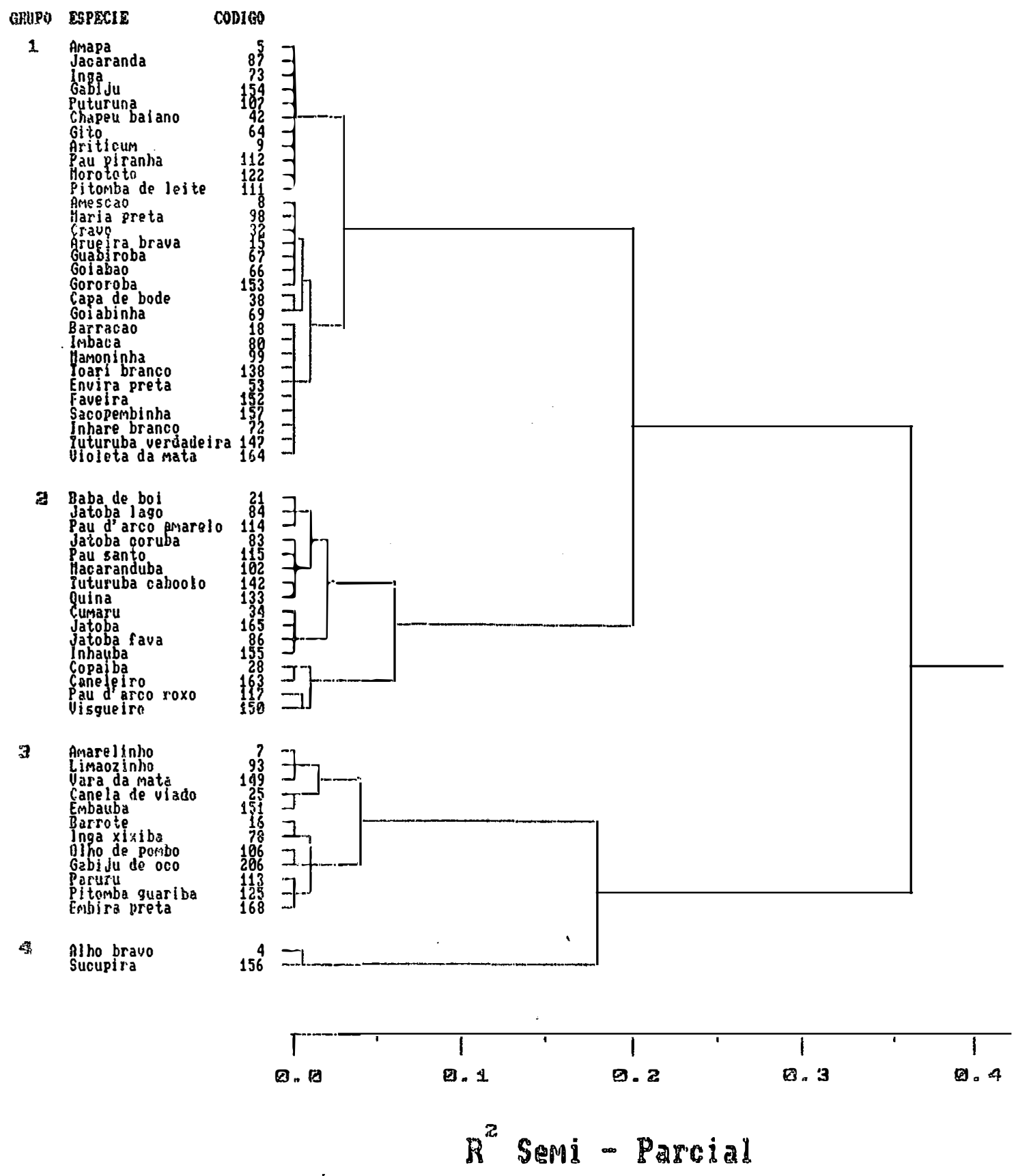




\title{
ANEXO 7
}

\author{
Grupos de Padrões de
}

Distribuição de Diâmetros 


\begin{tabular}{|c|c|c|c|c|}
\hline GRUPO & ESPÉCIE & CÓDIGO & $\hat{c}$ & $\hat{b}$ \\
\hline \multirow[t]{30}{*}{1} & Amapá & 5 & 1,38268 & 11,3295 \\
\hline & Amescão & 8 & 1,25182 & 11,7064 \\
\hline & Ariticum & 9 & 1,29825 & 6,0358 \\
\hline & Arueira brava & 15 & 1,19991 & 9,9318 \\
\hline & Barração & 18 & 1,13290 & 11,2716 \\
\hline & Cravo & 32 & 1,27746 & 10,7549 \\
\hline & Capa de bode & 38 & 1,16864 & 6,6256 \\
\hline & Chapéu baiano & 42 & 1,47809 & 11,7732 \\
\hline & Envira preta & 53 & 1,20812 & 13,1580 \\
\hline & Gitó & 64 & 1,47831 & 8,8393 \\
\hline & Goiabão & 66 & 1,33962 & 13,2705 \\
\hline & Guabiroba & 67 & 1,22603 & 9,6262 \\
\hline & Goiabinha & 69 & 1,21193 & 7,4736 \\
\hline & Inharé branco & 72 & 1,01167 & 11,8467 \\
\hline & Ingá & 73 & 1,33078 & 8,4651 \\
\hline & Imbaca & 80 & 1,12298 & 11,7531 \\
\hline & Jacarandá & 87 & 1,35297 & 10,5320 \\
\hline & Maria preta & 98 & 1,25367 & 12,0293 \\
\hline & Mamoninha & 99 & 1,15331 & 11,4653 \\
\hline & Puturuna & 107 & 1,36722 & 8,2595 \\
\hline & Pitomba de leite & 111 & 1,44404 & 5,7893 \\
\hline & Pau piranha & 112 & 1,32599 & 6,9876 \\
\hline & Morotot6 & 122 & 1,35216 & 5,9250 \\
\hline & Toari branco & 138 & 1,17545 & 11,3933 \\
\hline & Tuturuba verdadeira & 147 & 1,11067 & 10,1785 \\
\hline & Faveira & 152 & 1,13887 & 12,6785 \\
\hline & Gororoba & 153 & 1,27941 & 14,4286 \\
\hline & Gabiju & 154 & 1,31188 & 9,3366 \\
\hline & Sacopembinha & 157 & 1,17449 & 12,6915 \\
\hline & Violeta da mata & 164 & 1,06627 & 10,6926 \\
\hline
\end{tabular}


continuação

\begin{tabular}{|c|c|c|c|c|}
\hline GRUPO & ESPÉCIE & CóDIGO & $\hat{c}$ & $\hat{b}$ \\
\hline \multirow[t]{16}{*}{2} & Baba de boi & 21 & 1,01460 & 15,8804 \\
\hline & Copaśba & 28 & 1,28043 & 30,2118 \\
\hline & Cumaru & 34 & 0,89090 & 23,4718 \\
\hline & Jatobá coruba & 83 & 1,10132 & 17,6134 \\
\hline & Jatobá lago & 84 & 0,97397 & 15,2764 \\
\hline & Jatobá fava & 86 & 1,05494 & 26,2757 \\
\hline & Maçaranduba & 102 & 1,11440 & 19,3468 \\
\hline & Pau d'arco amarelo & 114 & 0,96513 & 19,3291 \\
\hline & Pau santo & 115 & 1,16129 & 17,4845 \\
\hline & Pau d'arco roxo & 117 & 1,21021 & 36,0329 \\
\hline & Quina & 133 & 1,25028 & 18,8364 \\
\hline & Tuturuba caboclo & 142 & 1,11834 & 19,6774 \\
\hline & Visgueira & 150 & 1,53564 & 33,2458 \\
\hline & Inhaubá & 155 & 1,15737 & 24,2809 \\
\hline & Caneleiro & 163 & 1,28272 & 27,1203 \\
\hline & Jatobá & 165 & 0,93500 & 24,1711 \\
\hline \multirow[t]{12}{*}{3} & Amarelinho & 7 & 1,83258 & 3,2400 \\
\hline & Barrote & 16 & 1,60055 & 21,8613 \\
\hline & Canela de viado & 25 & 2,11716 & 5,9527 \\
\hline & Ingá xixiba & 78 & 1,64478 & 23,9392 \\
\hline & Limãozinho & 93 & 1,69107 & 7,4757 \\
\hline & Olho de pombo & 106 & 1,81134 & 13,4898 \\
\hline & Paruru & 113 & 1,57112 & 16,5163 \\
\hline & Pitomba guariba & 125 & 1,67664 & 14,8339 \\
\hline & Vara da mata & 149 & 1,70806 & 5,5562 \\
\hline & Embaúba & 151 & 1,99751 & 11,0295 \\
\hline & Embira preta & 168 & 1,58093 & 12,8580 \\
\hline & Gabiju de oco & 206 & 1,74620 & 10,9775 \\
\hline \multirow[t]{2}{*}{4} & Alho bravo & 4 & 2,01683 & 47,4804 \\
\hline & Sucupira & 156 & 1,86860 & 38,4352 \\
\hline
\end{tabular}




\section{ANEXO 8}

Indices Fitossociológicos das Espécies Estudadas

por Grupos Representativos dos

Padrões da Distribuição de Diâmetros 


\begin{tabular}{|c|c|c|c|c|c|c|c|c|c|}
\hline GRUPOS & ESPÉCIES & $\mathrm{N}$ & FAI & DAI & DoAI & IVI & MORISITA & \multicolumn{2}{|c|}{ DESVIO } \\
\hline 1 & $\begin{array}{l}\text { Amapá } \\
\text { Amescão } \\
\text { Ariticum } \\
\text { Arueira brava } \\
\text { Barração } \\
\text { Cravo } \\
\text { Capa de bode } \\
\text { Chapéu baiano } \\
\text { Envira preta } \\
\text { Gitó } \\
\text { Goiabão } \\
\text { Guabiroba } \\
\text { Goiabinha } \\
\text { Inharé branco } \\
\text { Ingá } \\
\text { Imbaca } \\
\text { Jacarandá } \\
\text { Maria preta } \\
\text { Mamoninha } \\
\text { Puturuna } \\
\text { Pitomba de leite } \\
\text { Pau piranha } \\
\text { Morototó } \\
\text { Toari branco } \\
\text { Tuturuba verdadeira } \\
\text { Faveira } \\
\text { Gororoba } \\
\text { Gabiju } \\
\text { Sacopembinha } \\
\text { Violeta da mata }\end{array}$ & $\begin{array}{r}45 \\
758 \\
257 \\
36 \\
99 \\
133 \\
35 \\
681 \\
47 \\
1481 \\
579 \\
51 \\
75 \\
44 \\
183 \\
80 \\
90 \\
218 \\
384 \\
538 \\
289 \\
280 \\
315 \\
207 \\
188 \\
43 \\
62 \\
294 \\
85 \\
53\end{array}$ & $\begin{array}{l}0,34 \\
0,98 \\
0,79 \\
0,28 \\
0,60 \\
0,59 \\
0,28 \\
0,94 \\
0,31 \\
0,97 \\
0,98 \\
0,31 \\
0,45 \\
0,40 \\
0,67 \\
0,51 \\
0,57 \\
0,85 \\
0,86 \\
0,98 \\
0,73 \\
0,84 \\
0,86 \\
0,83 \\
0,76 \\
0,33 \\
0,48 \\
0,92 \\
0,50 \\
0,36\end{array}$ & $\begin{array}{r}1,14 \\
19,13 \\
6,49 \\
0,91 \\
2,50 \\
3,36 \\
0,88 \\
17,19 \\
1,19 \\
37,38 \\
14,62 \\
1,29 \\
1,89 \\
1,11 \\
4,62 \\
2,02 \\
2,27 \\
5,50 \\
9,69 \\
13,58 \\
7,30 \\
7,07 \\
7,95 \\
5,23 \\
4,75 \\
1,09 \\
1,57 \\
7,42 \\
2,15 \\
1,34\end{array}$ & $\begin{array}{l}0,06 \\
1,00 \\
0,19 \\
0,04 \\
0,12 \\
0,15 \\
0,03 \\
0,81 \\
0,07 \\
1,37 \\
0,82 \\
0,05 \\
0,06 \\
0,06 \\
0,17 \\
0,11 \\
0,10 \\
0,28 \\
0,51 \\
0,48 \\
0,21 \\
0,23 \\
0,23 \\
0,26 \\
0,21 \\
0,06 \\
0,09 \\
0,32 \\
0,12 \\
0,07\end{array}$ & $\begin{array}{r}1,47 \\
13,78 \\
4,96 \\
1,19 \\
2,86 \\
3,29 \\
1,12 \\
12,10 \\
1,49 \\
21,68 \\
11,33 \\
1,40 \\
2,01 \\
1,62 \\
3,98 \\
2,42 \\
2,60 \\
5,24 \\
7,84 \\
9,25 \\
5,18 \\
5,47 \\
5,82 \\
5,00 \\
4,45 \\
1,46 \\
2,11 \\
6,28 \\
2,49 \\
1,65\end{array}$ & $\begin{array}{l}2,13 \\
1,13 \\
1,56 \\
2,51 \\
1,32 \\
2,36 \\
1,77 \\
1,65 \\
2,52 \\
1,34 \\
1,21 \\
3,31 \\
1,74 \\
0,93 \\
1,81 \\
1,39 \\
1,38 \\
1,45 \\
1,46 \\
1,13 \\
1,61 \\
1,47 \\
1,95 \\
1,25 \\
1,59 \\
1,85 \\
1,16 \\
1,33 \\
1,48 \\
1,66\end{array}$ & $\begin{array}{l}1,57 \\
2,15 \\
2,66 \\
1,61 \\
1,37 \\
3,09 \\
1,30 \\
6,11 \\
1,81 \\
6,73 \\
2,40 \\
2,33 \\
1,63 \\
0,97 \\
2,70 \\
1,36 \\
1,39 \\
2,12 \\
3,04 \\
1,78 \\
3,03 \\
2,50 \\
4,42 \\
1,60 \\
2,26 \\
1,41 \\
1,11 \\
2,11 \\
1,46 \\
1,39\end{array}$ & n.s. \\
\hline
\end{tabular}


continuação

\begin{tabular}{|c|c|c|c|c|c|c|c|c|c|}
\hline GRUPOS & ESPÉCIES & $\mathrm{N}$ & FAI & DAI & DoAI & IVI & MORISITA & \multicolumn{2}{|c|}{ DESVIO } \\
\hline 2 & $\begin{array}{l}\text { Baba de boi } \\
\text { Copaíba } \\
\text { Cumaru } \\
\text { Jatobá coruba } \\
\text { Jatobá lago } \\
\text { Jatobá fava } \\
\text { Maçaranduba } \\
\text { Pau d'arco amarelo } \\
\text { Pau santo } \\
\text { Pau d'arco roxo } \\
\text { Quina } \\
\text { Tuturuba caboclo } \\
\text { Visgueira } \\
\text { Inhaubá } \\
\text { Caneleiro } \\
\text { Jatobá }\end{array}$ & $\begin{array}{r}37 \\
203 \\
63 \\
207 \\
30 \\
178 \\
144 \\
75 \\
326 \\
70 \\
88 \\
123 \\
38 \\
217 \\
388 \\
32\end{array}$ & $\begin{array}{l}0,28 \\
0,83 \\
0,52 \\
0,88 \\
0,20 \\
0,70 \\
0,68 \\
0,49 \\
0,90 \\
0,50 \\
0,59 \\
0,62 \\
0,35 \\
0,88 \\
0,85 \\
0,17\end{array}$ & $\begin{array}{l}0,93 \\
5,12 \\
1,59 \\
5,23 \\
0,76 \\
4,49 \\
3,64 \\
1,89 \\
8,23 \\
1,78 \\
2,22 \\
3,26 \\
0,96 \\
5,48 \\
9,79 \\
0,81\end{array}$ & $\begin{array}{l}0,06 \\
0,82 \\
0,22 \\
0,46 \\
0,05 \\
0,73 \\
0,36 \\
0,18 \\
0,68 \\
0,46 \\
0,21 \\
0,30 \\
0,16 \\
0,69 \\
1,41 \\
0,11\end{array}$ & $\begin{array}{r}1,27 \\
7,87 \\
2,86 \\
6,14 \\
1,00 \\
6,92 \\
4,65 \\
2,72 \\
8,35 \\
4,14 \\
3,18 \\
4,06 \\
1,98 \\
7,40 \\
12,51 \\
1,24\end{array}$ & $\begin{array}{l}2,51 \\
1,34 \\
1,04 \\
1,11 \\
3,03 \\
1,28 \\
1,42 \\
1,59 \\
1,31 \\
1,28 \\
1,24 \\
2,57 \\
1,00 \\
1,15 \\
1,87 \\
5,32\end{array}$ & $\begin{array}{l}1,62 \\
1,78 \\
1,03 \\
1,27 \\
1,68 \\
1,58 \\
1,69 \\
1,50 \\
2,15 \\
1,22 \\
1,24 \\
3,31 \\
1,00 \\
1,37 \\
4,86 \\
2,54\end{array}$ & $\begin{array}{l}\text { n.8. } \\
\text { n.8. } \\
\text { n.8. }\end{array}$ \\
\hline 3 & $\begin{array}{l}\text { Amarelinho } \\
\text { Barrote } \\
\text { Canela de viado } \\
\text { Ingá xixiba } \\
\text { Limãozinho } \\
\text { Olho de pombo } \\
\text { Paruru } \\
\text { Pitomba guariba } \\
\text { Vara da mata } \\
\text { Embaúba } \\
\text { Embira preta } \\
\text { Gabiju de oco }\end{array}$ & $\begin{array}{r}70 \\
398 \\
34 \\
39 \\
62 \\
111 \\
82 \\
49 \\
161 \\
43 \\
59 \\
54\end{array}$ & $\begin{array}{l}0,48 \\
0,89 \\
0,26 \\
0,32 \\
0,38 \\
0,61 \\
0,56 \\
0,38 \\
0,68 \\
0,31 \\
0,41 \\
0,10\end{array}$ & $\begin{array}{r}1,77 \\
10,05 \\
0,86 \\
0,98 \\
1,57 \\
2,80 \\
2,07 \\
1,24 \\
4,06 \\
1,09 \\
1,49 \\
1,36\end{array}$ & $\begin{array}{l}0,03 \\
0,98 \\
0,02 \\
0,09 \\
0,05 \\
0,15 \\
0,13 \\
0,12 \\
0,11 \\
0,05 \\
0,08 \\
0,06\end{array}$ & $\begin{array}{r}1,88 \\
10,44 \\
1,02 \\
1,55 \\
1,65 \\
3,12 \\
2,65 \\
1,92 \\
3,49 \\
1,34 \\
1,86 \\
0,98\end{array}$ & $\begin{array}{r}2,00 \\
1,30 \\
2,82 \\
1,54 \\
2,79 \\
1,90 \\
1,30 \\
1,50 \\
1,80 \\
2,44 \\
1,64 \\
16,11\end{array}$ & $\begin{array}{r}1,80 \\
2,37 \\
1,69 \\
1,24 \\
2,26 \\
2,14 \\
1,28 \\
1,27 \\
2,47 \\
1,69 \\
1,43 \\
10,11\end{array}$ & n.8. \\
\hline 4 & $\begin{array}{l}\text { Alho bravo } \\
\text { Sucupira }\end{array}$ & 43 & $\begin{array}{l}0,36 \\
0,35\end{array}$ & $\begin{array}{l}1,04 \\
1,09\end{array}$ & $\begin{array}{l}0,27 \\
0,23\end{array}$ & $\begin{array}{l}2,60 \\
2,35\end{array}$ & $\begin{array}{l}1,18 \\
1,17\end{array}$ & $\begin{array}{l}1,08 \\
1,08\end{array}$ & $\begin{array}{l}n .8 . \\
n .8 .\end{array}$ \\
\hline
\end{tabular}

\section{OBSERVAÇÖBS:}

$\mathrm{N}$ - Número de árvores medidas;

FAI - Freqüência absoluta (ocorrências);

DAI - Densidade absoluta (ind./ha);

DoAI - Dominância absoluta $\left(m^{2} / h a\right)$;

IVI - Indice de Valor de Importância;

MORISITA - Indice de Dispersão de Morisita;

DESVIO - Desvio do índice de Morisita em relação à dispersão aleatória, n.s. indica que o desvio não é significativo ao nível de $5 \%$ de probabilidade. 